University of Redlands

\title{
Prioritizing Invasive Species Management in the Carlsbad Hydrologic Unit
}

\begin{abstract}
A Major Individual Project submitted in partial satisfaction of the requirements
for the degree of Master of Science in Geographic Information Systems

$$
\text { by }
$$
\end{abstract}

Michelle Midori Tateyama

\author{
Ruijin Ma, Ph.D., Committee Chair \\ Russell Weaver, Ph.D.
}

July 2014 
Prioritizing Invasive Species Management in the Carlsbad Hydrologic Unit

Copyright (C) 2014

by

Michelle Midori Tateyama 
The report of Michelle Midori Tateyama is approved.
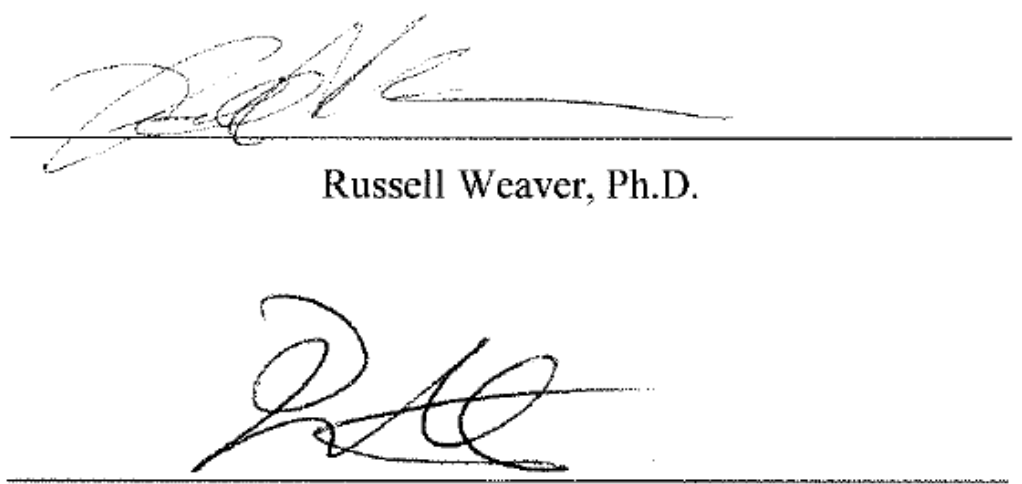

Ruijin Ma, Ph.D., Committee Chair

July 2014 



\section{Acknowledgements}

I would like to thank everyone who helped and supported me throughout the course of this project. First, I would like to thank my advisor, Ruijin Ma, for all his assistance with my project. Thanks to my client, San Elijo Lagoon Conservancy and in particular David Varner, for their involvement and help throughout the project. I would also like to thank my parents, Lane and Joan, for their financial and emotional support during this time. Lastly, a special thanks to all my cohort mates for their continued help and support. 



\begin{abstract}
Prioritizing Invasive Species Management in the Carlsbad Hydrologic Unit by

Michelle Midori Tateyama
\end{abstract}

The Carlsbad Hydrologic Unit contains diverse habitats that support a large number of rare and threatened plant and animal species. These habitats are at risk from infestations of invasive plant species, which can take over habitats displacing native plants and associated wildlife. San Elijo Lagoon Conservancy (SELC) protects native habitats by performing conservation, habitat restoration, and invasive species mitigation. The Conservancy needed to focus its resources on targeting the invasive species infestations that pose the greatest risk to native habitats and associated wildlife while working with a limited budget.

The project created a user-friendly and repeatable tool for SELC to prioritize invasive species infestations for mitigation. SELC is a non-profit organization with limited resources and wanted to focus on the activities that maximize their resources to conserve native habitats. The project was accomplished by developing an ArcGIS tool that ranks known invasive species infestations from low to high priority based on their potential risk to native habitats, probability to spread due to surrounding disturbances and transport mechanisms, and their location accessibility. This tool was developed using Python and ArcGIS. An analysis using the tool ranked 112 out of 12,504 known invasive species infestations ranked as high priority locations for mitigation. 



\section{Table of Contents}

Chapter 1 - Introduction ......................................................................................... 1

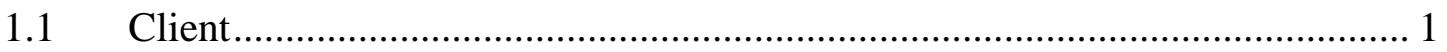

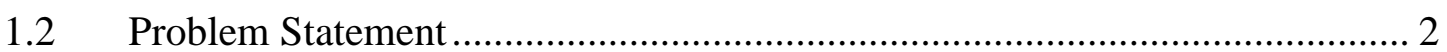

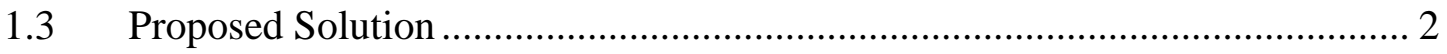

1.3.1 Goals and Objectives .............................................................. 2

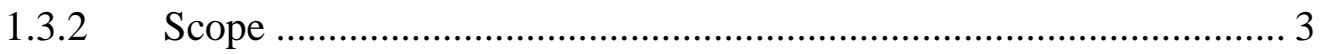

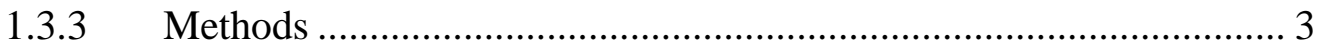

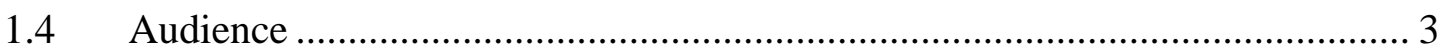

1.5 Overview of the Rest of this Report …………............................................... 3

Chapter 2 - Background and Literature Review ................................................................. 5

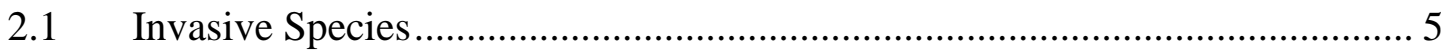

2.2 Prioritizing Habitat Conservation ............................................................ 5

2.3 Invasive Species Prioritization .................................................................. 6

$2.4 \quad$ Multi-criteria Decision Analysis ................................................................ 7

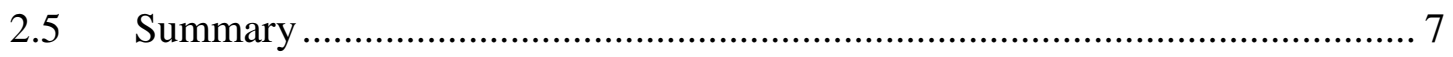

Chapter 3 - Systems Analysis and Design.......................................................................... 9

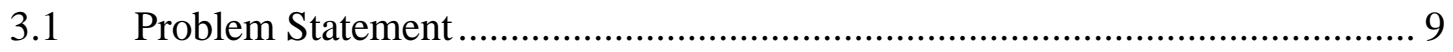

3.2 Requirements Analysis ........................................................................... 9

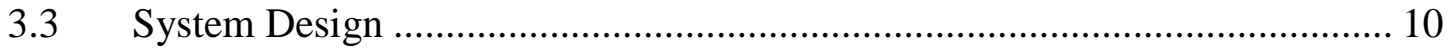

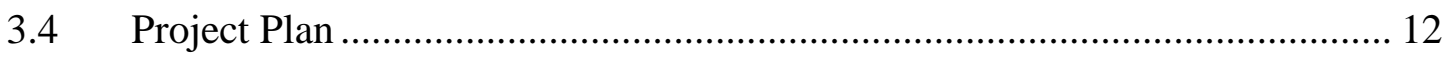

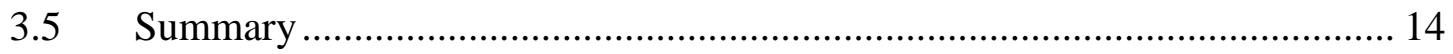


Chapter 4 - Database Design............................................................................................... 15

4.1 Conceptual Data Model ........................................................................ 15

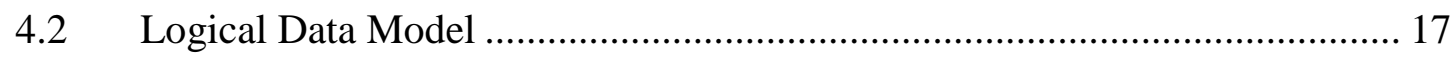

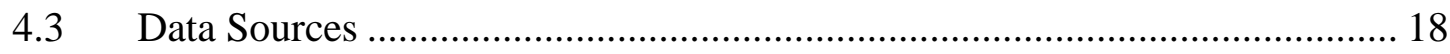

4.4 Data Scrubbing and Loading …………………........................................ 19

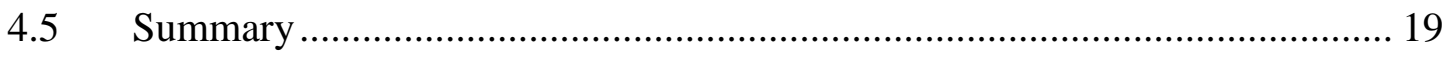

Chapter 5 - Implementation................................................................................................... 21

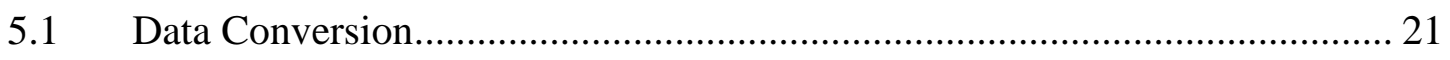

5.1.1 Vector to Raster........................................................................... 21

5.1.2 Proximity Calculation.............................................................. 22

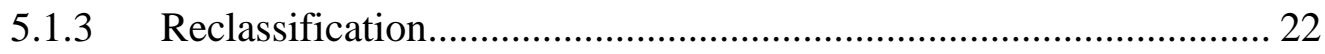

5.1.4 Data Conversion Tool.................................................................. 25

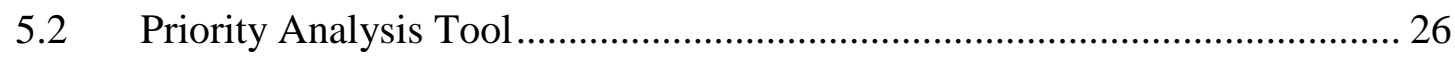

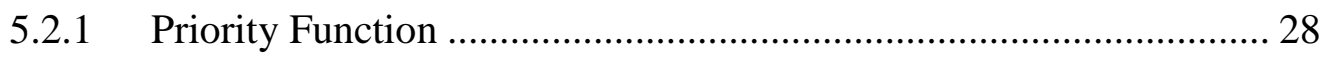

5.2.1.1 Risk to Native Habitats .....................................28

5.2.1.2 Disturbance and Spread ................................282

5.2.1.3 Location Accessibility....................................283

5.2.1.4 Final Weighted Overlay and Function Outputs ..........283

5.2.2 Weights Table ………………………….................................... 303

5.2.2.1 Listed Invasive Species.............................. 286

5.2.2.2 Default Entry ...................................... 287

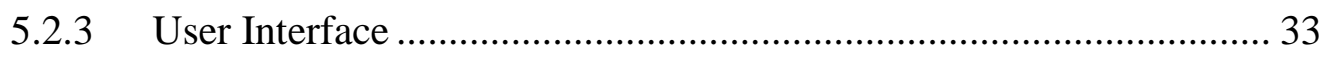

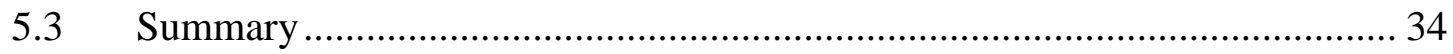


Chapter 6 - Results and Analysis....................................................................................... 37

6.1 Data Conversion Analysis.......................................................................... 37

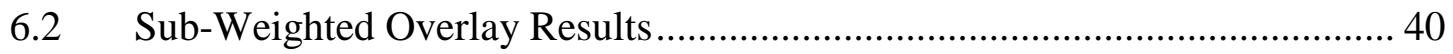

6.2.1 Habitat Risk Results .................................................................. 41

6.2.2 Disturbance \& Spread Results........................................................ 42

6.2.3 Location Accessibility Results ......................................................... 43

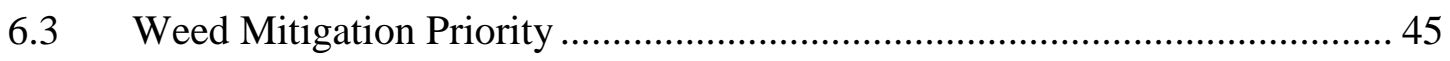

6.4 Invasive Species Infestations to Mitigate ………………................................ 46

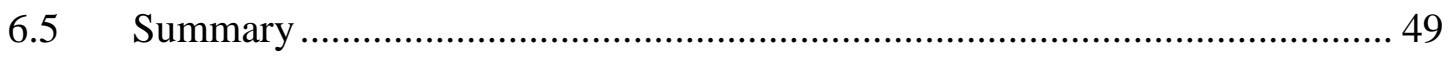

Chapter 7 - Conclusions and Future Work ....................................................................... 51

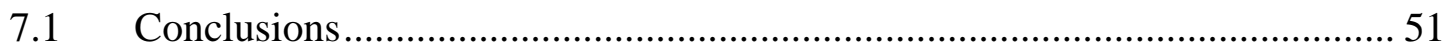

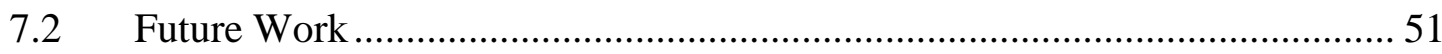

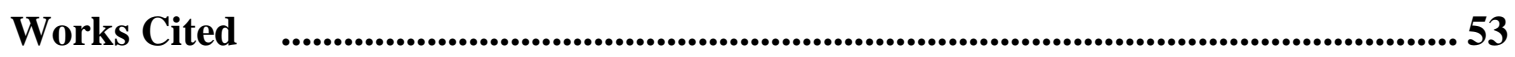

Appendix A. Table of Reclassified Vegetation Types.................................................... 57

Appendix B. Invasive Prioritization Tool Description \& Help ................................... 59

Appendix C. Invasive Prioritization Tool Script ................................................................ 61

Appendix D. Invasive Prioritization Tool's Item Description/Tool Help ................. 67 



\section{Table of Figures}

Figure 1-1. Scope of the project development. ................................................ 1

Figure 3-1. System design................................................................................ 11

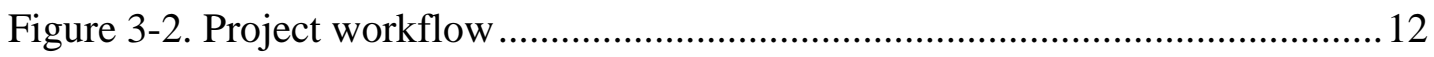

Figure 3-3. Original planned timeline of the project summarized in a Gantt chart... 13

Figure 3-4. Timeline of the project summarized in a Gantt chart............................. 14

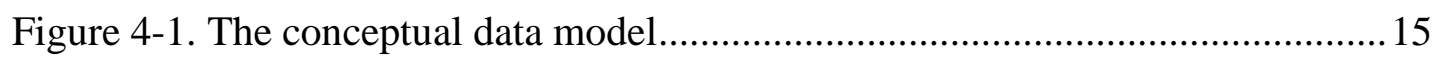

Figure 4-2. The land base conceptual data model............................................. 16

Figure 4-3. The invasive species and habitat conceptual data model ...................... 16

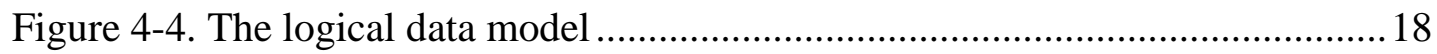

Figure 5-1. Workflow of the data conversion ............................................... 21

Figure 5-2. Data Conversion tool workflow diagram ..........................................25

Figure 5-3. User interface of the Data Conversion Tool ......................................26

Figure 5-4. Overall workflow diagram ....................................................... 27

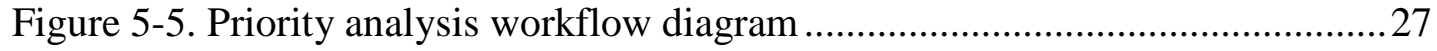

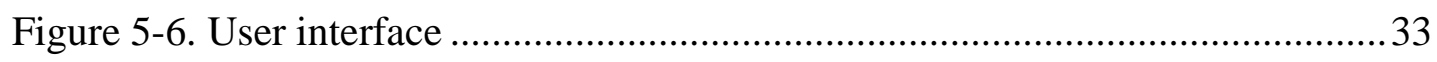

Figure 6-1. Vegetation Types reclassified at full extent of study area .....................3 37

Figure 6-2. Vegetation Types reclassified near the San Elijo Lagoon ......................38

Figure 6-3. Conserved lands reclassified at full extent of study area ......................39

Figure 6-4. Conserved lands reclassified near the San Elijo Lagoon ....................... 40

Figure 6-5. Risk to native habitat weighted overlay results for Cortaderia sp.........41

Figure 6-6. Rank distribution of raster cells in the habitat risk model ....................42

Figure 6-7. Disturbance and Spread weighted overlay results ............................. 42 
Figure 6-8. Rank distribution of raster cells in the disturbance and spread model ... 43

Figure 6-9. Location accessibility weighted overlay for Cortaderia sp................... 44

Figure 6-10. Rank distribution of raster cells in the accessibility model ................. 44

Figure 6-11. Mitigation Priority for Cortaderia $s p$............................................. 45

Figure 6-12. Rank distribution of polygons for Cortaderia sp. ........................... 46

Figure 6-13. Prioritized Cortaderia sp. infestations........................................... 46

Figure 6-14. Prioritized invasive species infestations ....................................... 47

Figure 6-15. Distribution of infestations location ranks................................... 48

Figure 6-16. Map displaying the highest priority infestations ............................. 48 


\section{List of Tables}

Table 1. Description of project requirements..................................................... 9

Table 2. Reclassification of proximity to Roads and Railroads raster datasets .......... 23

Table 3. Reclassification of remaining raster datasets ....................................... 23

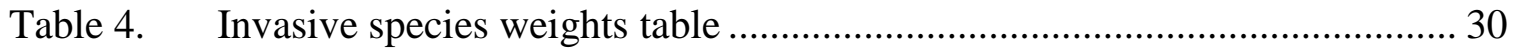





\section{List of Acronyms and Definitions}

$\begin{array}{ll}\text { SELC } & \text { San Elijo Lagoon Conservancy } \\ \text { CHU } & \text { Carlsbad Hydrologic Unit } \\ \text { GIS } & \text { Geographic Information Systems }\end{array}$





\section{Chapter 1 - Introduction}

This chapter outlines the project's client, problem, scope, and solution. The client for this project was San Elijo Lagoon Conservancy, located in Encinitas, California (Section 1.1). San Elijo Lagoon Conservancy needed to prioritize its efforts for performing invasive species mitigation (Section 1.2). The project addressed this objective by creating a tool that ranks potential locations from low to high priority (Section 1.3). This report is intended for restoration ecologists with basic familiarity with geographic information systems (Section 1.4).

\subsection{Client}

The client for this project was San Elijo Lagoon Conservancy (SELC), located in Encinitas, California. SELC is a non-profit organization that works to protect and enhance habitats for native plant and animal species living in the San Elijo Lagoon Ecological Reserve and throughout the entire Carlsbad Hydrologic Unit (Figure 1-1). SELC's Habitat Management Program is responsible for managing habitat restoration and invasive species control in the Carlsbad Hydrologic Unit. The point of contact for this project was SELC's Resource Management Director, David Varner. SELC's Habitat Management Program sought a tool to help them determine where they should focus their efforts for invasive species mitigation given their limited resources.

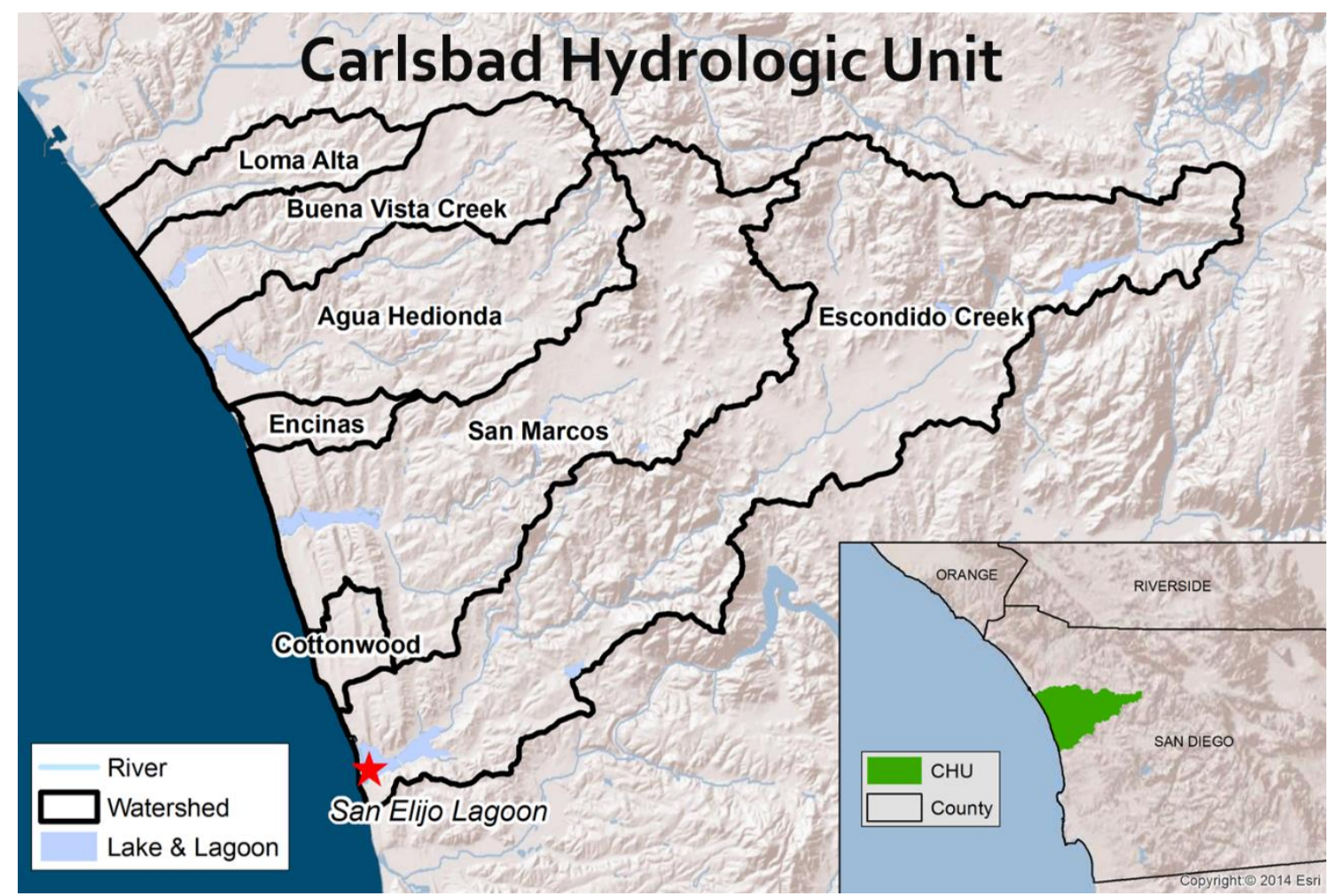

Figure 1-1. Scope of the project development. 


\subsection{Problem Statement}

San Elijo Lagoon Conservancy's Habitat Management Program needed a way to determine where they should focus their efforts for invasive species control in a simple and repeatable process. San Diego's Carlsbad Hydrologic Unit (CHU) is especially important to protect from invasive species due to the large variety of habitats located within it and the even larger number of rare plant and animal species living there. The CHU is located in northern San Diego County and is composed of seven different watersheds that drain into the Pacific Ocean. The CHU contains more than 200 square miles of land consisting of mixed land uses, including conserved lands, agricultural lands, residential areas, and disturbed open spaces. This is a large area for a small non-profit organization with limited resources to manage, therefore it was important to prioritize their efforts. There are numerous invasive species locations throughout the CHU but not every plant poses the same potential threat to sensitive native habitats. Therefore, an assessment of where invasive species mitigation should occur was essential.

\subsection{Proposed Solution}

This section presents the solution that was implemented to address San Elijo Lagoon Conservancy's problem of prioritizing invasive species infestations for mitigation. There were a number of goals and a series of objectives that the project needed complete to solve the Conservancy's problem (Section 1.3.1). The details of the project's scope, including the extent and timeline for the project are presented in Section 1.3.2. Weighted overlay analysis was the main methodology used to prioritize invasive species treatment locations (Section 1.3.3).

\subsubsection{Goals and Objectives}

The overarching goal of this project was to use GIS to protect and preserve native habitats for rare plants and animals and for human benefit, as well. Protecting native habitats is essential for preserving ecosystem functionality and maintaining the health of native plant and animal species. Preserving natural areas is also critical for people, especially children to learn how the environment they live in functions and how everything in nature is connected.

To achieve these goals the project completed a series of specific objectives. The main objective for this project was to deliver a tool that enables San Elijo Lagoon Conservancy to prioritize their efforts for performing invasive species control. In order to complete this objective, the project first collected the required data and supporting information. The next objective was the development of a geodatabase, which organizes and stores all of the data. The other key objective for this project was to develop a tool to prioritize invasive species infestations for treatment. The model would explore invasive species' distribution patterns and prioritize treatment locations based on the different parameters effecting their distribution. It would also consider which individual parameters would pose the highest potential for negative impact on native habitats. Correctly prioritizing treatment locations could greatly reduce the spread of invasive species, thus minimizing their effects on native habitats. The final deliverable provided 
San Elijo Lagoon Conservancy's Habitat Management Program with a tool to allow them to prioritize their efforts using GIS.

\subsubsection{Scope}

The scope of the project was limited to focusing on two invasive species to determine invasive species treatment locations. The selection of the invasive species was determined after discussion with the client. Future enhancement and expansion of this project would allow treatment for additional invasive species. The spatial extent of the project covers the entire Carlsbad Hydrologic Unit. However, this could be expanded on in future work.

The developer was responsible for gathering background information about the project's topic, creating the tool's methodology, developing the tool, and providing user guide documentation. The client was responsible for providing the project data and determining the project requirements. The client was also responsible for assisting the developer with classifying raster datasets and determining the weights used in the analysis.

\subsubsection{Methods}

This project used a combination of waterfall and agile development approaches to manage the general steps taken to achieve the project's objectives. Following the waterfall approach, requirements were obtained from the client at the beginning of the project, the project was completed in phases, and the final product was delivered to the client at the completion of the project. However, like the agile development methodology, the client continued to be involved throughout the course of the project and at the end of each phase. There were reviews of the project's development with the client. In these meetings the successes and needed improvements of each phase were discussed with the client.

Weighted overlay analysis was the main methodology used to prioritize invasive species treatments. The project produced a prioritization score for each invasive species infestation based on weighted criteria values. The criteria values were weighted based on potential risk to sensitive habitats, probability of spread, and location accessibility. The score produced by the tool ranked which invasive species infestations were in most need of treatment. Python and ArcPy modules were used to develop this tool.

\subsection{Audience}

Restoration ecologists with a basic knowledge of GIS are the main audience for this report. Restoration ecologists have expertise in botany and ecology, but may have limited familiarity with GIS. The audience will have general knowledge of GIS terminology but more advanced topics will be explained in simple terms.

\subsection{Overview of the Rest of this Report}

Chapter two provides background information and a literature review on invasive species and using weighted overlay analysis to prioritize infestations. Project requirements, 
system design, and the project plan are described in chapter three. The project's database design is discussed in chapter four. This chapter also includes information about data sources and required data scrubbing. Chapter five provides a detailed explanation of the implementation of the project. The results of the project are analyzed in chapter six. Chapter seven concludes the project and provides examples of future work that could build off this project. 


\section{Chapter 2 - Background and Literature Review}

San Diego's Carlsbad Hydrologic Unit is made of seven watersheds and contains high biodiversity with a large number of threatened and endangered species. San Elijo Lagoon Conservancy (SELC) worked to control the spread of invasive species in the Carlsbad Hydrologic Unit (San Elijo Lagoon Conservancy, 2013a). As part of their work, SELC has used GIS to map over 12,500 invasive species infestations in the Carlsbad Hydrologic Unit (San Elijo Lagoon Conservancy, 2013b). SELC had been using this invasive species data to track where invasive species had been located, plan treatment strategies, and keep records for reporting processes. Treatment strategies had been developed "along with consideration of physiology, life cycle, predicted impact, and dispersal mechanisms of a particular invasive species, project staff prioritized intervention based on proximity to or likelihood of path to infestation of designated conserved lands" (San Elijo Lagoon Conservancy, 2013a, p. 9). The SELC's restoration ecologist developed these treatment strategies, however prioritizing these invasive species treatments was a complicated, manual, and time-consuming task.

\subsection{Invasive Species}

Invasive species are becoming a leading problem in the field of conservation science (Randall, 2000). To eradicate non-native invasive plant species it is essential to understand what makes species invasive and how they affect native habitats. Rejmamek and Richardson (1996) researched the question of "what attributes make some plant species more invasive?" (p. 1655). They discovered that plants had a greater chance of being invasive if they had a "short juvenile period and short interval between large seed crops mean early and consistent reproduction and hence rapid population growth" (p.1658). Plants with these attributes propagate faster than competing plants, allowing these plant species to outcompete other species and therefore become invasive. Invasive species "can reduce the amount of light, water, nutrients, and space available to native species, alter hydrological patterns, soil chemistry, moisture-holding capacity and erodibility, and change fire regimes" (Dark, 2004, p. 1). These effects often result in invasive plants outcompeting native species. When invasive species outcompete native plants, additional changes to the ecosystem occur such as the loss of habitats for native animals (Randall, 2000). Therefore, invasive species could reduce the ability of the habitat to support native flora and fauna and decrease biodiversity. The loss of biodiversity could impact future discoveries of new medicines and increases the effects of global climate change (Endangered Species International, 2011).

\subsection{Prioritizing Habitat Conservation}

Developing a prioritization of which individual native species are the most important to protect is a common strategy used by conservation scientists. Regan, Hier, Franklin, Deutschman, Schmalbach, Winchell, and Johnson (2008) developed a method for prioritizing the protection of native species based on "the type and cause of threat, the degree to which a risk factor contributes to the overall risk a species faces, and the spatial 
and temporal scale of the risk factor" (p. 465). Prioritizing which species are in most need of protection is helpful when conservation scientists' resources are limited. However, developing conservation strategies based solely on which species have the highest priority for protection could result in a plan that does not take into consideration other important factors that would affect conservation and habitat restoration.

A similar conservation strategy identifies risks to habitats and develops a conservation strategy based on those risk factors. Bradley (2010) developed a risk model for assessing the impacts of invasive species and changes in climate and land use that could have a negative impact on sagebrush ecosystems. To assess the potential impact of invasion of non-native species, Bradley (2010) developed maps depicting the risk of invasion for the state of Nevada and used these maps to develop conservation strategies. This study focused on the spread of one invasive species, cheatgrass, and found an association between the prevalence of cheatgrass and elevation. The author also discovered that the presence of roads, farms, and power lines increased the potential for sagebrush degradation. GIS provided essential tools for combining various threats to habitats and developing an effective management strategy (Bradley, 2010). The implementation of GIS in a risk assessment model could allow project leaders to discover relationships between different layers of data that may not been found otherwise. This method usually provides a framework for the beginning stages of habitat conservation.

\subsection{Invasive Species Prioritization}

An alternative approach to habitat conservation is prioritizing the treatment of invasive species populations instead of prioritizing the protection of rare native species. The study performed by Shartell, Nagel, and Storer (2011) used ArcGIS 9.2 ModelBuilder and weighted overlay analysis tools to analyze and predict future propagation of the invasive species garlic mustard. A number of GIS datasets were weighted based on their relationships with three defined phases of invasion: introduction, establishment, and spread. Focusing on these three phases allowed the model to analyze factors that have effects on propagation. A similar study performed by (Forsyth, Maitre, O'Farrell, \& Van Wilgen (2012) prioritized areas to perform invasive species control based on risk to water resources, biodiversity, natural vegetation, and invasiveness of alien species. These approaches to habitat conservation were effective because they allowed conservation scientists to determine which populations of invasive species had the highest potential for degrading the quality of native habitats plants, which was important since invasive species were a major threat to the health of native plants (Regan, et al., 2008).

A number of additional studies used similar categories of data to determine spatial prioritization: spread potential of the plant, potential impacts on native habitats, species, and ecosystems, and cost effectiveness (Brunel, et al., 2010; Wilgen, et al., 2011; Darin G. M., Schoenig, Barney, Panetta, \& DiTomaso, 2010). The methodology used by Darin et al. (2010) specifically used three criteria: impact, invasiveness, and feasibility of eradication. They developed a tool that calculated a score for each infestation and prioritized them based on their importance to be removed. The criteria used to calculate the score were impact, invasiveness, and probability of eradication. The authors used ArcGIS to calculate "the distance to high-valued assets and vectors of spread for each population, and assigned a score depending on the distance" (p. 134). Spatial analysis was key to determining which invasive species should be treated. All variables inside the 
three criteria were weighted based on their importance and then combined to create an output prioritizing the infestations.

\subsection{Multi-criteria Decision Analysis}

Geographic Information Systems are regularly used to perform multi-criteria decision analysis and often used the methodology of ordered weighted averaging (Malczewski, 2000). This methodology has been used to solve a number of land use, suitability, and environmental planning problems (Malczewski, 2000). Ordered weighted averaging is a useful solution to these problems because it combines spatial data with decision-maker's expertise in the field of interest and analyzes the tradeoffs between the different options. "Weights or criterion priorities allow the decision-maker to specify the perceived importance of individual factors relative to the others included in the evaluation" (Carver, 1991, p. 324). This allows the decision-makers to have control over the importance of each factor involved in the analysis. However, the accuracy of the results of the analysis are largely reliant on the quality of data and the decision-maker's knowledge on the subject (Store \& Kangas, 2001).

"The weighted linear combination (WLC) model is one of the most widely used GISbased decision rules" (Malczewski, 2000, p. 5). The WLC decision rule creates a normalized weight by summing the standardized values inside each dataset that are multiplied by the normalized weight for each feature. These calculations resulted in a surface that is prioritized based on a number of layers with common values, weighted based on their importance in the model.

Malczewski (2006) defined a number of steps that were required before the model can be implemented, the feature layers need to be selected, transformed to ranked units, and then assigned weights. These steps were similar to the steps involved when using the ArcGIS tool Weighted Overlay for multi-criteria decision analysis.

The ArcGIS tool Weighted Overlay "overlays several rasters using a common measurement scale and weights each according to its importance" in a user friendly interface (Esri, 2014b). Esri defined similar steps as Malczewski (2006) to use the tool, however they also advised the decision-maker to divide the problem into sub-models to help guide a user to clearly define the parts that make up the problem and ultimately produce improve results (Esri, 2014a).

\subsection{Summary}

The rich native habitats of the Carlsbad Hydrologic Unit (CHU) needed to be protected and conserved. GIS and multi-criteria decision analysis could provide an effective way of identifying the risks to native habitats in the $\mathrm{CHU}$ and developing a mitigation plan. Prioritizing individual rare native plant species was a common and effective way of developing conservation and treatment plans. Prioritizing individual invasive plant species based on a number of weighted criteria would produce the best mitigation plan to protect sensitive native habitats. 



\section{Chapter 3 - Systems Analysis and Design}

This chapter outlines the project's problem statement, requirements analysis, system design, and project plan. San Elijo Lagoon Conservancy needed to prioritize invasive species treatment locations in a simple and repeatable process (Section 3.1). There were a number of requirements obtained from the client that needed to be fulfilled by the completion of the project (Section 3.2). The project developed a tool using Python 2.7 and ArcGIS 10.2 to solve the client's problem (Section 3.3). The project was broken down into phases: requirements gathering, model design, data collection and cleansing, geodatabase creation, model development and testing, and deployment (Section 3.4).

\subsection{Problem Statement}

San Elijo Lagoon Conservancy's Habitat Management Program was in need of a tool that would help them determine where to focus their efforts for invasive species mitigation. The Carlsbad Hydrologic Unit (CHU) contains more than 200 square miles of land consisting of mixed land uses, including conserved lands, agricultural lands, residential areas, and disturbed open spaces. There are numerous invasive species locations throughout the CHU but not every plant poses the same potential threat to the surrounding native habitats. Therefore, an assessment of where invasive species control should occur is essential.

Prioritizing invasive species control is also important due to the limited funds and staffing available to the non-profit conservancy. It is too difficult, time consuming, and expensive for San Elijo Lagoon Conservancy to treat every invasive species located in the CHU. Therefore, mitigation has to be focused on the areas posing the greatest potential threat to native habitats.

\subsection{Requirements Analysis}

The project had a number of functional and non-functional requirements. Table 1 shows a description of each requirement.

\section{Table 1. Description of project requirements}

\begin{tabular}{|l|l|l|l|}
\hline ID & Requirement & Type & Description \\
\hline $\mathbf{1}$ & $\begin{array}{l}\text { Manage data in a centralized } \\
\text { location }\end{array}$ & Functional & $\begin{array}{l}\text { The data obtained shall be } \\
\text { stored in a single location and } \\
\text { cleaned. }\end{array}$ \\
\hline $\mathbf{2}$ & $\begin{array}{l}\text { Rank invasive species } \\
\text { infestations locations }\end{array}$ & Functional & $\begin{array}{l}\text { The tool shall rank prioritized } \\
\text { treatment locations on a scale } \\
\text { from 1-5. Treatment locations } \\
\text { need to be ranked for user to }\end{array}$ \\
\hline
\end{tabular}




\begin{tabular}{|l|l|l|l|}
\hline 3 & $\begin{array}{l}\text { Specify weights for overlay } \\
\text { analysis }\end{array}$ & Functional & $\begin{array}{l}\text { make final decision about } \\
\text { where to perform treatments. }\end{array}$ \\
\hline $\mathbf{5}$ & Generate priority map & Functional & $\begin{array}{l}\text { The project shall allow users to } \\
\text { alter weights of the variables } \\
\text { and add new species to the } \\
\text { table. The weights of variables } \\
\text { can be altered based on user's } \\
\text { advanced knowledge of } \\
\text { invasive species. }\end{array}$ \\
\hline $\mathbf{6}$ & ArcGIS 10.2.2 & $\begin{array}{l}\text { The project shall develop a } \\
\text { map of prioritized treatment } \\
\text { locations. }\end{array}$ \\
\hline
\end{tabular}

The first project requirement was to store all project data in a structured format. The data needed to be delivered to the client at the completion of the project in a consistent and structured format. Therefore, the data obtained had to be cleaned and stored in a single location. The client needed the organized data onsite in order to run the prioritization tool.

There were several requirements associated with the development of the prioritization tool. It was required that the tool had to rank known invasive species infestations on a scale from one to five. The ranked infestations would allow users to visualize the highest priority areas and allow them to make the final decision of how to develop a mitigation plan. The project was required to allow users to easily update the weights of factors as well as species information.

A final map displaying the prioritized treatment locations was required for a visual representation of the tool's output. The client required that the final delivered tool had to be able to run on all computers in the Habitat Management Department. The department consists of five computers with ArcGIS 10.2.2 and required that the developed tool be able to run on each of the computers.

\subsection{System Design}

The final products of the project were a geodatabase, a tool that ranks invasive species infestations, the resulting feature class, and a hard copy map displaying the results. The tool allowed users to perform a series of weighted overlays to rank invasive species treatment locations. The output feature class contained species' scientific names and a prioritization scores ranked from one to five. The infestations with the highest prioritization score are those that posed the highest potential to harm surrounding native 
habitats and they were relatively easy to remove given the assumptions of the model. The map would provide a visual representation of where the Conservancy should focus their efforts.

Figure 3-1 shows the system design of the project. The project used a geodatabase to store the data in an organized and structured format. The datasets were converted from the original shapefiles to feature classes using feature class to feature class processing tool in ArcGIS. The geodatabase did not only store the data, but also help maintain data integrity. The project used a series of weighted overlays that could only be performed using GIS. The weighted overlay analysis allowed all the various factors that affect the species potential to harm native habitats to be used to develop a mitigation plan. The tool encapsulated these weighted overlays in one easy to use dialog box. The tool needed to be a repeatable process that is simple for novice GIS users to run. The project also had to allow users to assign weights used for the overlay analysis on individual invasive species. A user would be able to easily modify and adjust weights of specific species and add new species. The use of Python to develop the tool was essential to achieve this functionality.

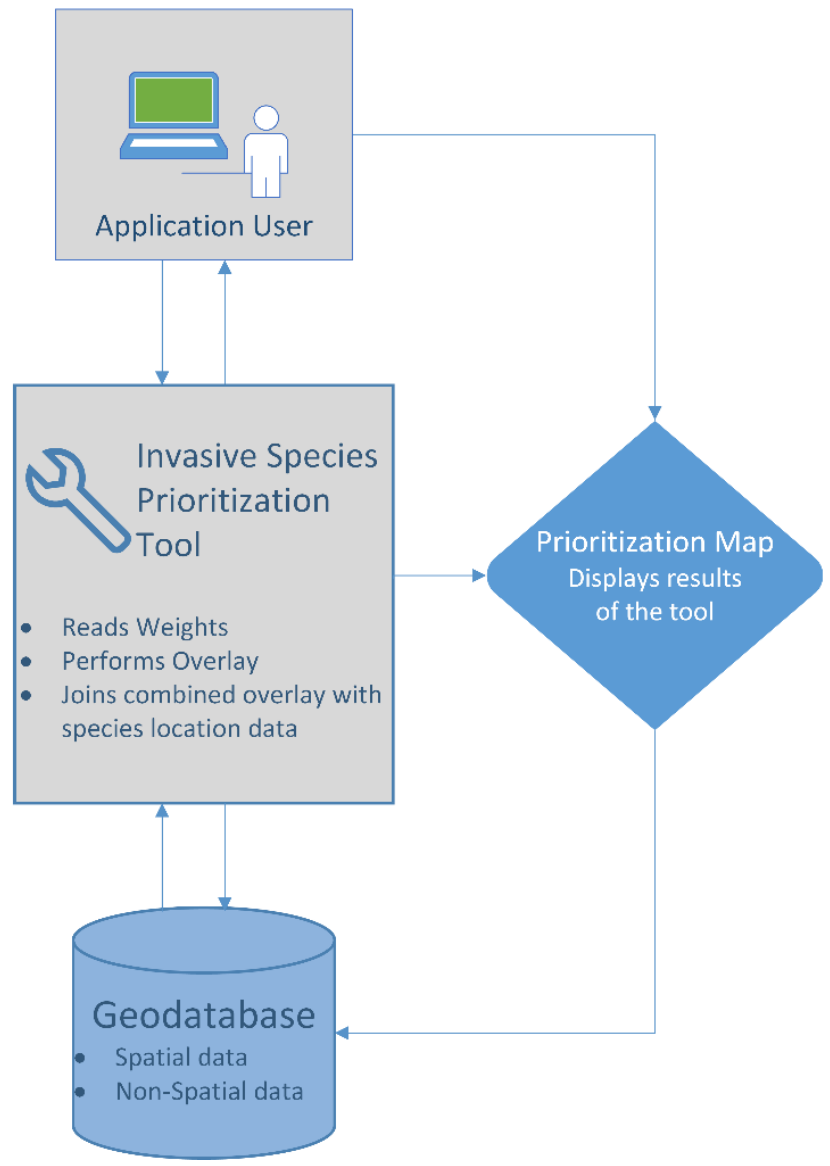

\section{Figure 3-1. System design}

A hard copy map displaying the results of the tool was created. The production of a hard copy map was helpful for non-GIS users that needed to understand the results of the tool. The client needed to have the same version of ArcGIS software on their computers in order to be able to successful run the tool on any computer in that department. 


\subsection{Project Plan}

Figure 3-2 displays the project workflow in six stages: requirements gathering, model design, data collection and cleansing, geodatabase creation, model development, and deployment.

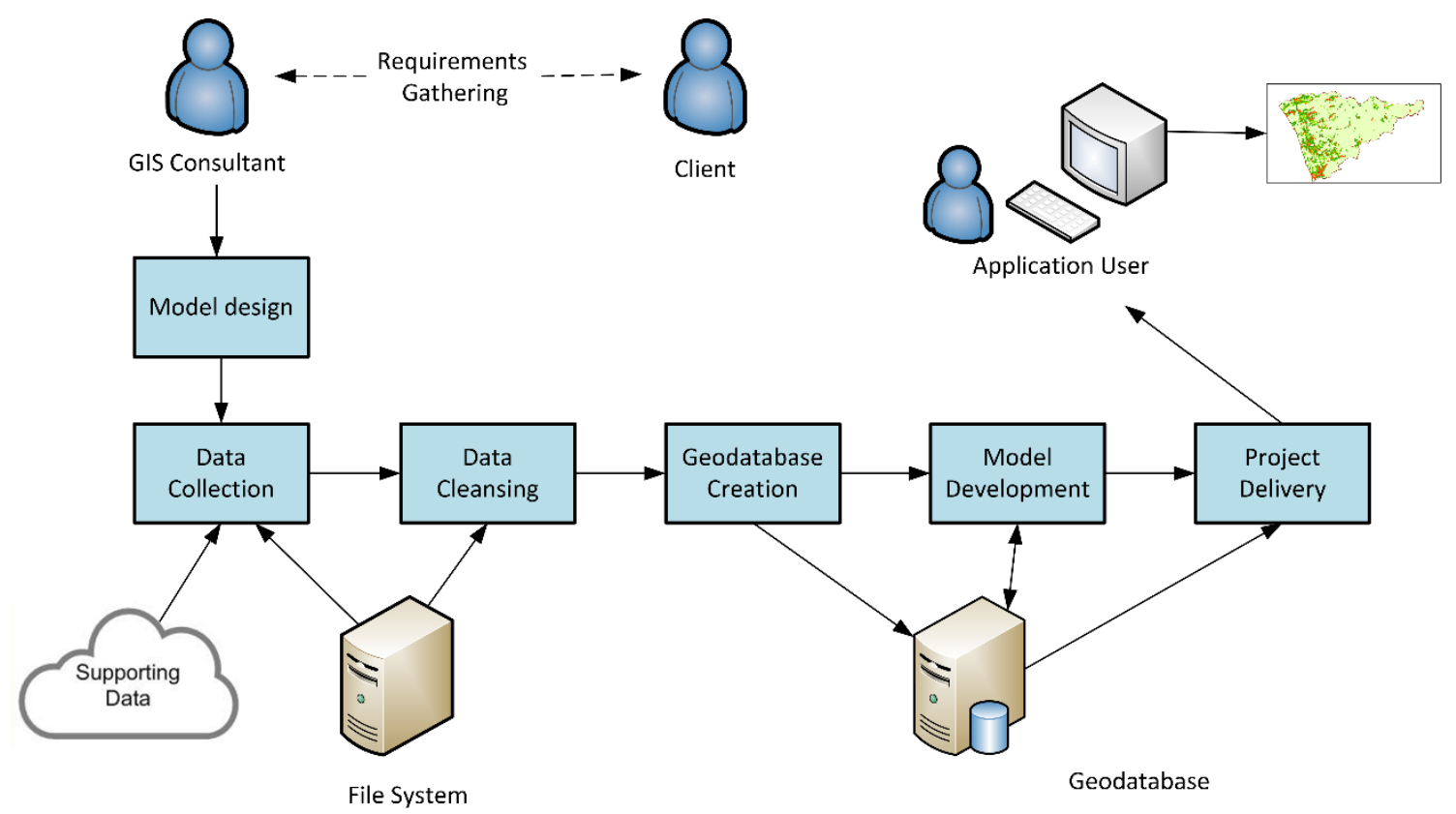

Figure 3-2. Project workflow

The original planned timeline is displayed in Figure 3-3. During the analysis and design phase of the project, project requirements were identified from regular meeting with the client. The requirements were used to develop the system design. The original project plan was to collect data prior to model design. 


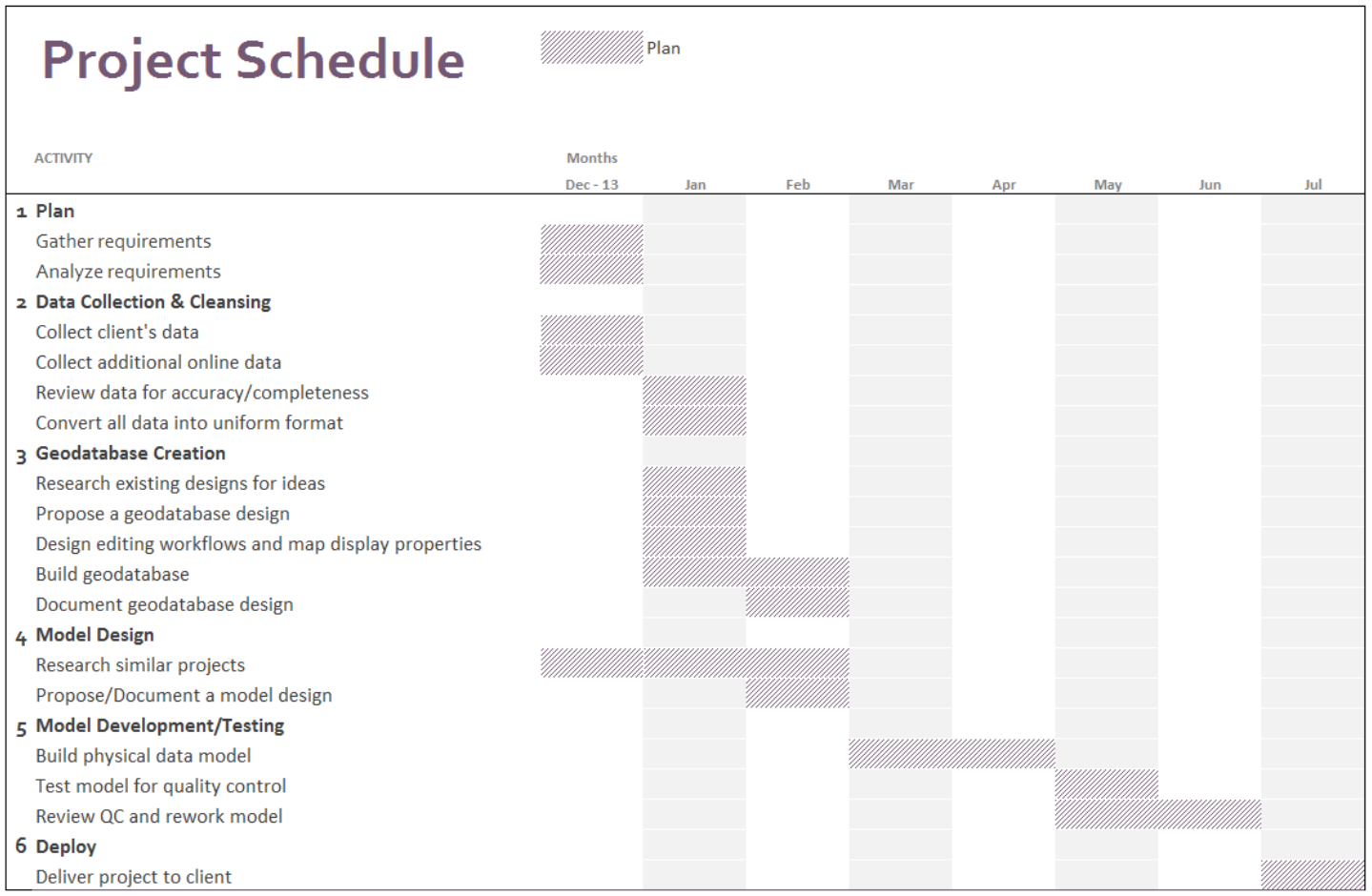

Figure 3-3. Original planned timeline of the project summarized in a Gantt chart.

However, the project plan was altered to first design the model and then collect the data required to support that model design. The final completed timeline for project development is displayed in Figures 3-4.

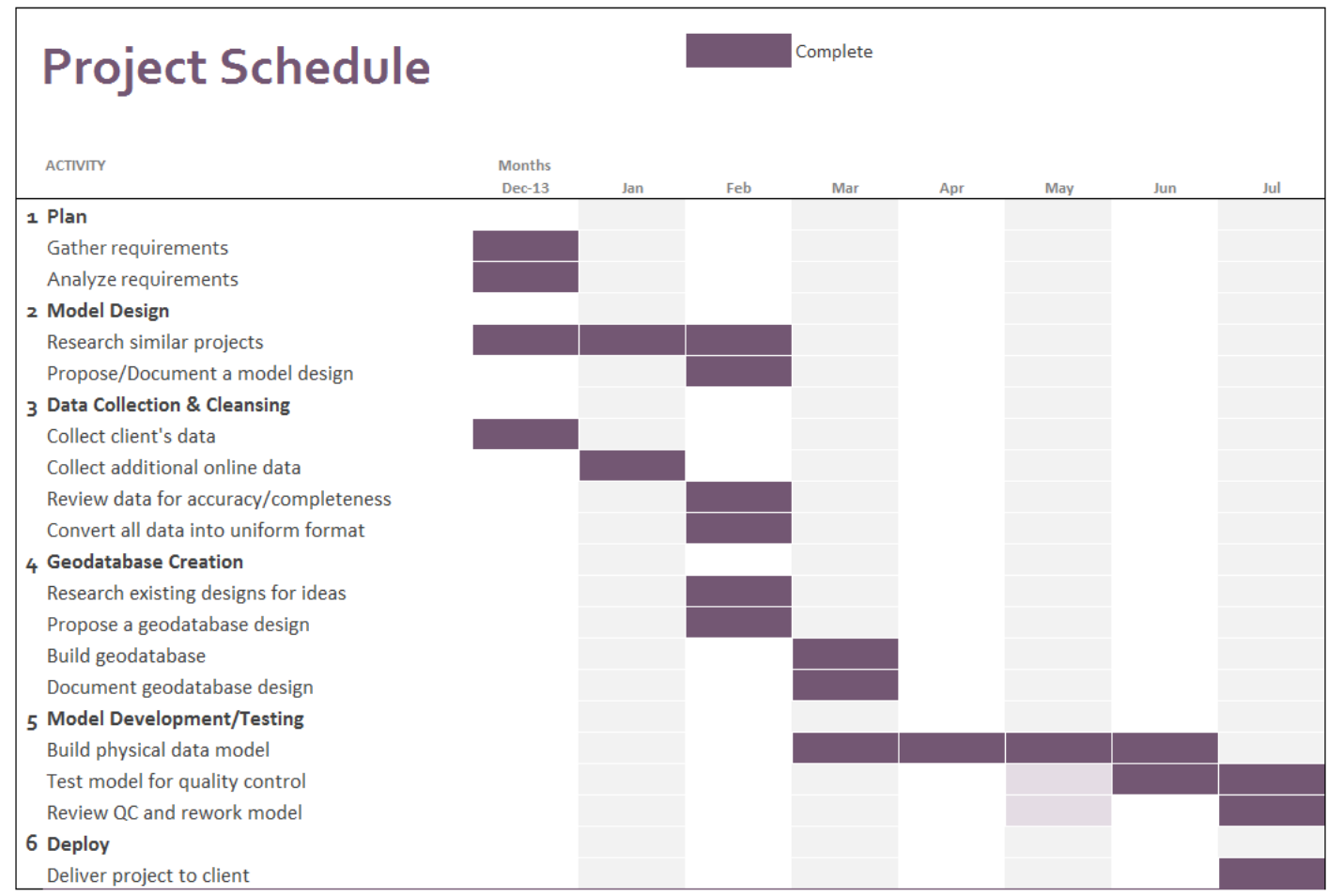


Figure 3-4. Timeline of the project summarized in a Gantt chart.

Data acquisition occurred during the development phase of the project. The client's file system was the main source for the data. However, additional data not available on the client's file system were collected online from SanGIS. All of the required data and supporting information were acquired by the end of January 2014, one month behind the planned schedule. The assessment and conversion of the data was completed one month behind the original schedule as well, due to the delay in data collection.

The next stage of the project was the creation of the geodatabase and quality assurance. Data obtained from multiple sources were not in a uniform format needed for the project, therefore data cleansing was critical. The development of a geodatabase and data cleansing were completed by the end of March 2014, one month behind the original schedule.

The tool was developed using the underlying processes of weighted overlay analysis. The creation of the tool required the majority of the project's workload and time. The project devoted four months to this phase. Two additional months were spent to develop the tool than originally planned. After a framework for the model was completed, the project devoted forty days starting in the month of May to testing, improving, and enhancing the model. Testing for quality control was necessary to ensure the reliability of the tool. The final phase of the project was delivering the tool and geodatabase to the client.

\subsection{Summary}

San Elijo Lagoon Conservancy needed a tool to help prioritize invasive infestations in a repeatable and uniform process. The requirements obtained from the client during the first phase of the project outlined the system design of the project. These requirements lead to the project using Python 2.7 and ArcGIS 10.2 to create the prioritization tool. The project was broken down into several phases to complete the development of the tool and achieve all project requirements. 


\section{Chapter 4 - Database Design}

Chapter 4 describes the project's conceptual data model, logical data model, data sources, data collection, and data cleansing. The conceptual data model describes the associations among the features used to develop the tool (Section 4.1). The details of the project's logical model are defined in Section 4.2. The data source and data scrubbing are discussed in sections 4.3 and 4.4 .

\subsection{Conceptual Data Model}

The conceptual data model illustrates the relationships among the entities in the project's areas of interest. The three figures below show how invasive species and their habitat relate to one another as well as how the conservancy inputs are associated. The conceptual model can be broken down into two sub-models: invasive species habitat conceptual data model and land base model. Figure 4-1 illustrates the complete conceptual data model showing the associations between the land base model and invasive species habitat conceptual data model.

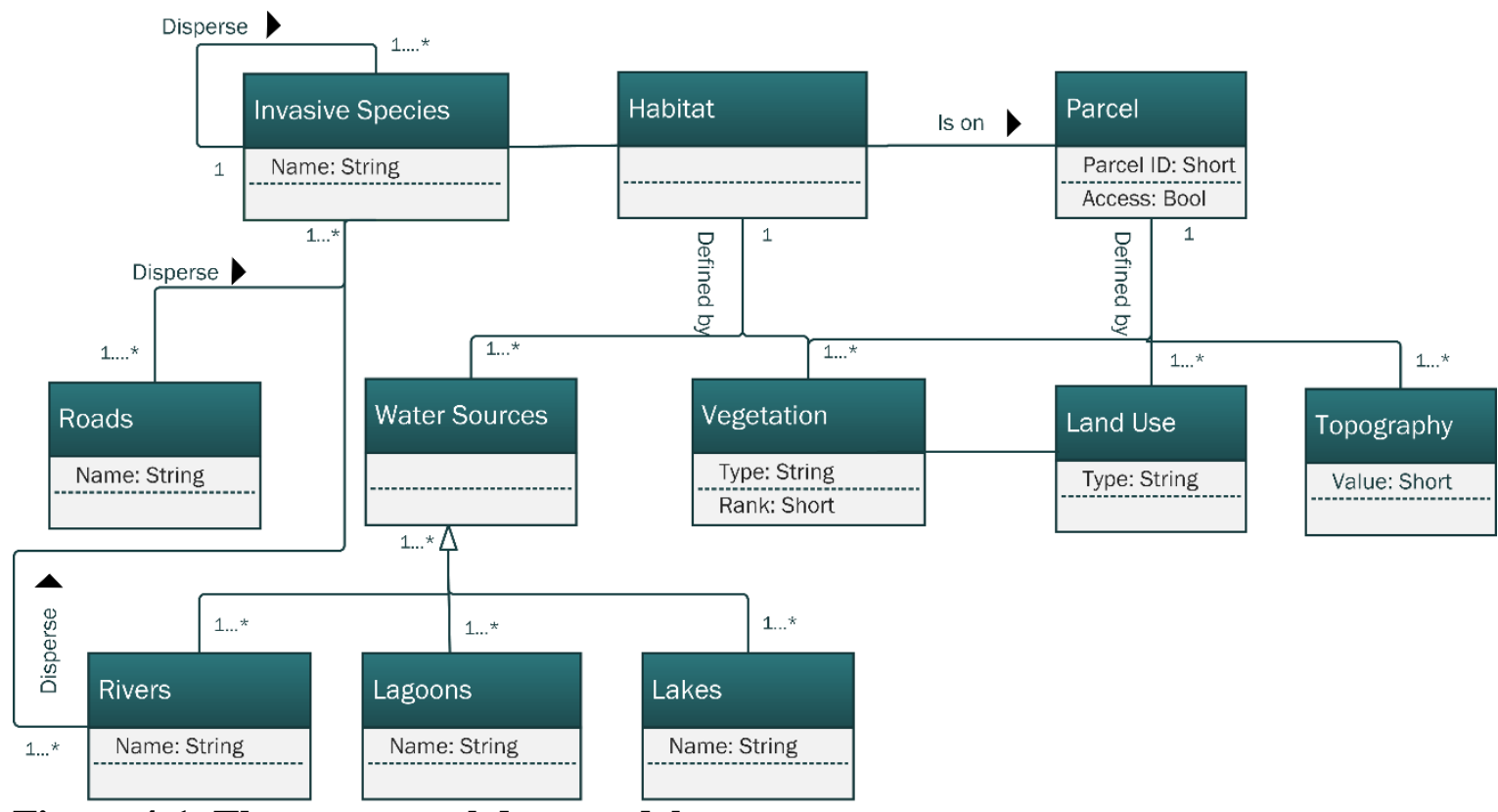

Figure 4-1. The conceptual data model

Figure 4-2 breaks down the complete conceptual model and illustrates the relationships between land base features used in the model. The Conservancy specifically requested that vegetation types, parcel access, land use, and slope be used to determine where to develop mitigation plans. 


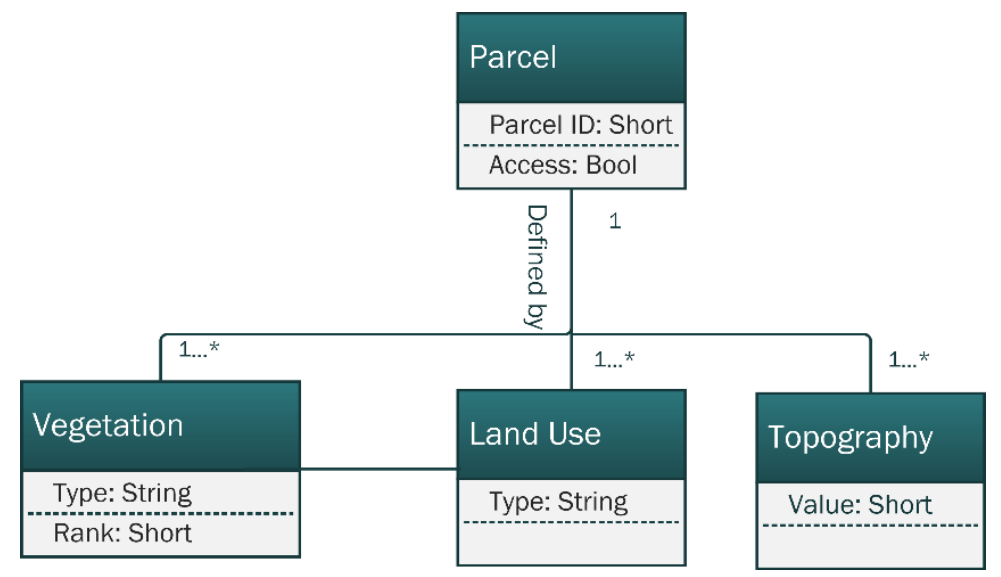

Figure 4-2. The land base conceptual data model

Parcels are defined by their land use, vegetation type, and topography. All parcels have specific vegetation classes on them. The topography of the parcel defines the steepness of the terrain. Land use describes the legal status of a parcel, whether it is privately owned, a conserved land, or an ecological reserve. Conserved lands are preserved open spaces that legally cannot be developed in order to protect native habitats and animal species. Ecological reserves were also created due to the rare native types of animals and vegetation that exist on them, but conserved for scientific research and educational purposes.

Figure 4-3 shows the relationships involved in the invasive species habitat conceptual data model. The locations and spread of invasive plant species are related to the habitat where they are found.

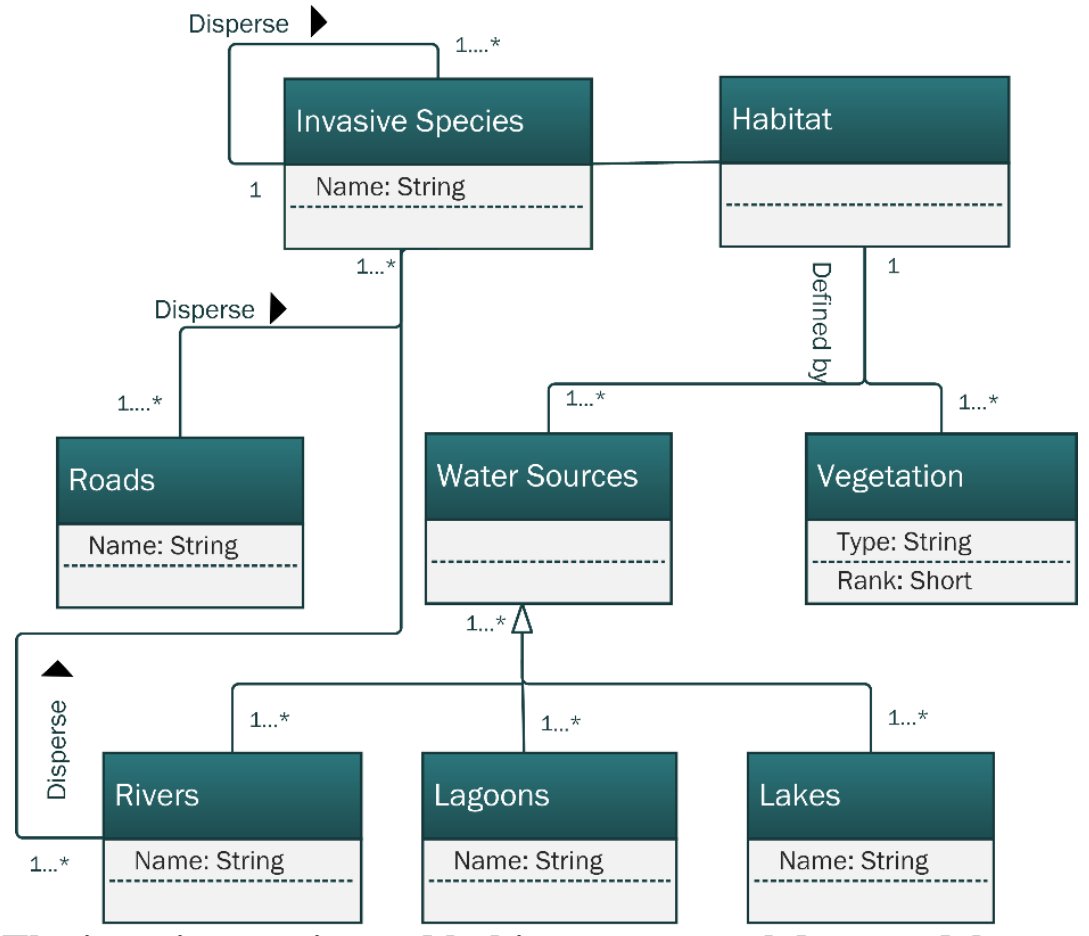

Figure 4-3. The invasive species and habitat conceptual data model 
A habitat is determined by its vegetation type and the water sources available to it. Rivers, lagoons, and lakes are three categories of water sources that affect a habitat. Water sources are also related to the types of vegetation that can exist in that habitat. Other invasive species, roads, and rivers affect the dispersion of invasive species. The presence of other invasive species can influence the spread of that invasive infestation. Invasive species can outcompete native species and degrade native habitats; therefore, degraded habitats are more vulnerable to other invasive species. Roads, slope, and rivers directly affect the dispersion for invasive species as they are systems of transportation for propagation of seeds. Slope is related to the direction of dispersion as seeds are more likely to spread to areas of equal or lower elevation rather than higher elevations.

\subsection{Logical Data Model}

Several hydrologic, ecologic, and urban datasets were required for the series of weighted overlays and the resulting map. The most important dataset was the invasive species infestations in the Carlsbad Hydrologic Unit. Each feature in the dataset was either a polygon identifying individual invasive species or a polygon identifying a cluster of invasive species. The data contained attribute information describing the species scientific name, observation date, and percent cover. The invasive species data were required to have high positional accuracy and needed to be current within the last ten years. The hydrologic datasets included rivers, lakes, and lagoons. The project required ecologic datasets for vegetation types, conserved lands, and slope. The urban datasets included roads, railroads, parcels, and San Elijo Lagoon Conservancy parcel right of access.

The project acquired large-scale data, which needed to be projected in the NAD 1983 California State Plane projection VI with the Federal Information Processing Standard code 0406. California State Plane projection was chosen due to the high accuracy it provide inside the study area and its common use by local government agencies. The extent of the datasets was the boundary of the Carlsbad Hydrologic Unit.

The project's logical data model was managed in an ArcGIS Geodatabase. Figure 44 illustrates the design of the logical data model used for the project. The geodatabase contained feature datasets, feature classes, rasters, and a standalone table. Four feature datasets contained the original vector data: Land Base, Hydrology, Transportation, and Ecology. The Land Base feature dataset included parcel and San Elijo Lagoon Conversancy's Parcel Access feature classes. The Hydrology feature dataset contained Rivers \& Streams, Lakes \& Lagoons, and Basins. Roads and Railways were grouped together in the Transportation feature dataset. The Ecology feature dataset included Vegetation Types, Conserved Lands, Ecological Reserves, At Risk Species, and Invasive Species. 


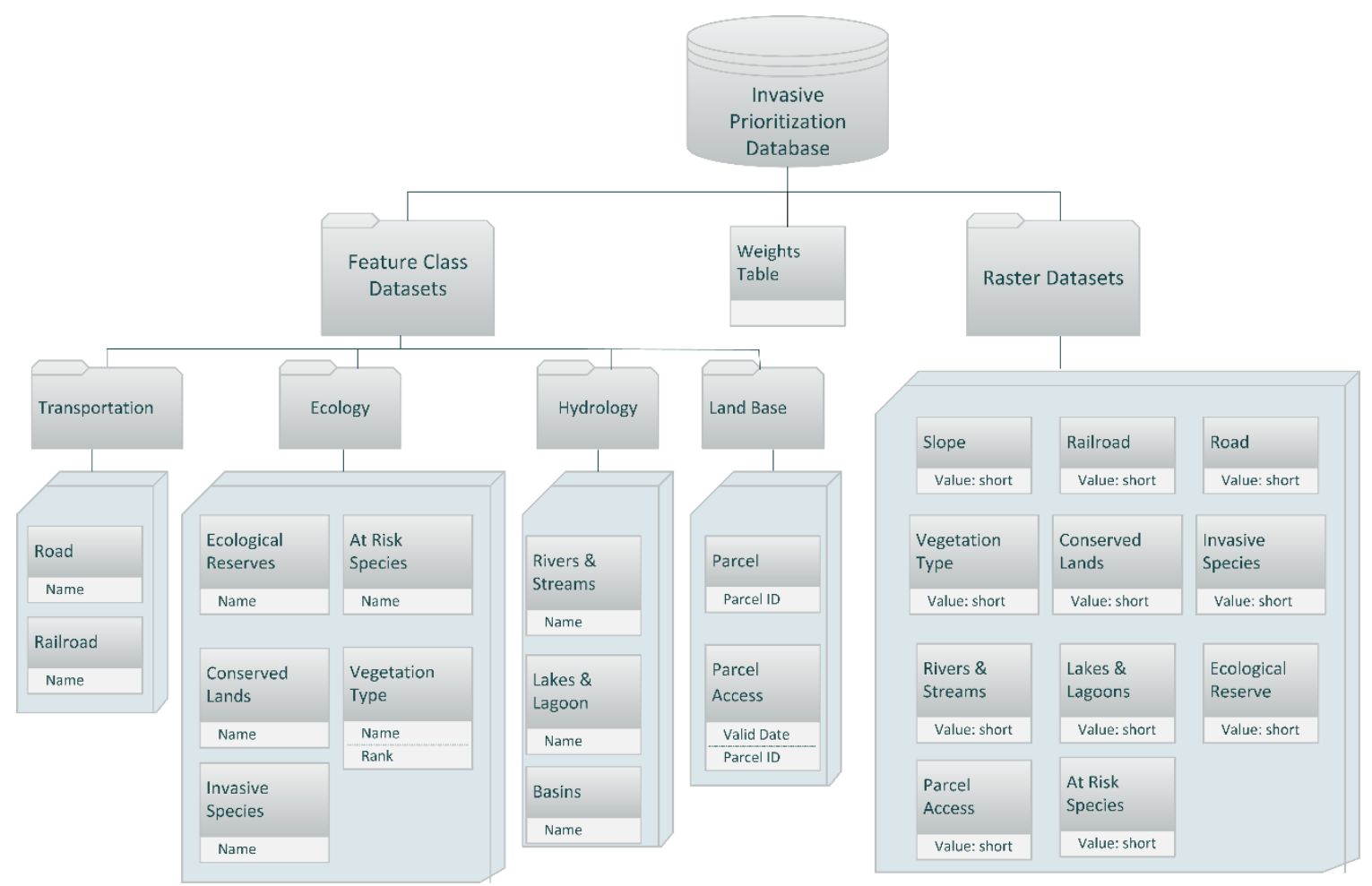

Figure 4-4. The logical data model

The ArcGIS tool Weighted Overlay requires that all input data are in raster format. Therefore, each dataset used in the weighted overlays had to be converted from vector to raster data format. The final reclassified rasters were stored in the geodatabase as rasters. The rasters contained proximity data to Railroads, Roads, Conserved Lands, Invasive Species, Rivers \& Streams, Lakes \& Lagoons, and At Risk Species. The values of the slope raster were reclassified values calculated from the original Digital Elevation Model. The Parcel Access raster contained values of either one or zero based on whether the Conservancy has access to each individual parcel. The Vegetation Types dataset was reclassified based on importance of preserving each individual type.

\subsection{Data Sources}

The data were sourced from SanGIS and directly from the client. The data obtained from SanGIS were originally collected by the Integrated Pest Control Division in the Department of Agriculture. SanGIS owns the rights to this dataset. SanGIS required users of the data to source SanGIS when the data are used in written reports, publications, and presentations. SanGIS also prohibits users from altering their data and redistribute them as if they were original SanGIS data.

The invasive species infestation data were sourced directly from the client, San Elijo Lagoon Conservancy (SELC). SELC is the original source of the data and owns the rights to this dataset. Ecologists working for SELC collected the invasive species data in the field and remotely in the office using satellite imagery. This dataset did not need to adhere to any licensing constraints in this project. 


\subsection{Data Scrubbing and Loading}

The vector data were originally in shapefile format and were converted into feature classes. The shapefiles were imported individually into the geodatabase using the ArcMap tool Feature to Feature Class. The data sourced from SanGIS did not require any clean up. The invasive species shapefile obtained from the client required cleansing as it contained non-standardized names of invasive species. Time was spent to update the dataset names.

The feature classes used to perform weighted overlays had to be converted from vector to raster data types. Euclidean distance was calculated to railroads, roads, conserved lands, invasive species, rivers, lagoons, and lakes. All raster datasets were reclassified based on priority, set by the client.

\subsection{Summary}

The conceptual data model illustrated the associations between features in the project's areas of interest. The schema for the logical model was developed based on the relationships identified in the conceptual data model. The majority of the data were provided by the client and were originally sourced from SanGIS. The datasets were delivered in shapefile format and converted to feature classes. Feature classes used in the weighted overlays were further converted into raster datasets and reclassified. 



\section{Chapter 5 - Implementation}

This chapter describes the implementation of the project. Section 5.1 goes over the data conversion, preparation, and the Data Conversion Tool. Section 5.2 describes how the Priority Analysis Tool was developed using a weighted overlay function and a supporting weights table. The user interface of the Priority Analysis Tool is discussed at the end of Sections 5.2.

\subsection{Data Conversion}

The original project data were acquired in vector format, with the exception of the Digital Elevation Model, which was in raster format. Weighted overlay can only be performed on raster data, requiring all vector data to be converted to raster format. Additionally, Euclidean distances were calculated as proximity to features including Roads, Conserved Lands, Invasive Species, Lakes \& Lagoons, Railroads, Rivers \& Streams, State Ecological Reserves, and At Risk Species. All raster data were reclassified to values ranging from one to five based on previous studies and client requests. Figure 5-1 shows the workflow of the preliminary data processing.

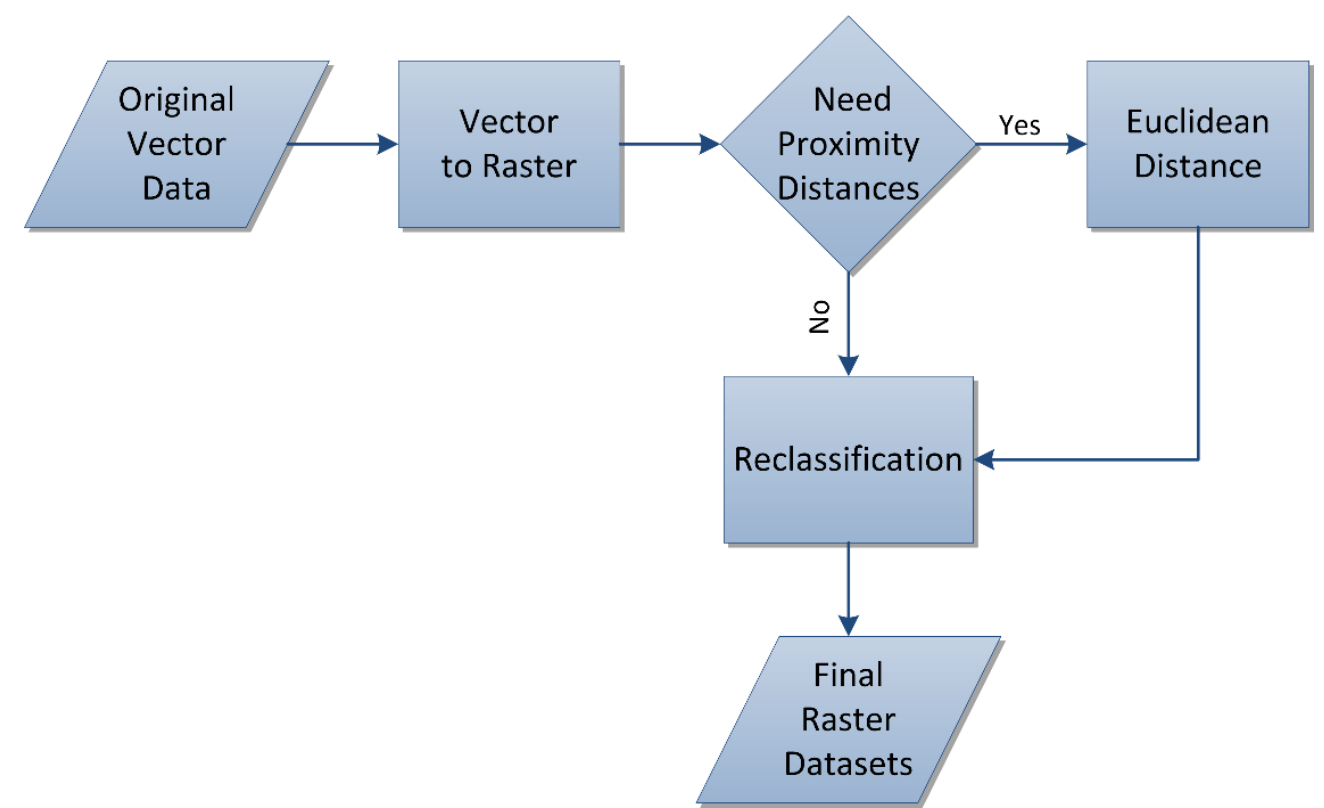

Figure 5-1. Workflow of the data conversion

\subsubsection{Vector to Raster}

The data that were converted to raster format included: Roads, Conserved Lands, Invasive Species, Lakes \& Lagoons, Parcel Access, Railroads, Rivers \& Streams, State Ecological Reserves, Vegetation Types, and At Risk Species. These data were converted from vectors to rasters using the ArcMap conversion tool Feature to Raster. The parameters used for this tool were input features, field, output raster, and cell size. All 
features were converted to rasters with a cell size of five-by-five feet. The small cell size was chosen to be able to accurately represent the small features in the datasets; for example individual plant locations and narrow streams. The fields used to define the values of the output raster had to be integer values. The only important aspect of the Roads, Conserved Lands, Invasive Species, Lakes \& Lagoons, Railroads, Rivers \& Streams, State Ecological Reserves, and At Risk Species datasets were their physical locations, since the attributes associated with them are not required for the tool analysis. Therefore, the fields to base the rasters on were arbitrarily chosen.

The Vegetation Types and Parcel Access data were converted to rasters based on unique fields. The vector Vegetation Types data had a field of Rank. This field contained integer values ranging from one to five ranking the category of vegetation based on how important it is to protect and preserve. The client provided the rankings for each type of vegetation, which were used to populate the Rank field. For example, urban developed areas and intensive agriculture were given a ranking of one while southern riparian scrub and coastal sage scrub were ranked with the highest importance of five. When converting to raster, the field of Rank was used as the raster values.

The vector Parcel Access data contained an integer field stating if San Elijo Lagoon Conservancy had current access to a parcel to perform invasive species treatments. This field contained the date the permission was valid through and was used as the value to create the raster dataset. This resulted in a raster containing parcels either with permission or without permission. After all the datasets were converted to raster data types further pre-processing on the datasets was required including calculating proximity distances and reclassifying the datasets.

\subsubsection{Proximity Calculation}

Euclidian distance was calculated for all features that required proximity distances. These distances were created using the ArcMap Spatial Analyst tool Euclidian Distance. This tool calculates the Euclidean distance to the closest feature for every cell in the raster.

Euclidean distance was calculated on the Roads, Conserved Lands, Invasive Species, Lakes \& Lagoons, Railroads, Rivers \& Streams, State Ecological Reserves, and At Risk Species rasters to determine the proximity to these features. Proximity to Roads was generated using Euclidean distance to define the areas that are closer and further away from any Road feature. Proximity distances were also calculated the rest of the listed features to all locations within the Carlsbad Hydrologic Unit.

\subsubsection{Reclassification}

All raster data were reclassified using the ArcMap Spatial Analyst tool Reclassify. To perform the weighted overlay calculations, it was necessary that all raster datasets contained integer values. Therefore, it was essential that all raster data were reclassified based on a normalized scale. Table 2 shows how the Roads and Railroads rasters were reclassified. 
Table 2. Reclassification of proximity to Roads and Railroads raster datasets

\begin{tabular}{|c|c|c|}
\hline Raster & Ranges & Reclassification \\
\hline \multirow{4}{*}{ Roads } & $<32 \mathrm{ft}$. & 5 \\
& $32-82 \mathrm{ft}$. & 4 \\
& $82-164 \mathrm{ft}$. & 3 \\
& $164-328 \mathrm{ft}$. & 2 \\
& $>328 \mathrm{ft}$. & 1 \\
\hline \multirow{5}{*}{ Railroads } & $<32 \mathrm{ft.}$ & 5 \\
& $32-82 \mathrm{ft}$. & 4 \\
& $82-164 \mathrm{ft}$. & 3 \\
& $164-328 \mathrm{ft}$. & 2 \\
& $>328 \mathrm{ft}$. & 1 \\
\hline
\end{tabular}

The Euclidean distance tool calculated how far each cell was away from the nearest road or railroad feature. The values in the Roads and Railroads proximity rasters were reclassified into integer values ranging from one to five based on a defined range of values. Several scientific papers that studied the effects of roads on seed dispersal were reviewed to determine this range of values, especially the study performed by Hansen and Clevenger (2005). This study found that there was a significant decrease in presence of invasive species with increasing distance from roads and railroads. Therefore, the probability of seed dispersal decreases as the distance increases from these transportation vectors.

Euclidean distances calculated for Conserved Lands, Ecological Reserves, Lakes \& Lagoons, Rivers \& Streams, Invasive Species, and At Risk Species were reclassified based on the same range values. These range values were based on the distance away from each feature in the raster. For example areas that were farther away from an ecological reserve were reclassified with lower values than closer areas, therefore having a lower priority. Table 3 shows the exact values of the ranges that were determined by the client, based upon their expertise in the field.

Table 3. Reclassification of remaining raster datasets

\begin{tabular}{|l|c|c|}
\hline Raster & Ranges & Reclassification \\
\hline \multirow{5}{*}{ Conserved Lands } & $<50 \mathrm{ft}$. & 5 \\
& $50-100 \mathrm{ft.}$ & 4 \\
& $100-500 \mathrm{ft}$. & 3 \\
& $500-1,000 \mathrm{ft}$. & 2 \\
& $>1,000 \mathrm{ft}$. & 1 \\
\hline \multirow{5}{*}{ Invasive Species } & $<50 \mathrm{ft}$. & 5 \\
& $50-100 \mathrm{ft}$. & 4 \\
& $100-500 \mathrm{ft}$. & 3 \\
& $500-1,000 \mathrm{ft}$. & 2 \\
& $>1,000 \mathrm{ft}$. & 1 \\
\hline
\end{tabular}




\begin{tabular}{|c|c|c|}
\hline Lakes \& Lagoons & $\begin{array}{c}<50 \mathrm{ft} . \\
50-100 \mathrm{ft} . \\
100-500 \mathrm{ft} . \\
500-1,000 \mathrm{ft} . \\
>1,000 \mathrm{ft} .\end{array}$ & $\begin{array}{l}5 \\
4 \\
3 \\
2 \\
1\end{array}$ \\
\hline Parcel Access & $\begin{array}{c}\text { Access Current } \\
\text { No Access }\end{array}$ & $\begin{array}{l}5 \\
1 \\
\end{array}$ \\
\hline Rivers \& Streams & $\begin{array}{c}<50 \mathrm{ft} . \\
50-100 \mathrm{ft} . \\
100-500 \mathrm{ft} . \\
500-1,000 \mathrm{ft} . \\
>1,000 \mathrm{ft} .\end{array}$ & $\begin{array}{l}5 \\
4 \\
3 \\
2 \\
1\end{array}$ \\
\hline Slope & $\begin{array}{c}<5 \text { degrees } \\
5-25 \text { degrees } \\
25-40 \text { degrees } \\
40-60 \text { degrees } \\
>60 \text { degrees }\end{array}$ & $\begin{array}{l}5 \\
4 \\
3 \\
2 \\
1\end{array}$ \\
\hline Ecological Reserves & $\begin{array}{c}<50 \mathrm{ft} . \\
50-100 \mathrm{ft} . \\
100-500 \mathrm{ft} . \\
500-1,000 \mathrm{ft} . \\
>1,000 \mathrm{ft} .\end{array}$ & $\begin{array}{l}5 \\
4 \\
3 \\
2 \\
1\end{array}$ \\
\hline Vegetation Types & see Appendix A & $\begin{array}{l}5 \\
4 \\
3 \\
2 \\
1\end{array}$ \\
\hline At Risk Species & $\begin{array}{c}<50 \mathrm{ft} . \\
50-100 \mathrm{ft} . \\
100-500 \mathrm{ft} . \\
500-1,000 \mathrm{ft} . \\
>1,000 \mathrm{ft} .\end{array}$ & $\begin{array}{l}5 \\
4 \\
3 \\
2 \\
1\end{array}$ \\
\hline
\end{tabular}

The Vegetation Types raster reclassification was also determined by the client. The original dataset contained 59 different types of vegetation covers. These vegetation classes were ranked from one to five based on their importance for preservation, with five being the most important to protect (Appendix A).

The Parcel Access raster was reclassified based on whether the Conservancy had permission to access the parcel to perform invasive species mitigation on the property. Slopes calculated from DEM were reclassified based on the difficulty to perform treatments on. Steep areas with a slope over 60 degrees would be difficult and costly to access, therefore these areas were given the lowest priority of one. 


\subsubsection{Data Conversion Tool}

The data conversion performed on the original data used ArcMap desktop tools; it was a tedious and time consuming process. Therefore, a Data Conversion Tool was created for the client to easily update the data in the Invasive Prioritization geodatabase. The client updates their GIS datasets several times a year and the tool should run the most up-todate data in order to get the most accurate and current results. The Data Conversion Tool was created for the user to update the datasets that required proximity distances in a simple process. Figure 5-2 shows the workflow diagram of the Data Conversion Tool.

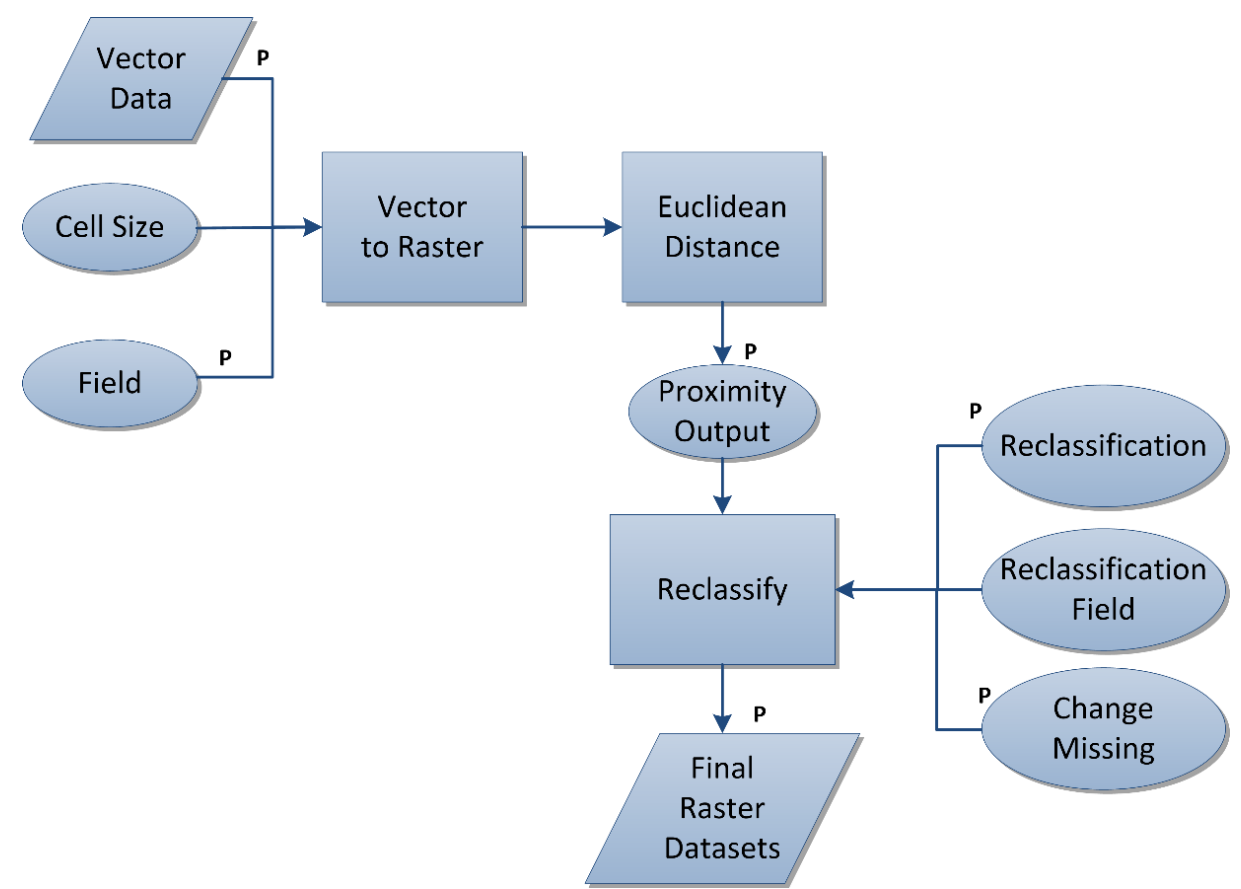

Figure 5-2. Data Conversion tool workflow diagram

The Conservancy acquired the majority of their GIS data in vector format, which has to be converted to rasters to be used in weighted overlay. After the data were converted, Euclidian distance is calculated on the non-continuous raster datasets and then reclassified. This process would require the user to run three separate tools in ArcGIS. With the Data Conversion Tool, the user only has to run one dialog box and enter only a fraction of the input parameters. Figure 5-3 shows the user interface of the tool. 


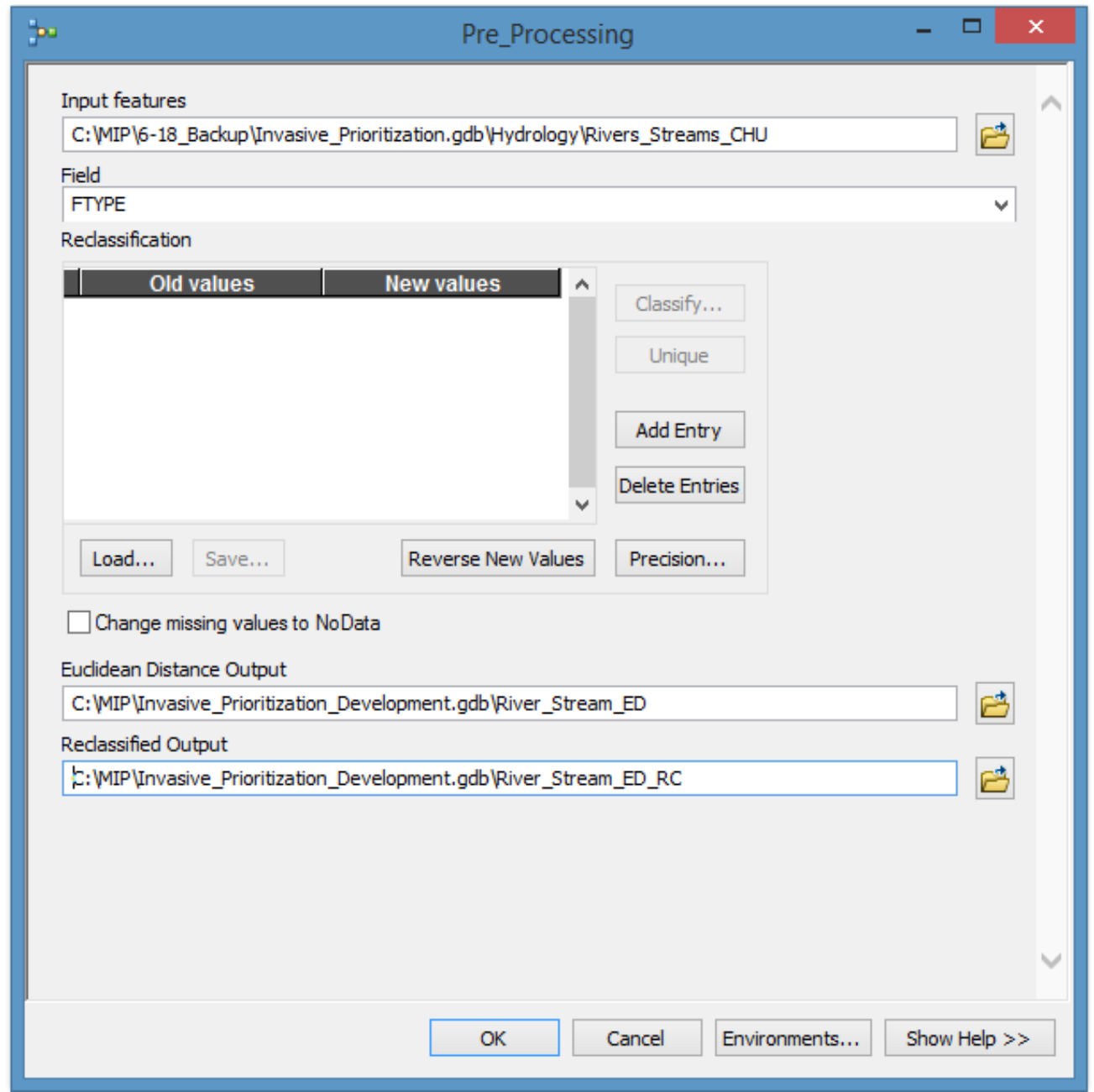

Figure 5-3. User interface of the Data Conversion Tool

\subsection{Priority Analysis Tool}

After preliminary data processing was completed on all the features, the tool development was completed using Python and ArcGIS's ArcPy modules. Appendix C presents the tool's entire Python script. The tool was created to allow users to perform a series of weighted overlays to rank invasive species infestation for mitigation. Figure 5-4 shows the overall workflow of the Priority Analysis Tool. 


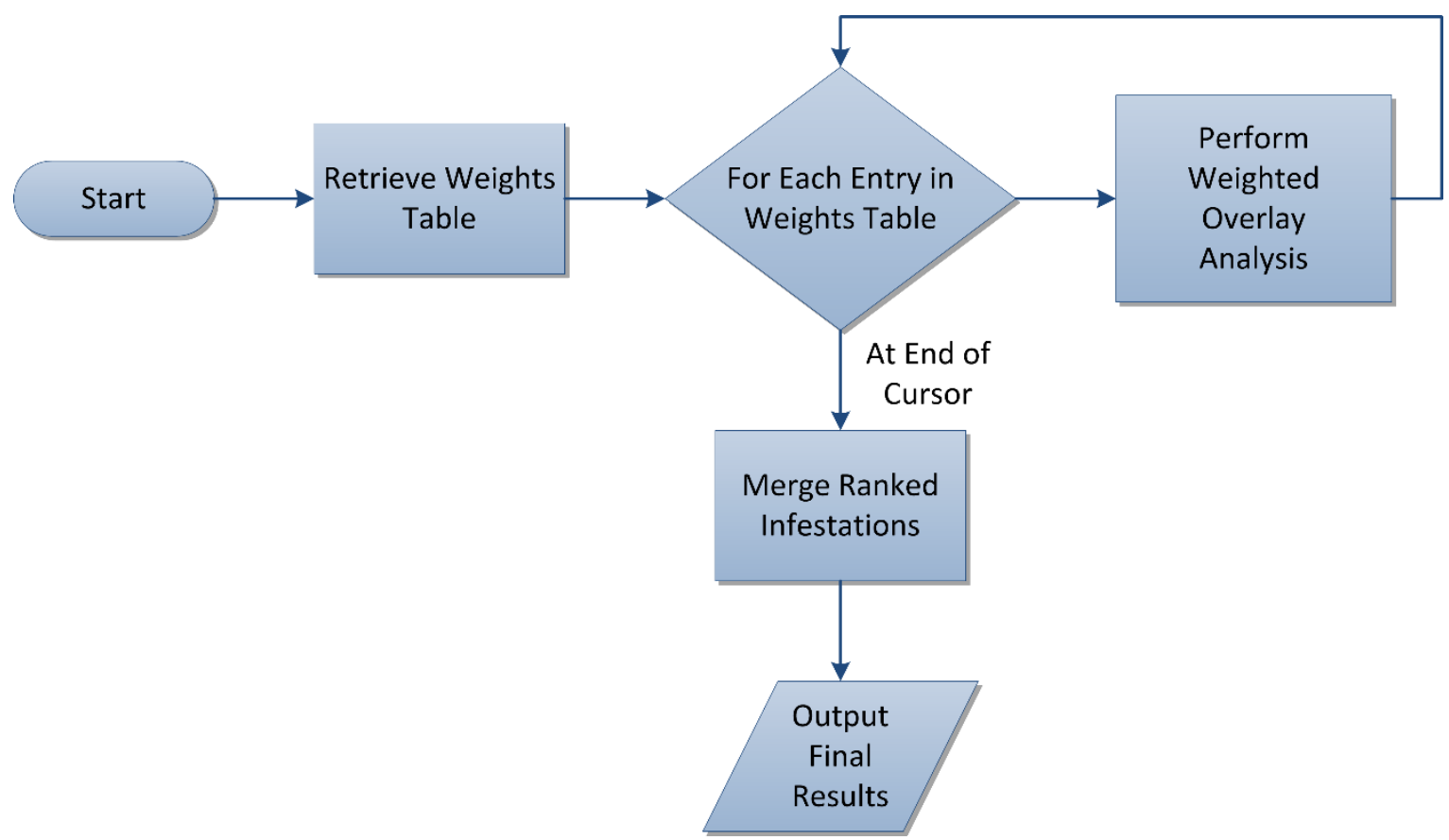

Figure 5-4. Overall workflow diagram

The tool began with retrieving species' names and associated weights from the weights table. Then for each entry inside the table, a custom-built weighed overlay process was performed. After this process was performed on each species or entry within the weights table, the outputs of each weighed overlay process were merged together to create the final output.

Figure 5-5 is a diagram depicting the Priority Analysis Tool performing three subweighted overlays and then combining them to create the final weighted overlay. Then joining this with the selected invasive species data after the output was converted from raster to vector data type.

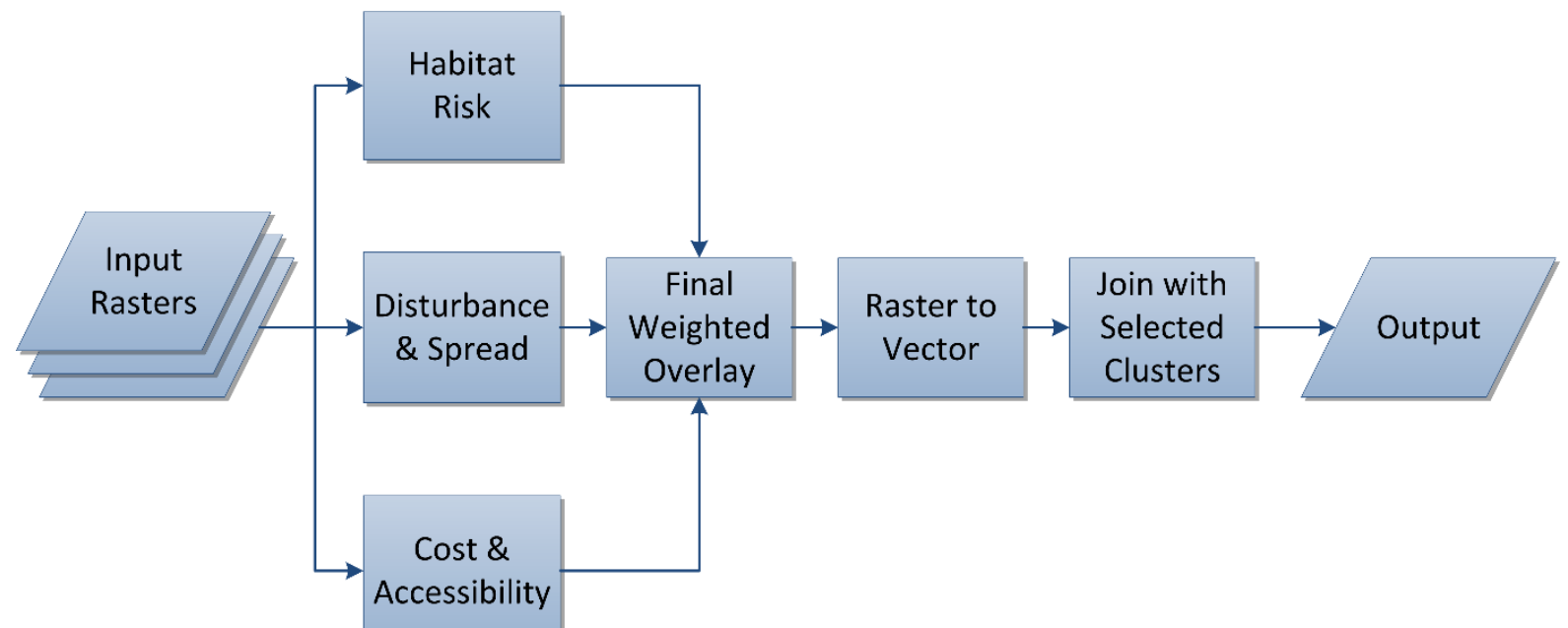

Figure 5-5. Priority analysis workflow diagram 
This process was performed for each species listed in the weights table. The final output of the tool was a feature class that contained all invasive species infestations with a prioritization score ranked from one to five. The species locations with the highest rank were prioritized based on their benefit of eradication for native habitats and accessibility.

The Priority Analysis Tool was also developed to allow the users to continually update the data and thus the priority map. A requirement of the tool was to be able to rank invasive species locations for mitigation based on individual invasive species properties. Different invasive species have different modes of propagation and can harm different aspects of native habitats, which can cause two species in the same location to have different priorities for mitigation. For example if there was an infestation of Arundo donax and Cortaderia sp. in the same location near a roadside with no rivers or streams around, then the Cortaderia sp. infestation would have higher priority for treatment due to the fact that Arundo donax primarily uses rivers as transportation corridors.

The tool was developed to perform the three sub-weighted overlays with different weights for different species. Python and ArcPy were essential to achieve this customization. The script contains a function that performs the series of weighted overlays, converts the final output surface to a vector data type, and then joins this feature class with the selected invasive species infestations.

\subsubsection{Priority Function}

A custom-built priority function was developed to perform the series of weighted overlays, convert the final output surface to a polygon data type, and then join this feature class with invasive species infestation data. This function was necessary to be able to calculate the series of weighted overlays using specific weights for different species without duplication of code.

There are a large number of parameters that have to be passed into the customized weighted overlay function. The parameters include the raster datasets, individual weights, remap values, and the selection of the invasive species infestations to join with the final output surface. After the function is called and the parameters are passed in, it defines a series of local variables for the in-processing rasters and saves them in memory. Next the function creates four weighted overlay tables and prepares the required inputs for ArcPy Spatial Analyst tool Weighted Overlay, which is used to calculate the three sub-weighted overlays and the final weighted overlay. This function is only called if the sum of each sub-weighted overlay is equal to one hundred, otherwise the user will be prompted to reweigh the layers and rerun the tool.

\subsubsection{Risk to Native Habitats}

The purpose of the risk to native habitats weighted overlay was to identify areas where invasive species pose the greatest risk to harming sensitive native habitats. The risk to native habitats weighted overlay table had to be created before the weighted overlay analysis could be performed. ArcPy Spatial Analyst module WOTable was used to create a table that specified which rasters were used in the weighted overlay, the percent influence of the rasters, and the fields the weighted overlay was based on. This module prepares the required inputs for ArcPy Spatial Analyst tool Weighted Overlay. 
The features used in the habitat risk weighted overlay were Ecological Reserves, Conserved Lands, Lakes \& Lagoons, Rivers \& Streams, Vegetation Types, and At Risk Species. The Vegetation Types dataset was reclassified based on each vegetation type's importance for protection from invasive species (Appendix A). Invasive species can also have negative effects on water quality; therefore it was important to include lakes, lagoons, rivers, and streams datasets in the analysis. A habitat is defined by these datasets and they are used to determine its level of significance to conserve.

\subsubsection{Disturbance \& Spread}

The disturbance and spread weighted overlay was calculated to identify areas where invasive species have the potential to propagate due to surrounding disturbances and transportation mechanisms. The data used in this weighted overlay were Railroads, Roads, Rivers \& Streams, and Invasive Species.

Rivers, railroads, and roads can be transport mechanisms for certain invasive species, which can lead to the plants spreading to other areas. The existence of invasive species can degrade habitats which can lead to increased chance of spread of other invasive species. Roads and railroads can also fragment and degrade the natural habitat and increase the probability of spread.

The WOTable module was also used to create the disturbance and propagation weighted overlay table. The resulting table was called by the ArcPy Weighted Overlay function as its only input parameter.

\subsubsection{Location Accessibility}

The location accessibility weighted overlay was calculated to determine which locations are most accessible with the lowest cost to perform invasive species mitigation on those areas. The Parcel Access, Roads, and Slope raster datasets were used to calculate where treatment costs would be the lowest due to their accessibility.

Parcel Access was used to identify where the Conservancy has permission to perform invasive plant mitigation. Permission acquisition is a time consuming and costly task. Therefore, to minimize costs of treatment, areas where the Conservancy already has access were prioritized. This was combined with the slope of the terrain. Steep areas are costly to treat due to their limited accessibility. Roads were also used to determine which areas are the most accessible. For example if an infestation was located a few miles away from the closest road, this treatment would be more costly due to increased time to perform treatments. These are all combined to produce the resulting accessibility surface.

\subsubsection{Final Weighted Overlay and Function Outputs}

The final weighted overlay combines the results of the three sub-weighted overlays to create the final priority map that was used to join with the selected invasive species infestations. The client provided the weights that were used in the final weighted overlay. Risk to native habitats and location accessibility were equally weighted, while slight preference was given to disturbance and spread.

After all the weighted overlay tables were prepared, the function passed these tables into the ArcPy function Weighted Overlay. The outputs of each sub-weighted overlay 
were saved in memory. These output rasters were only required for in-process analysis and did not need to be saved. These output raster datasets were used as the inputs for the final combined weighted overlay to generate a priority surface, which were also saved in memory.

The last step of the function was to spatially join the priority surface with the original invasive species infestation data. In order to use ArcPy function Spatial Join, both datasets had to be in vector format. Therefore, the priority surface was converted from raster to vector data type using the ArcPy function Raster to Polygon. Once the conversion was complete ArcPy function Spatial Join was used to combine these datasets. The output of the function is a vector dataset that contains invasive species location data prioritized from one to five for the invasive species selected. The final output of the whole tool will be a single feature class containing all the invasive species infestations ranked from one to five.

\subsubsection{Weights Table}

An external table was developed containing a list of species and their associated weights. The format of the table was an ArcMap standalone table and was stored in the Invasive Prioritization geodatabase. Each species in the table had weight values for the three subweighted overlays. The table was populated with weights for two species, Arundo donax and Cortaderia sp. The table also contained default values for any species not listed in the table. Table 4 shows the weights used for each species for the three sub-weighted overlays.

\section{Table 4. Invasive species weights table}

\begin{tabular}{|l|r|r|r|}
\hline Risk to Native Habitats & Arundo donax & Cortaderia sp. & Default \\
\hline Vegetation Types & 20 & 20 & 20 \\
\hline Ecological Reserves & 16 & 16 & 16 \\
\hline Lakes \& Lagoons & 13 & 13 & 13 \\
\hline Rivers \& Streams & 13 & 13 & 13 \\
\hline Conserved Lands & 14 & 14 & 14 \\
\hline At Risk Species & 24 & 24 & 24 \\
\hline & 100 & 100 & 100 \\
\hline
\end{tabular}

\begin{tabular}{|c|c|c|c|}
\hline Location Accessibility & Arundo donax & Cortaderia sp. & Default \\
\hline Parcel Access & 45 & 45 & 45 \\
\hline Slope & 30 & 30 & 30 \\
\hline Roads & 25 & 25 & 25 \\
\hline Total & 100 & 100 & 100 \\
\hline
\end{tabular}

\begin{tabular}{|l|r|r|r|}
\hline Disturbance \& Spread & \multicolumn{1}{|l|}{ Arundo donax } & \multicolumn{1}{l|}{ Cortaderia sp. } & Default \\
\hline Roads & 0 & 20 & 20 \\
\hline Railroads & 0 & 10 & 10 \\
\hline
\end{tabular}




\begin{tabular}{|lr|r|r|r|}
\hline Rivers \& Streams & 70 & 40 & 40 \\
\hline Invasive Species & 30 & 30 & 30 \\
\hline & Total & 100 & 100 & 100 \\
\hline
\end{tabular}

Arundo donax and Cortaderia sp. have different modes of transportation, therefore they should have different weights associated with their potential to spread due to surrounding transportation mechanisms. Arundo donax is not able to produce viable seeds in California and therefore proximity to roads and railroads will not increase the likelihood of spread for that species (Ge, Carruthers, Spencer, \& Yu, 2008). Instead of using seed dispersal, Arundo donax spreads from broken plant fragments that flow downstream and take root (Khudamrongswat \& Tayyar, 2004). Therefore for Arundo donax, Rivers \& Streams were given $70 \%$ of the influence for disturbance and spread. Cortaderia sp. propagates primarily through wind seed dispersal, therefore proximity to roads, railroads, and rivers were all used to determine the probability of spread (Starr, Starr, \& Loope, 2003).

The ArcPy function Search Cursor was used to read and store values from the weights table. The cursor looped through each row and saved the weights to local variables. Inside the same loop the variables were passed into the customized weighted overlay function.

The weights table was designed to simplify the tool's user interface and allow the user to easily add new species to the table. A user can alter species information without having to edit any of the Python code, which was especially important since users likely are restoration ecologist with no programming experience. The user can easily update the table in an ArcMap edit session and re-run the tool with those edited specifications. The tool was designed so the user can either simply run the tool with the pre-defined species and weights, update the weights for the existing species, or add a new species to the weights table to perform the analysis.

\subsubsection{Listed Invasive Species}

The priority function was called for each invasive species listed in the weights table. The function was also called once for all species not listed in the weights table and given the default values. Two separate loops were performed to enable this customization.

The species name was read into the program using the ArcPy function Search Cursor from the weights table. If the species name was not equal to Default, then all features with that species name were selected out of the original invasive species vector dataset. The species were selected to perform the spatial join at the end of the customized weighted overlay function. For the selection to run correctly, it was essential to standardize the names of the species in the weights table with the names in the Invasive Species vector feature class.

Two selections were performed for each species in the weights table. The first selection was performed using ArcPy function Select Layer by Attribute. The input layer was the invasive species infestation dataset. The selection type used was Add to Selection, which adds to the previous selection of that layer. However, if no selection already exists, then a new selection was created. This selection was continually added to during each loop to produce a layer with all species listed in the weights table selected 
out of the invasive species dataset. The first selection was necessary to run the priority function on the species in the Invasive Species feature class that were not listed in the weights table, which were labeled as Default in the weights table.

The second selection used the ArcPy function Select Analysis and selected all features in the invasive species dataset where the scientific name was equal to the name in the weights table. This selection was passed into the customized priority function to join with the final output surface.

After the individual species were joined with the final output surface, these layers were appended together to create a single feature class. In preparation for this append, an empty feature class was created using the ArcPy function Create Feature Class and saved in memory. For each loop in the weights table, the joined species data were appended to the newly created dataset. The final result in this loop was a feature class with all joined data containing the features of the names listed in the weights table. The species not listed in the weights table were appended at the end of the script.

\subsubsection{Default Entry}

If the name of the species in the invasive species infestation dataset was not listed in the weights table, then it was given a set of default values and combined with the outputs of the listed species. To enable the tool to be flexible and have the ability to grow, the tool had to be programmed using two search cursors to loop through the weights table. The default values were assigned to these species after the script performed the weighted overlay calculations on all of the species listed in the weights table. The default weighted overlays had to be run after all the other defined species in order to define which species were joined with the final output surface.

To select the species not listed in the weights table, a new selection was created. This was created using ArcPy function Select Layer by Attribute with Switch Selection as the selection type. The input layer was the first selection performed in the listed species loop that selected out all species that were listed in the weights table. The output of the selection was a layer saved in memory that contained all the invasive species that were not listed in the weights table. The output was passed into the customized priority function inside the second search cursor loop.

The second search cursor was executed with similar parameters and functionality. The species name was read into the script using the ArcPy function Search Cursor on the weights table. If the species name is equal to Default then the priority function was called and the selected invasive species data were passed into the function.

The final output surface for the Default species was converted to vector and then joined with the selected invasive species data. The joined feature class was then merged with the output feature of the listed species in the weights table. The ArcPy Merge function was used to perform this data management and resulted in a single feature class that contained all of the data in the original invasive species feature class prioritized from one to five. All features with a prioritization score of five were recommended for mitigation first. 


\subsubsection{User Interface}

The user interface was designed for users with little GIS experience. There are only two parameters a user is required to input: the source geodatabase and the output location. The source geodatabase tells the tool where to find the data used to perform the analysis. The code was developed for the tool to set the environment workspace based on the user's input. The ArcPy function Get Parameters As Text was used to define the environment settings. The second input is where the user would like to store the final output feature class. Figure 5-6 shows the actual user interface.

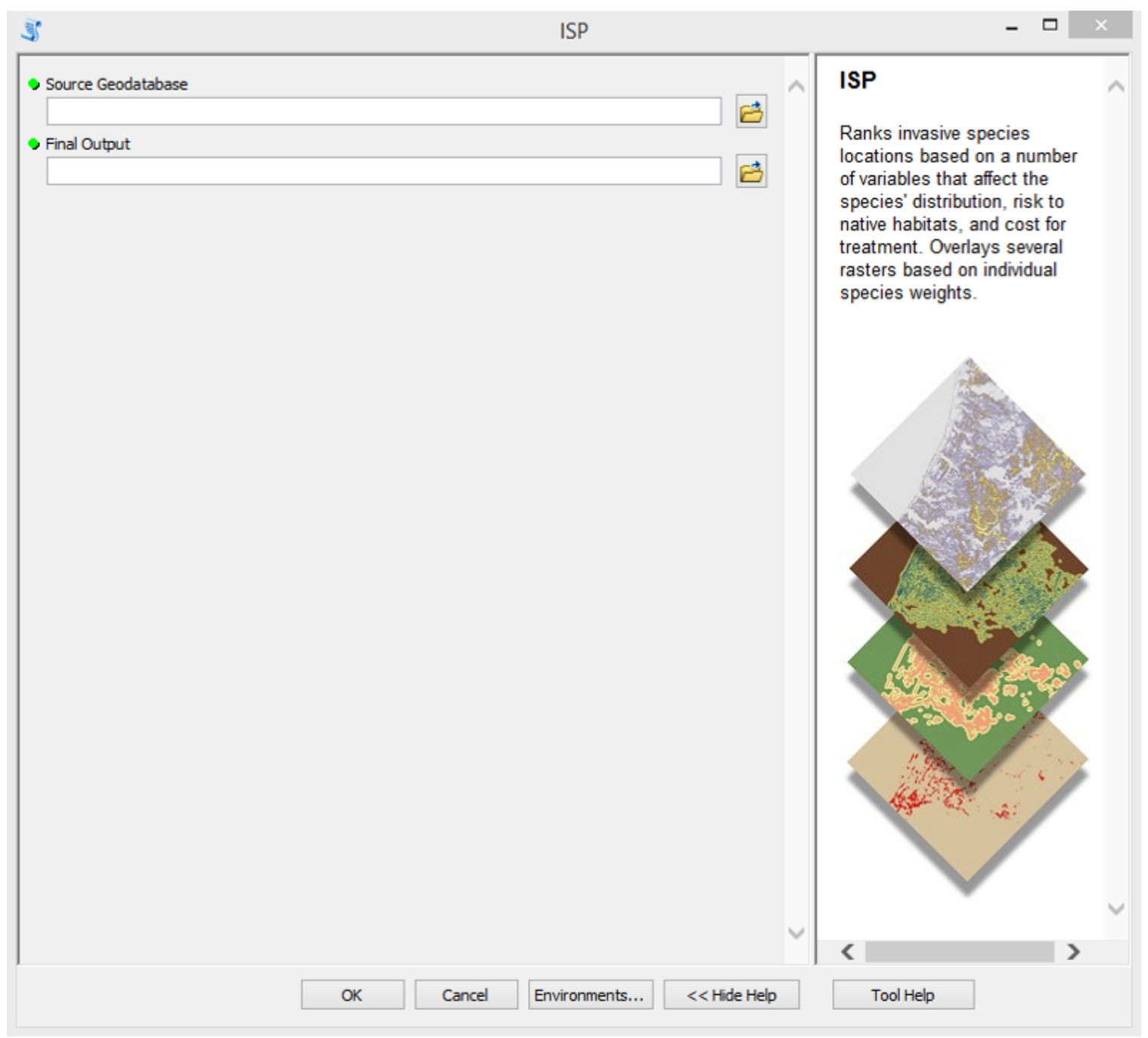

Figure 5-6. User interface

The item description for the tool provides a general summary of the tool's functionality and workflow diagram illustrating how the tool works (Appendix B). It was also developed to provide users with a detailed explanation of how the tool's spatial analysis is performed. The item description provides the appropriate syntax needed for the user inputs, in addition to an explanation of the user's inputs. The content of the item 
description is available either by right clicking the tool and selecting Item Description or by clicking the Tool Help box in the tool's interface. It was required to create and save the Item Description in ArcCatalog 10.2.2 instead of ArcMap 10.2.2 for the Tool Help box in the tool's user interface to work properly. Creating the Item Description directly from ArcMap 10.2.2 only updates the Item Description and does not update the Tool Help.

\subsection{Summary}

Data conversion and preliminary data processing using ArcGIS desktop was required on all original vector data. Since this was a manual and time consuming process, the Data Conversion Tool was created for the client to easily update the raster data in the future. Once the preliminary data processing was completed, the Priority Analysis Tool was developed using Python and ArcGIS's ArcPy. The tool was created to allow users to prioritize invasive species treatment locations. It was also developed to perform the three sub-weighted overlays with different weights for different species. A table containing the weights used in the sub-weighted overlays for each species was created to enable this functionality. The priority function was developed to perform the series of weighted overlays, convert the final output surface to a vector data type, and then join this feature class with selected invasive species infestations. The final output of the tool was a feature class containing infestations prioritized based on the minimized cost to perform mitigation with the greatest benefit for native habitats. 



\section{Chapter 6 - Results and Analysis}

This chapter discusses and analyzes the results from the implementation of the project described in Chapter 5. First, this chapter goes over data preparation and the Data Conversion Tool. Section 6.2 describes the results of the three weighted overlays for risk to native habitats, disturbance and spread, and location accessibility. The results of the final weighted overlay and the spatial join with the original invasive species infestation data are discussed in Sections 6.3 and 6.4.

\subsection{Data Conversion Analysis}

Preliminary data processing was required on each dataset before any weighted overlay analysis could be performed by the tool. All datasets were converted into raster format in order to perform the series of weighted overlays. Euclidian distance was calculated on the datasets that required proximity calculations. All datasets were then reclassified into unique values from one to five. Once the datasets were preprocessed, they were ready to be used for analysis. The development of the Data Conversion Tool also allows the client to maintain some of the original data in vector format such as the road network data.

The Vegetation Types, Slope, and Parcel Access datasets were reclassified based on the values of the original data. The Vegetation Types raster dataset was reclassified based on their importance of conserving. The results of the data conversion process for the Vegetation Types dataset at the full extent of the Carlsbad Hydrologic Unit is shown in Figures 6-1.

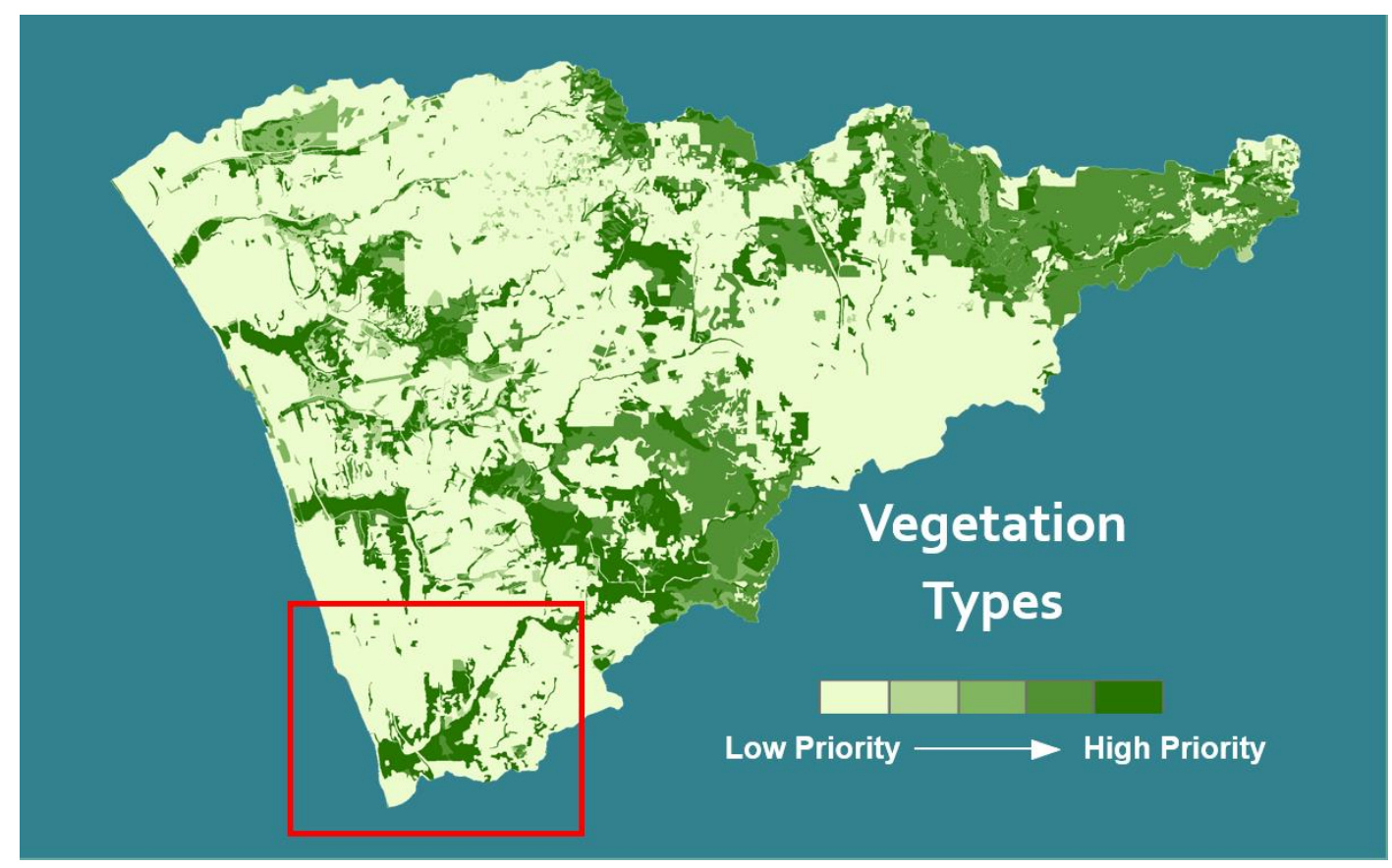

Figure 6-1. Vegetation Types reclassified at full extent of study area 
The area highlighted in the red rectangle from Figure 6-1 is displayed in Figure 6-2. The dataset is near the San Elijo Lagoon Ecological Reserve. The San Elijo Lagoon Ecological Reserve mostly contains high priority vegetation types. However, the surrounding urban areas have a low priority for protecting.

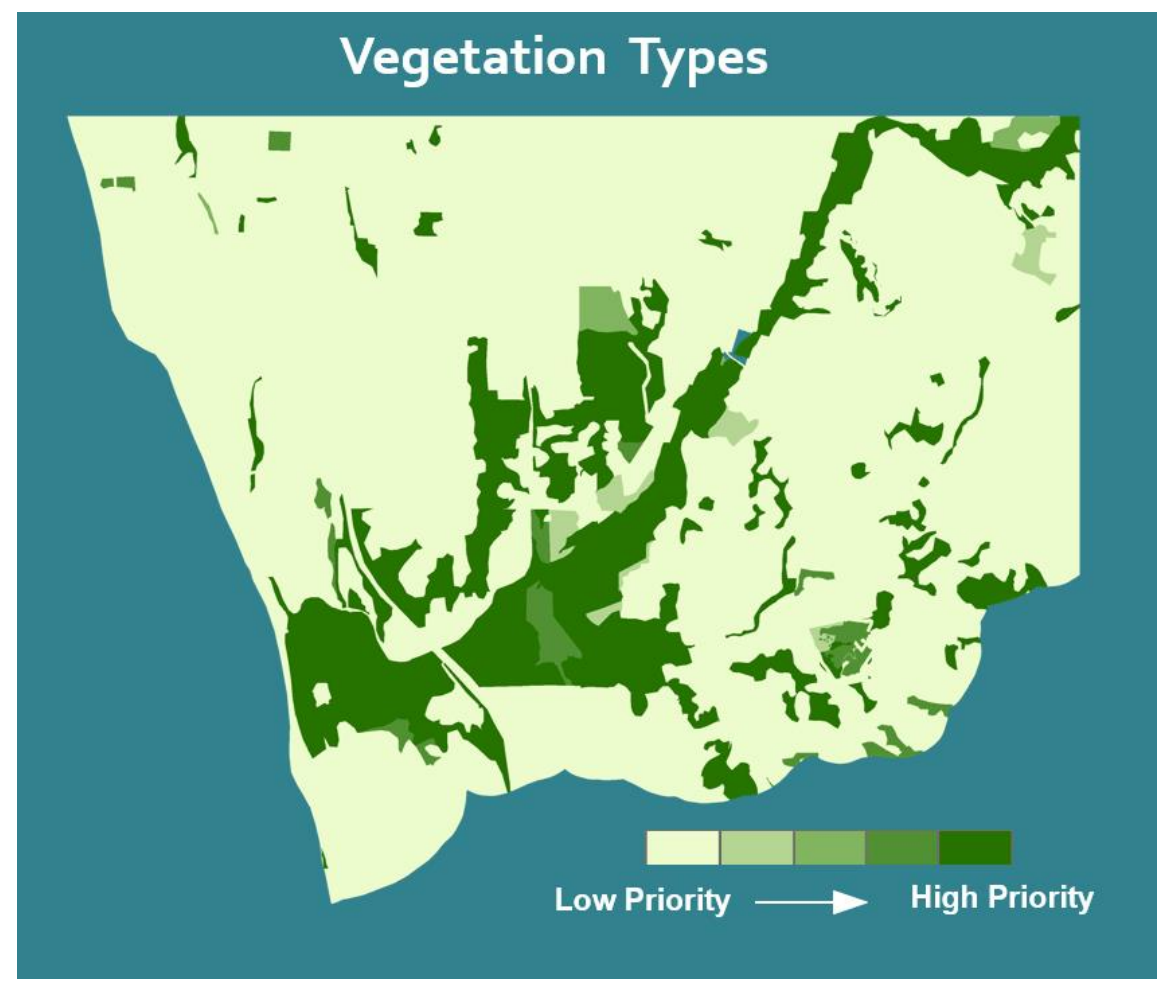

Figure 6-2. Vegetation Types reclassified near the San Elijo Lagoon

The ArcGIS tool Euclidean Distance was used to calculate proximity to the Roads, Conserved Lands, Invasive Species, Lakes \& Lagoons, Railroads, Rivers \& Streams, Ecological Reserves, and At Risk Species raster datasets. Figure 6-3 shows the reclassification of the dataset based on the proximity to the nearest feature at the full extent of the Carlsbad Hydrologic Unit. 


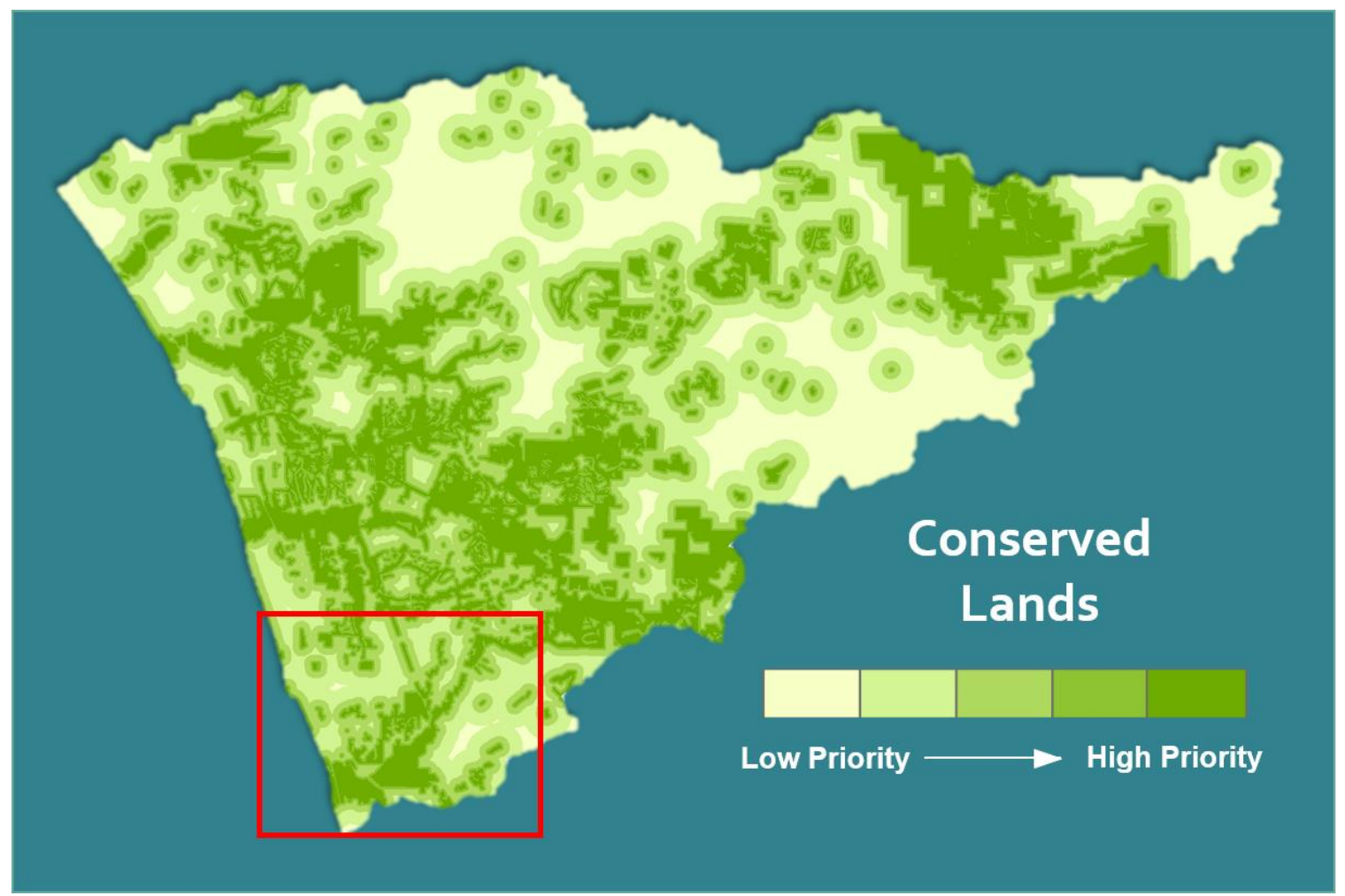

Figure 6-3. Conserved lands reclassified at full extent of study area

The area highlighted in the red rectangle from Figure 6-3 is displayed in Figure 6-4. The full extent of the San Elijo Lagoon Ecological Reserve is covered in the Conserved Lands dataset. This area has the highest priority for protection and the priority decreases further from the reserve. 


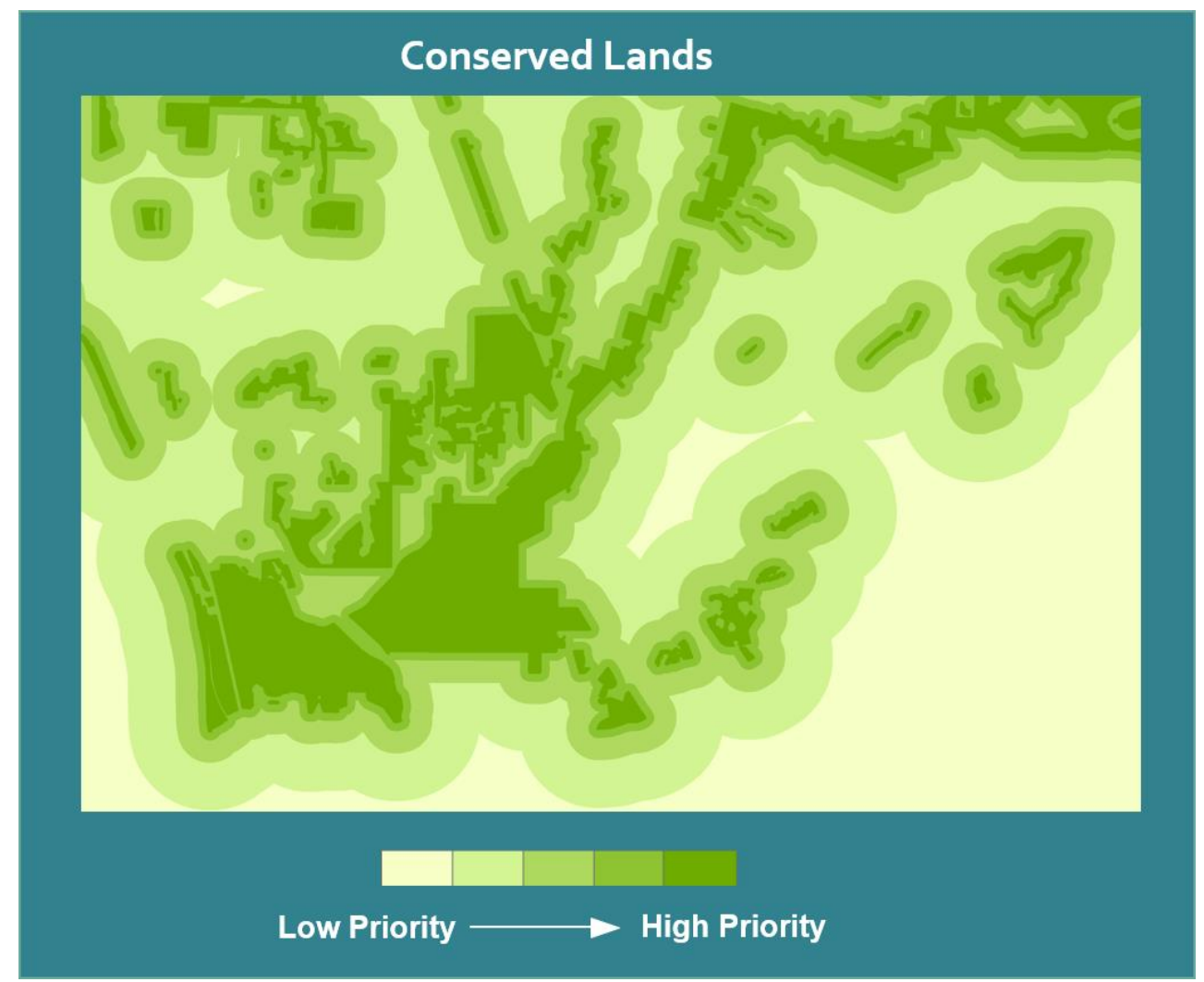

Figure 6-4. Conserved lands reclassified near the San Elijo Lagoon

The results of the reclassification on the Conserved Lands and Vegetation Types datasets shown above have similar high priority areas. Many conserved lands contain vegetation types that are important to protect, which is one reason they have been deemed conserved lands. However, there are surrounding areas where important native habitats exist that have not been designated as Conversed Lands; therefore it is important to include these areas in the analysis. Also, not all conserved lands contain the highest priority vegetation types based on the Conservancy's standards, so it was important to have information about each dataset included in the weighted overlay analysis.

The Data Conversion Tool simplified the client's needs to update the datasets used in the analysis. A number of the datasets are updated a few times a year and the client needed an easy way to update them. Using the tool, the client can easily update the datasets with minimal knowledge of the different steps involved in the conversion process. A user only needs to specify a few input parameters which were provided in an external document describing the protocol of the conversion tool. The client was able to use the conversion tool to update the datasets successfully.

\subsection{Sub-Weighted Overlay Results}

The priority map was generated from three factors: habitat risk, disturbance and spread, and location accessibility, which were in turn generated from weighted overlay processes. This section uses the weed Cortaderia Sp. as an example to illustrate the process to generate the three factor maps. 


\subsubsection{Habitat Risk Results}

The purpose of the risk to native habitats weighted overlay was to identify areas where invasive species pose the greatest risk to harming sensitive native habitats. The datasets used in the habitat risk weighted overlay were Ecological Reserves, Conserved Lands, Lakes \& Lagoons, Rivers, Vegetation Types, and At Risk Species. The weights and the results of the weighted overlay are displayed in Figure 6-5.

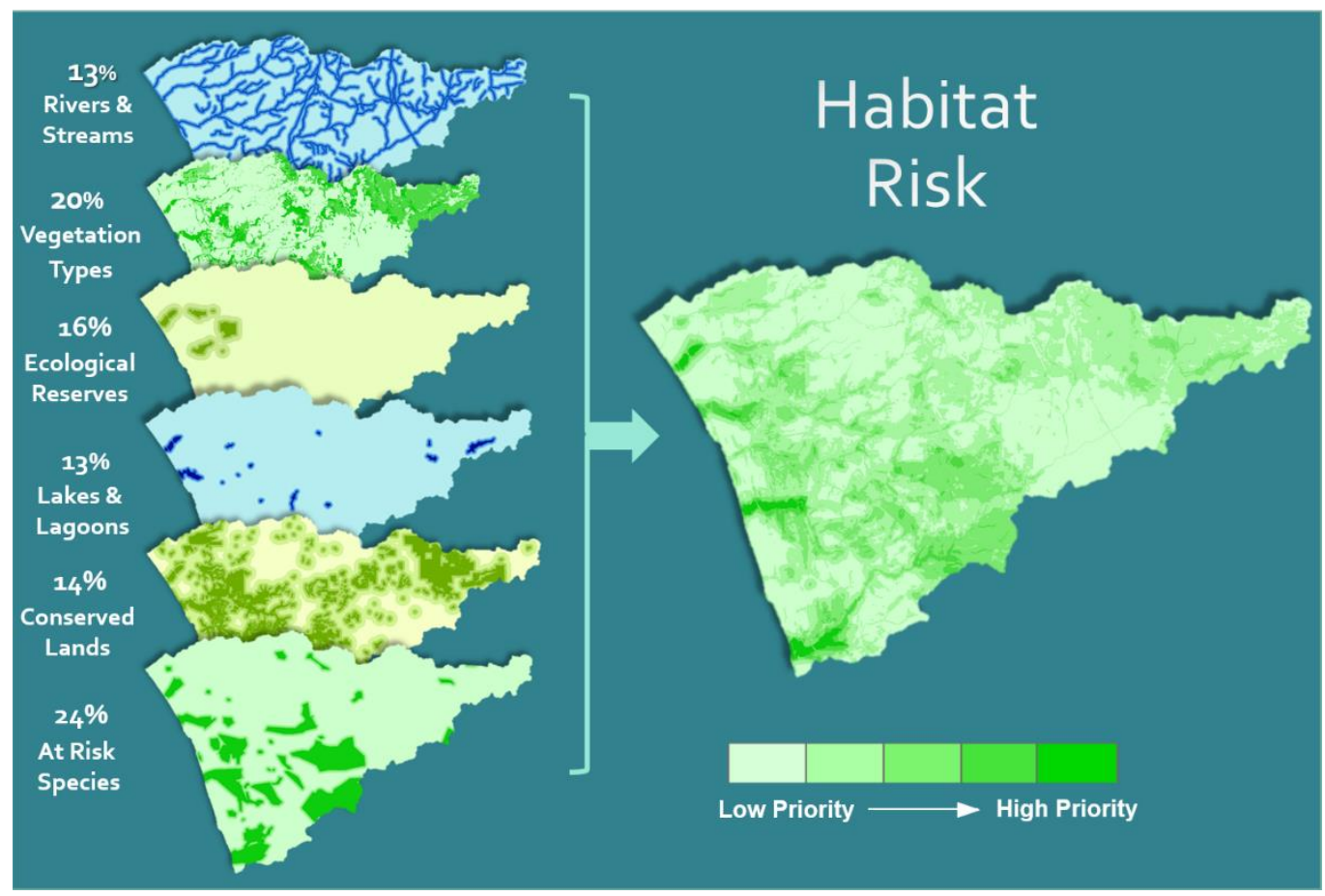

Figure 6-5. Risk to native habitat weighted overlay results for Cortaderia sp.

The areas in darker green are more important to protect from Cortaderia sp. infestations. Figure 6-6 shows the count of cells inside the raster dataset for each level of priority ranking. One percent of the raster cells were given the highest priority ranking of five for habitat risk. 


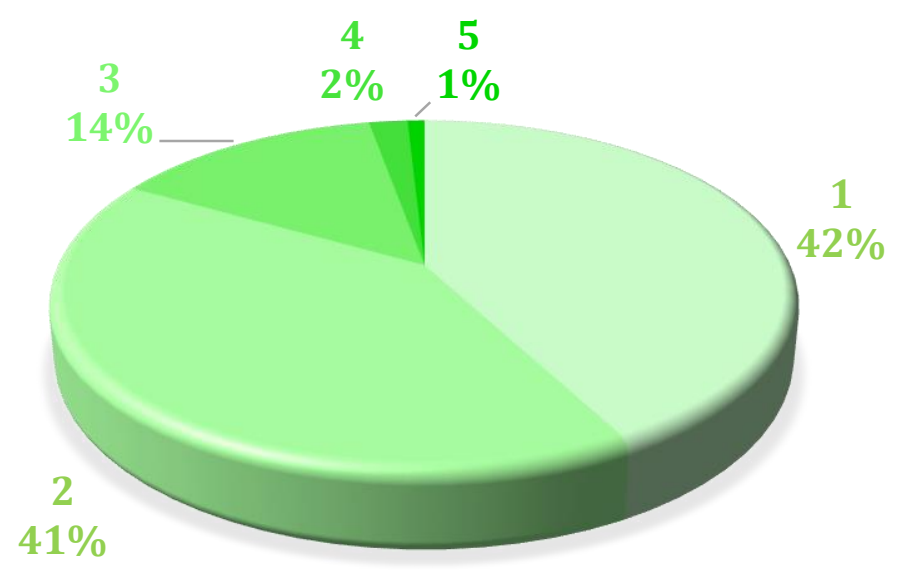

Figure 6-6. Rank distribution of raster cells in the habitat risk model

\subsubsection{Disturbance \& Spread Results}

The disturbance and spread surface was calculated using weighted overlay to identify areas where invasive species have the potential to propagate due to surrounding disturbances and transportation mechanisms. The datasets used in this weighted overlay were Railroads, Roads, Rivers, and Invasive Species. Figure 6-7 shows the results of the disturbance and spread weighted overlay calculation.

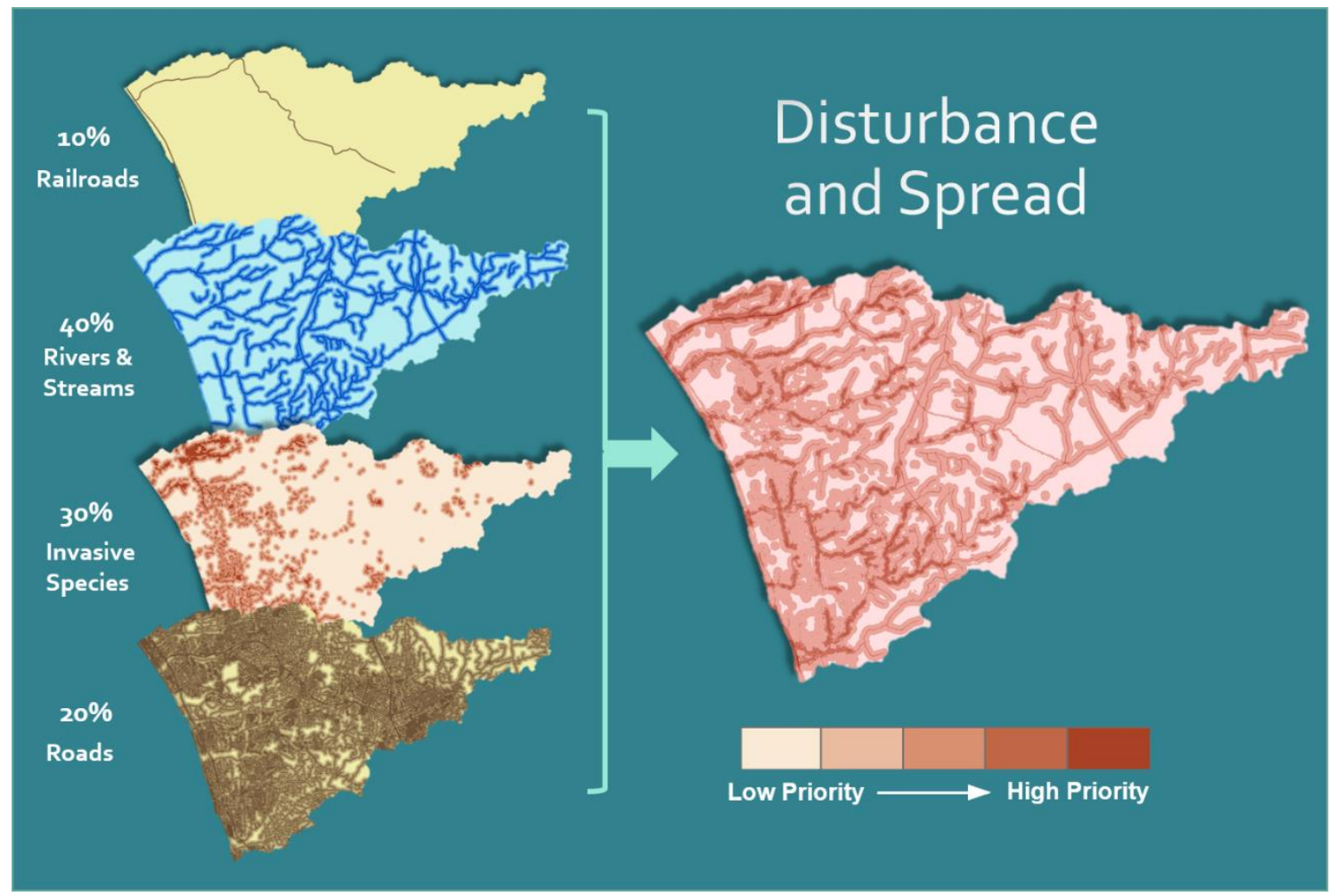

Figure 6-7. Disturbance and Spread weighted overlay results 
The areas in darker red have a higher probability of Cortaderia sp. spreading due to surrounding disturbances and transportation mechanisms. Figure 6-8 shows the percentage of cells inside the raster dataset for each priority ranking. The cells inside the study area that were given the highest priority of five for disturbance made up 0.004 percent of all the cell values.

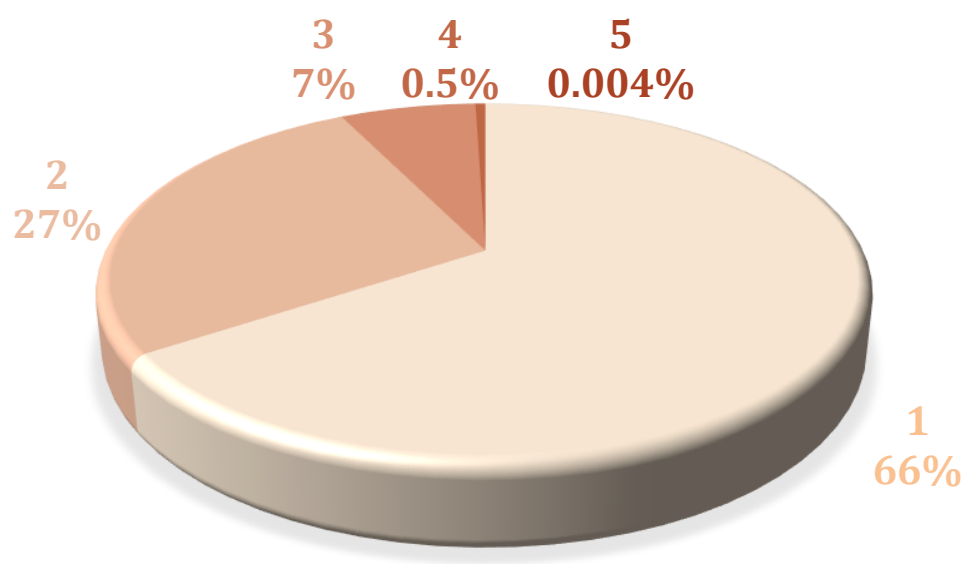

Figure 6-8. Rank distribution of raster cells in the disturbance and spread model

\subsubsection{Location Accessibility Results}

The location accessibility weighted overlay was calculated to determine which locations have the lowest cost to perform invasive species mitigation. The Parcel Access, Roads, Invasive Species, and Slope raster datasets were used to calculate treatment costs for each infestation. Figure 6-9 displays the resulting map of the location accessibility weighted overlay. 


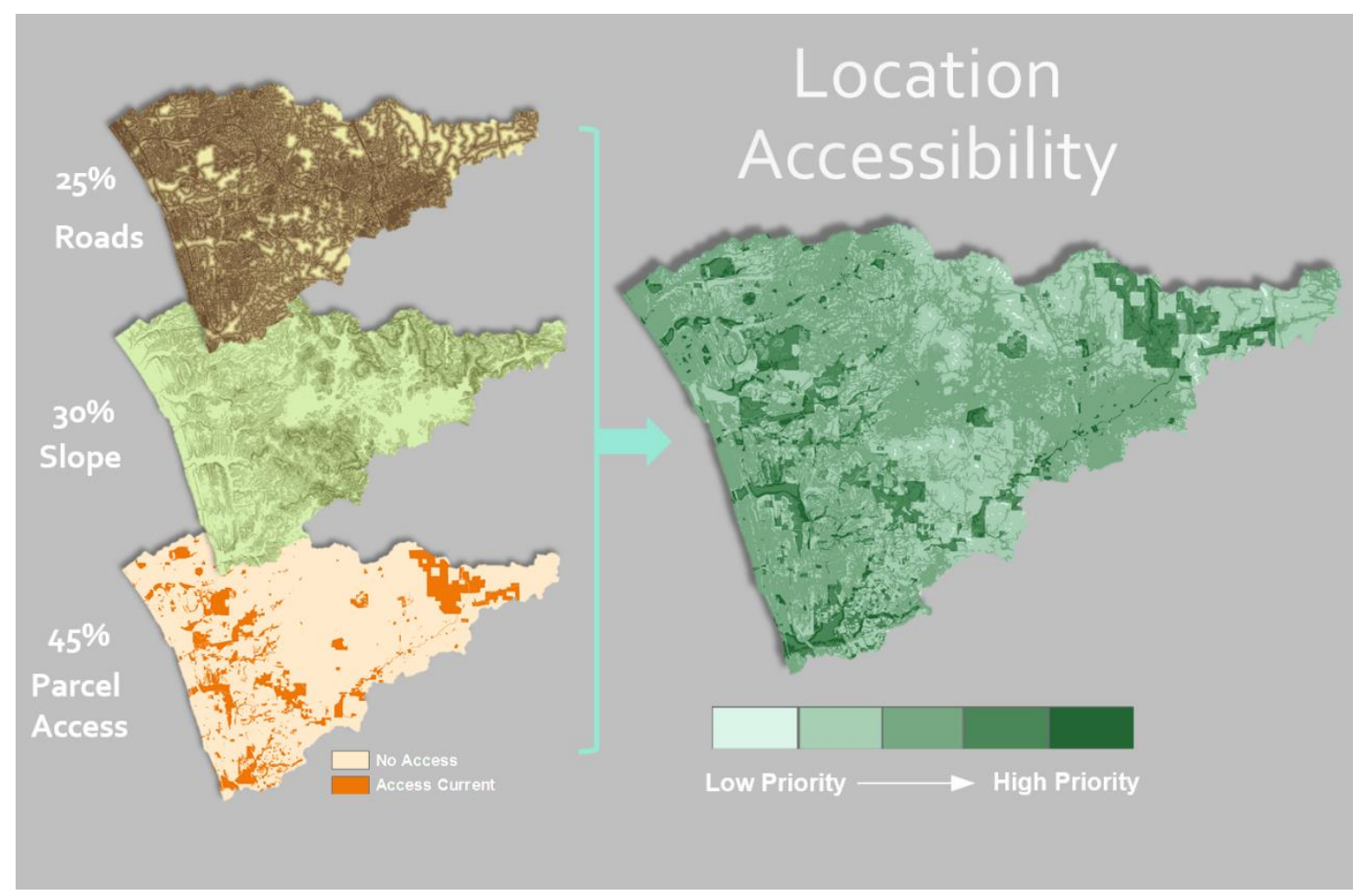

Figure 6-9. Location accessibility weighted overlay for Cortaderia sp.

The areas in darker green have a lower cost to treat Cortaderia $s p$. infestations. These dark green areas have close proximity to roads, minimal slope incline, and the Conservancy already has permission on those parcels to perform mitigation. Figure 6-10 displays the number of cells inside the raster dataset for each rank. Two percent of the cells inside the study area were given the highest priority for location accessibility.

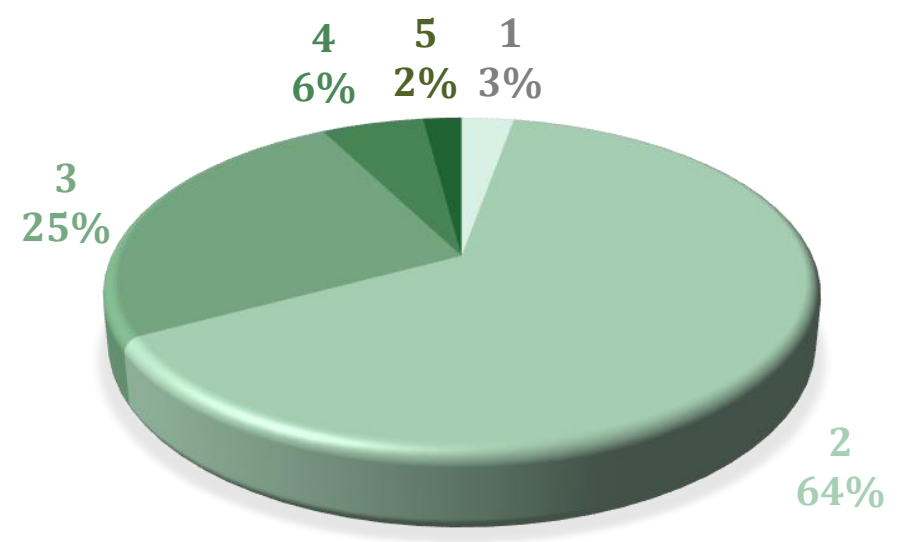

Figure 6-10. Rank distribution of raster cells in the accessibility model

All of the weights used for calculating the location accessibility weighted overlay were the same for the three entries in the table. Hardcoding the weights and running only 
the habitat risk and location accessibility weighted overlay once was considered. However, the client preferred to have ability to use different weights for new species added to the weights table.

\subsection{Weed Mitigation Priority}

A final weighted overlay was created for each weed species, resulting in three priority maps. The final weighted overlay combined the results of the three sub-weighted overlays to create the priority maps. Using the three factors of risk to habitats, disturbance and spread, and location accessibility, the priority to mitigate Cortaderia $S p$. was calculated using weighted overlay and is shown in Figure 6-11.

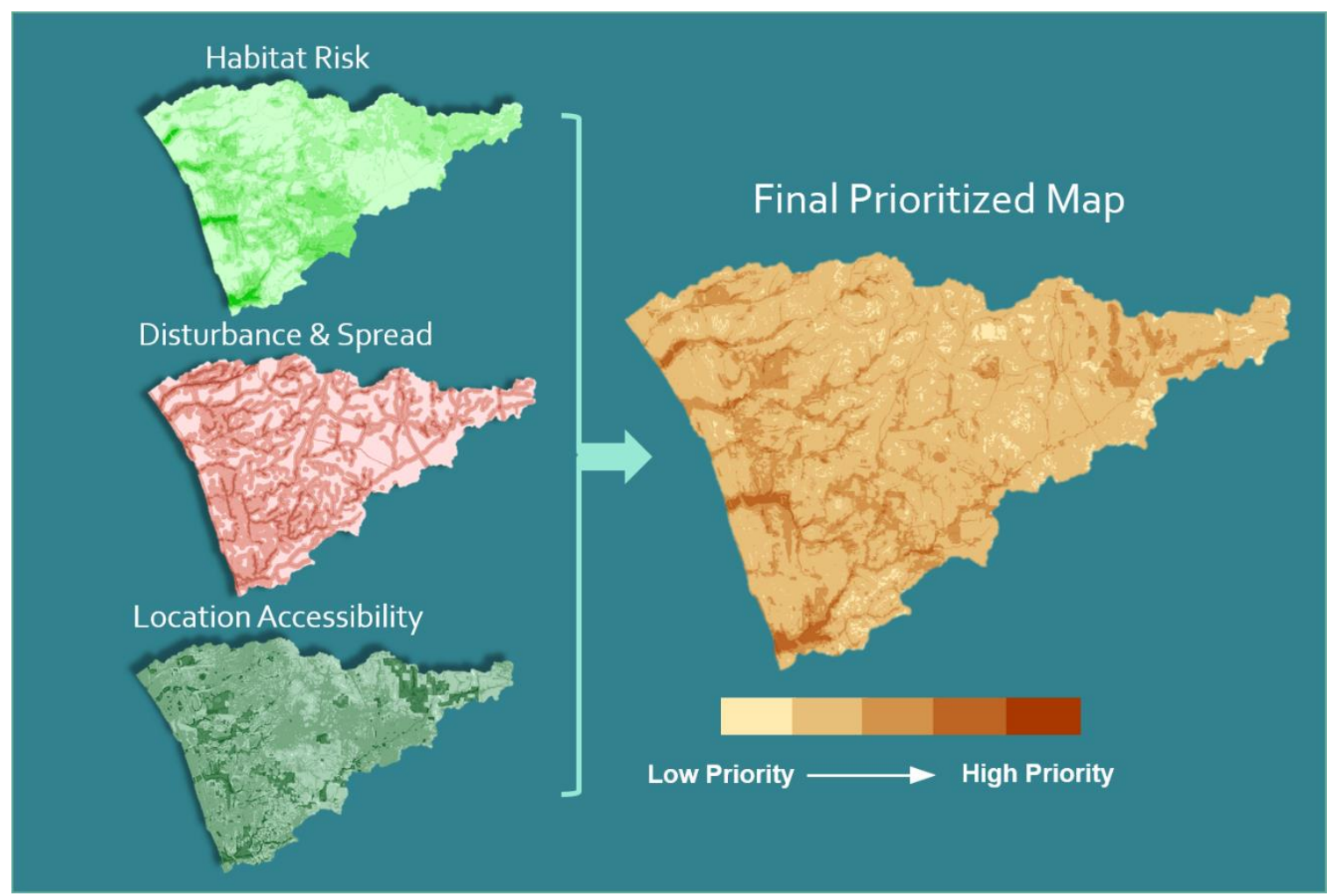

Figure 6-11. Mitigation Priority for Cortaderia sp.

The areas in darker orange were prioritized for mitigation due to their high risk to sensitive habits, high probability of spreading, and easy access to these areas. The priority data in raster format was converted to polygon for further process. Figure 6-12 shows the count of each polygon for the different priority rankings. Three tenths of a percent of the study area had the highest priority ranking. 


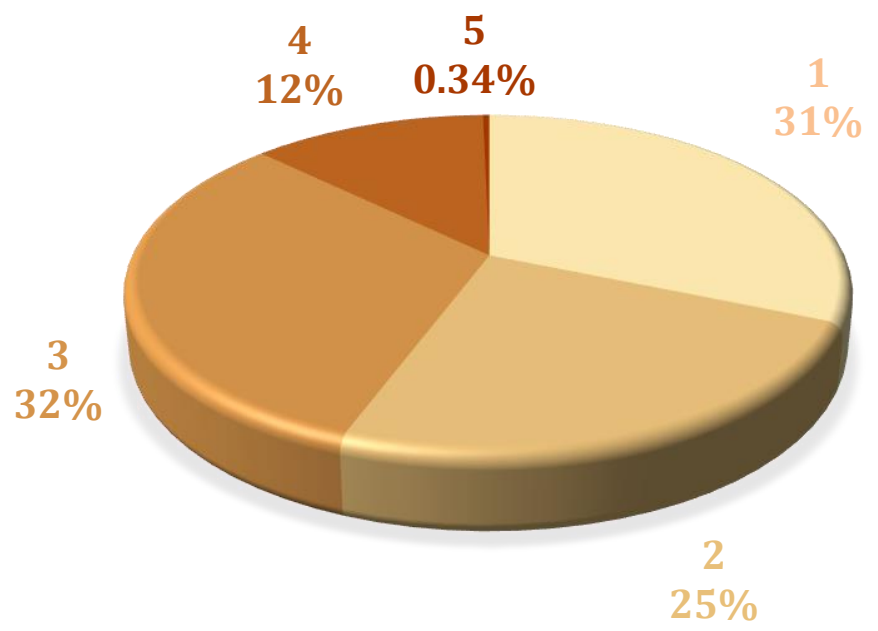

Figure 6-12. Rank distribution of polygons for Cortaderia sp.

\subsection{Invasive Species Infestations to Mitigate}

The final output of the priority function was a vector dataset that contained invasive species infestations prioritized from one to five. Cortaderia sp. 's weights and infestation locations were used to create the prioritized infestations map displayed in Figure 6-13. The areas in red were prioritized for mitigation.

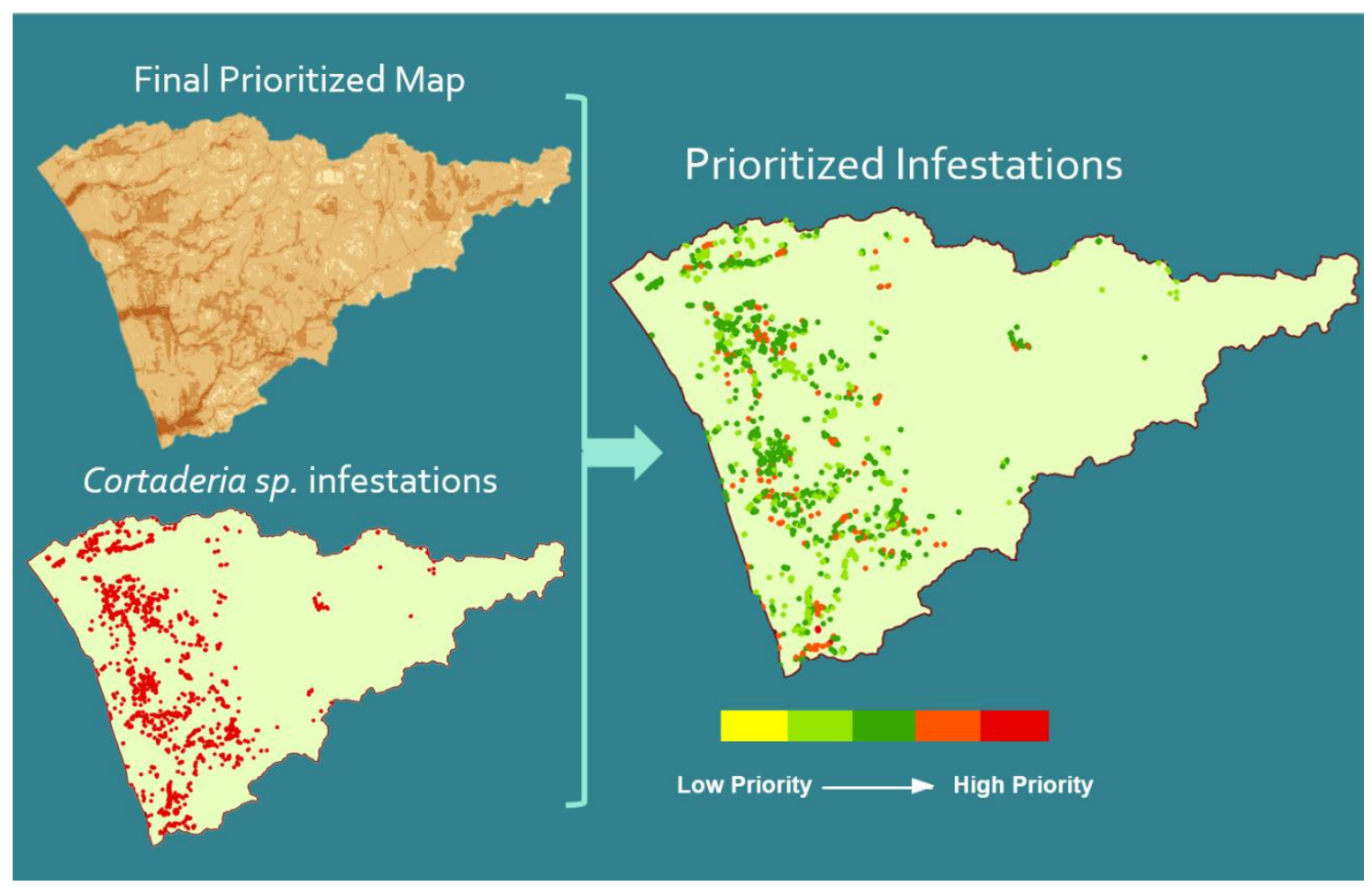

Figure 6-13: Prioritized Cortaderia sp. infestations 
The priority analysis was performed for each species identified by the client. The final step merged the priority maps for all species to create the final priority map. The priority map contained all infestations in the original dataset ranked from one to five (Figure 6-14).

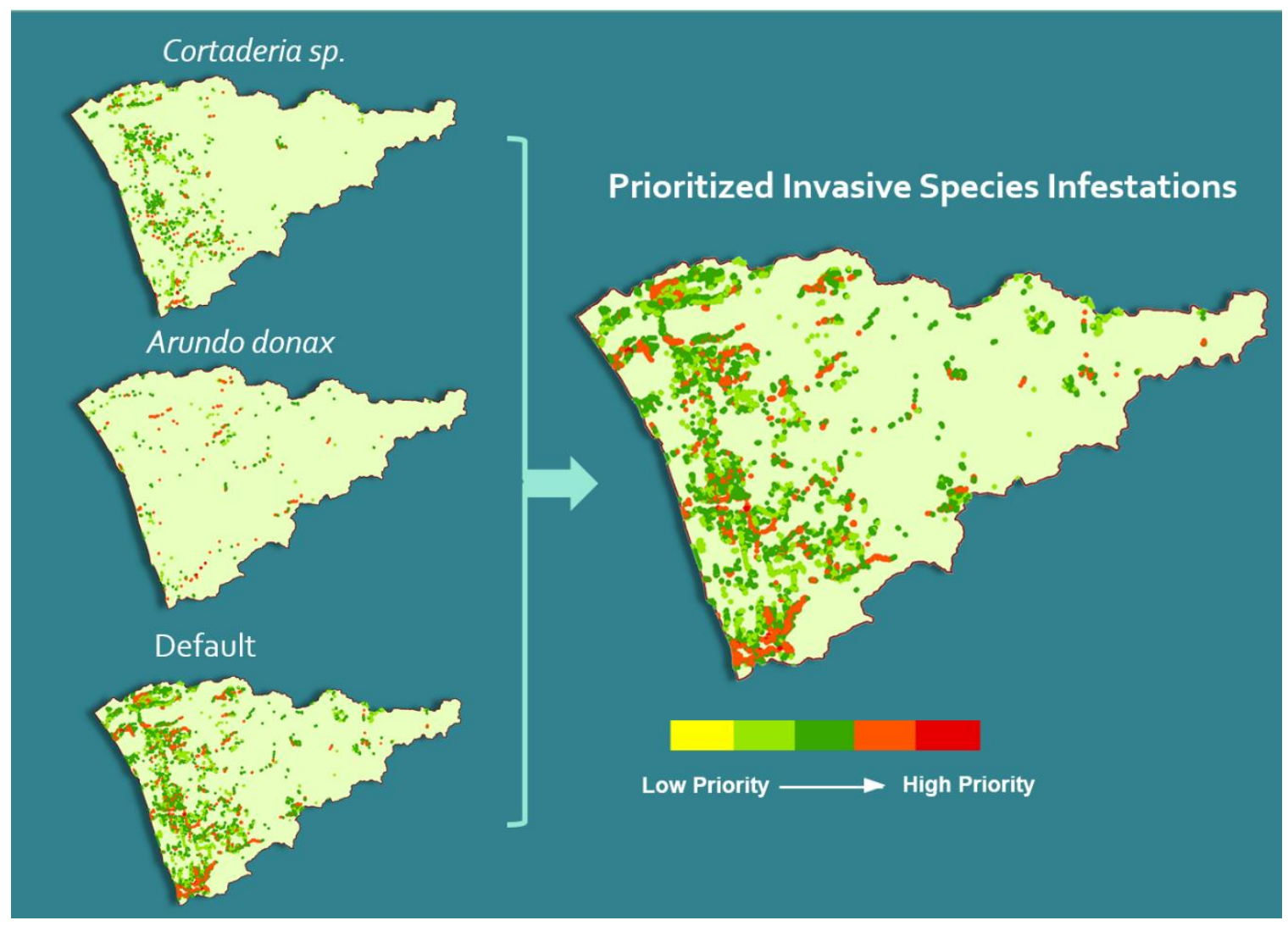

\section{Figure 6-14: Prioritized invasive species infestations}

Out of 12,504 invasive species infestations, 112 or 1 percent were ranked with the highest priority of five (Figure 6-15). The majority of these infestations are located within ecological reserves. Ten Arundo donax and four Cortaderia sp. infestations were ranked as the highest priority. 


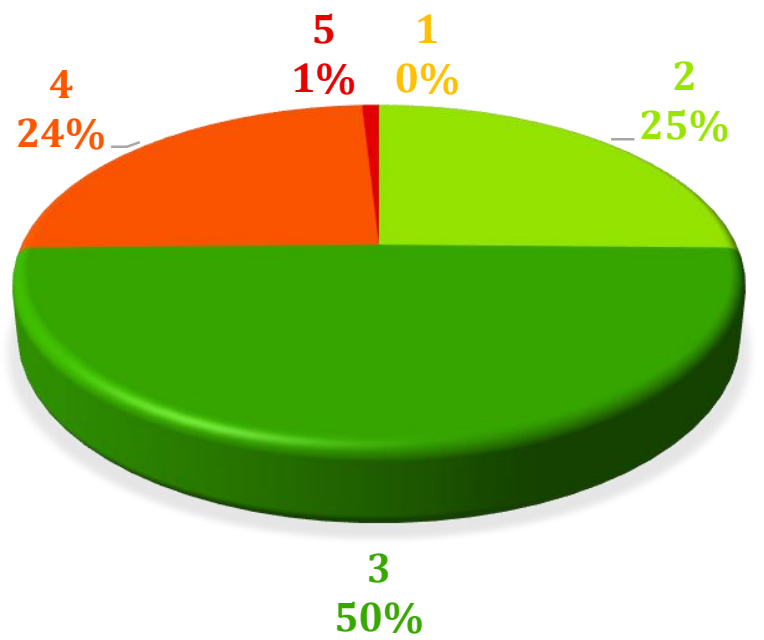

Figure 6-15. Distribution of infestations location ranks

The priority map is displayed in Figure 6-16 and shows where the highest priority invasive species infestation are located in the Carlsbad Hydrologic Unit. The production of this map was required for a visual representation of the tool's output.

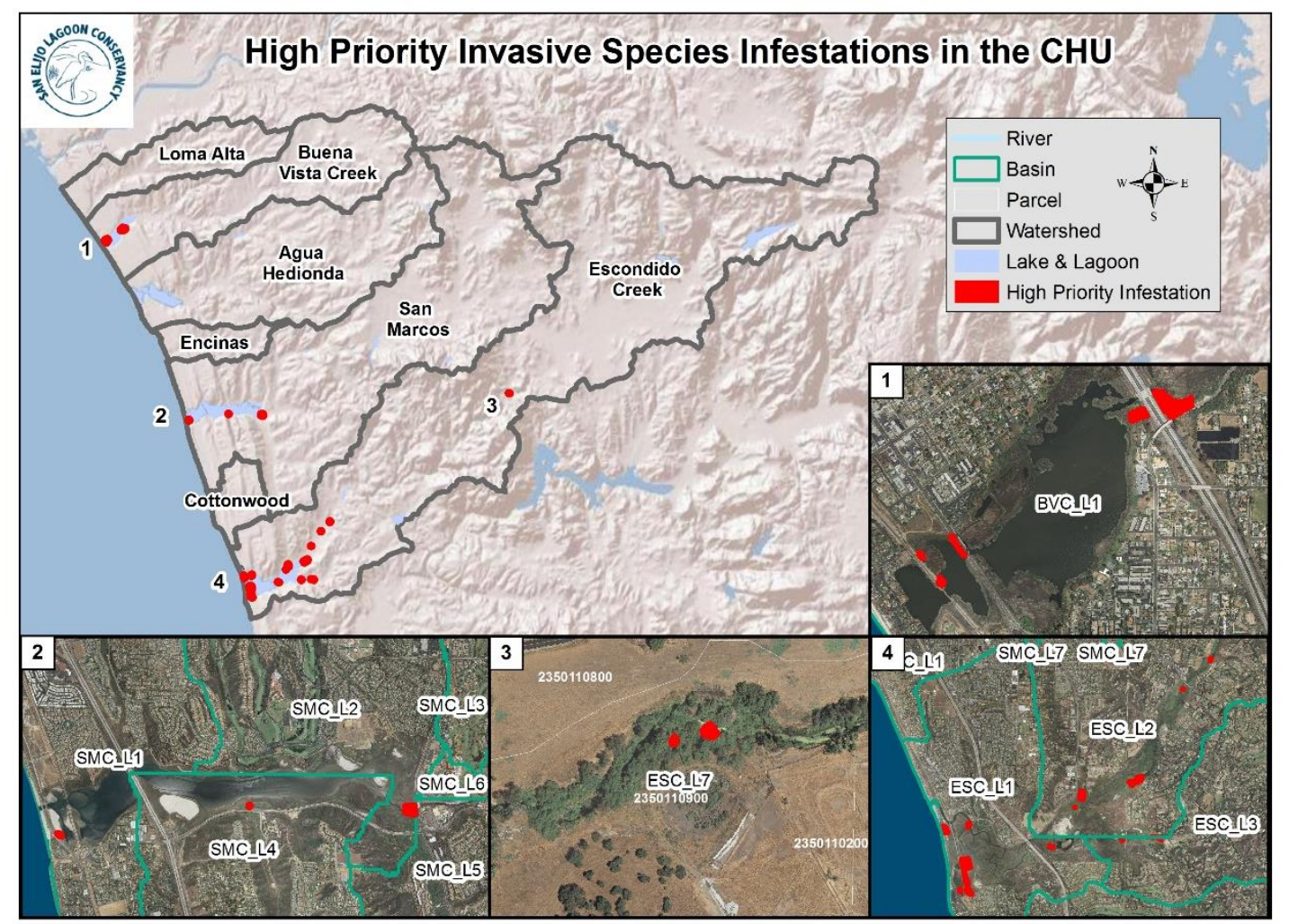

Figure 6-16. Map displaying the highest priority infestations 


\subsection{Summary}

A series of data conversions were performed on each dataset before it was used in the priority analysis. At the end of conversion all datasets were in raster format and reclassified based on the original values of the dataset or the proximity to a feature. The Data Conversion Tool was created for the client to easily update the vector datasets. After the weighted overlay analysis was performed for each species, all the prioritized infestations were merged together to create the final output of the tool. One hundred and twelve invasive species infestations were ranked with the highest priority for treatment due to their risk to native habitats, high potential to spread, and accessibility. These infestations were recommended to the Conservancy to mitigate prior to any other infestations. 



\section{Chapter 7 - Conclusions and Future Work}

\subsection{Conclusions}

The goal of the project was to create a user friendly tool that implements a repeatable process to prioritize invasive species infestations for mitigation. The client was a nonprofit organization with limited resources who wanted to focus on the activities that maximize their resources to conserve native habitats. The tool developed in this project helped the Conservancy focus their resources on targeting the invasive species infestations that pose the greatest risk to native habitats and associated wildlife.

The goal was accomplished by developing an ArcGIS tool that prioritized the invasive species infestations from one to five based on their potential risk to native habitats, potential to spread due to surrounding disturbances and transport mechanisms, and their location accessibility. This tool was developed using Python and ArcGIS, which were essential to achieve the level of customization in the tool. The Priority Analysis Tool ranks invasive species infestations based on specific characteristics of each species. The tool was designed in a way that allows a user to include new species in the calculations without having to alter any of the Python code. This allows the client to improve the results without having to know the technical details involved in the tool's development.

The tool was successfully delivered to the client and was able to run successfully on all of the computers in the organization's Habitat Management Department. The project data were delivered to the client in a centralized location in the form of a geodatabase and uploaded to their server for easy access for all members of the Habitat Management Department.

\subsection{Future Work}

This project accomplished the main goal set forth in Chapter 1. However, future work could build on this project to further the San Elijo Lagoon Conservancy's goal of protecting habitats for native plant and animal species. Some possible future projects that would help the Conservancy achieve their goals are discussed below.

The disturbance and spread calculation used four datasets: Rivers, Roads, Railroads, and Invasive Species. This weighted overlay analysis determines the probability of an invasive species spreading due to surrounding disturbances and transportation mechanisms. However this analysis does not determine where the invasive species are likely to disperse to if they spread. To enhance the tool, additional analysis would need to include locations of each infestation and wind patterns to determine potential seed dispersal patterns. It would also have to include rivers and topographic data to determine which direction the plants will propagate along rivers. Enhancing the tool to identify areas where invasive species are likely to spread and determining if these areas are near sensitive native habitats could also increase the value of the tool.

The priority analysis for location accessibility could be improved with the inclusion of a more detailed Parcel Access raster dataset. The dataset used in the project only contained information about where the Conservancy has access to parcels to perform 
invasive species treatments. Therefore, for each parcel was represented as current access or no access. Including more information about the difficulty of gaining access to each parcel based on its ownership and usage could improve the results of the priority analysis.

A valuable extension to this project would be to create a mobile application for the collection of invasive species infestation locations. Currently the Conservancy uses ArcPad installed on a small portable computer. However, this software is being phased out since Esri is moving toward mobile applications. The collection of invasive species infestations would be easier on a light weight mobile device instead of a heavy handheld computer. The development of a mobile application with database synchronization capability would also minimize the required updates and eliminate the need to have different versions of the infestation data on the collection device and on the client's server. The Priority Analysis Tool could easily be used to prioritize these newly collected invasive species infestations.

Currently the client has a website that displays the results of its mitigation efforts with pictures and text describing their efforts and results. This page contains useful information; however the message could be enhanced by providing an interactive web map. The goal of the web map would be to bring attention to the Conservancy's work and gain additional support to help fund these mitigation projects. A web application could also allow public users to add invasive species infestations that they have observed. 


\section{Works Cited}

Bradley, B. (2010). Assessing ecosystem threats from global and regional change: hierarchical modeling of risk to sagebrush ecosystems from climate change, land use and invasive species in Nevada, USA. Ecography, 33, 198-2008.

Brunel, S., Branquart, E., Fried, G., Valkenburg, J., Brundu, G., Starfinger, U., . . Baker, R. (2010). The EPPO prioritization process for invasive alien plants. Bulletin OEPP/EPPO Bulletin, 40, 407-422.

Carver, S. J. (1991). Integrating multi-criteria evaluation with geographical information systems. International Journal of Geographical Information Systems, 5(3), 321339.

Chornesky, E., \& Randall, J. (2003). The Threat of Invasive Alien Species to Biological Diversity: Setting a Future Course. Annals of the Missouri Botanical Garden, $90(1), 67-76$.

Darin, G. M., Schoenig, S., Barney, J. N., Panetta, F. D., \& DiTomaso, J. M. (2010). WHIPPET: A novel tool for prioritizing invasive plant populations for regional eradication. Journal of Environmental Management, 92(1), 131-139.

Dark, S. J. (2004). The biogeography of invasive alien plants in California: an application of GIS and spatial regression analysis. Diversity and Distributions, 10(1), 1-9.

Endangered Species International. (2011). Overview. Retrieved from Endangered Species International: http://www.endangeredspeciesinternational.org/overview4.html

Esri. (2014, January 4). Understanding overlay analysis. Retrieved from ArcGIS Resource Center: 
http://help.arcgis.com/en/arcgisdesktop/10.0/help/index.html\#//009z000000rs000

000.htm

Esri. (2014, January 6). Weighted Overlay (Spatial Analyst) . Retrieved from ArcGIS

Resource Center:

http://help.arcgis.com/en/arcgisdesktop/10.0/help/index.html\#//009z000000rq000

000.htm

Forsyth, G. C., Maitre, D. C., O'Farrell, P. J., \& van Wilgen, B. W. (2012). The prioritisation of invasive alien plant control projects using a multi-criteria decision model informed by stakeholder input and spatial data. Journal of Environmental Management, 103, 51-57.

Ge, S., Carruthers, R. I., Spencer, D. F., \& Yu, Q. (2008). Canopy assessment of biochemical features by ground-based hyperspectal data for an invasive species, giant reed (Arundo donax). Enviornment Monitoring Assessment, 147, 271-278.

Hansen, M. J., \& Clevenger, A. P. (2005). The influence of disturbance and habitat on the presence of non-native plant species along transport corridors. Biological Conservation, 125, 249-259.

Khudamrongswat, J., \& Tayyar, R. (2004). Genetic diversity of giant reed (Arundo donax) in the Santa Ana River. Weed Science, 52(3), 395-405.

Liu, S., Sheppard, A., \& Kriticos, D. (2011). Incorporating uncertainty and social values in managing invasive alien species: a deliberative multi-criteria evaluation approach. Biol Invasions, 13(10), 2323-2337.

Malczewski, J. (2000). On the Use of Weighted Linear Combination Methods in GIS:

Common and Best Practice Approaches. Transactions in GIS, 4(1), 5-22. 
Malczewski, J. (2006). Integrating multicriteria analysis and geographic information systems: the ordered weighted averaging (OWA) approach. Int. J. Environmental Technology and Management, 6(1), 7-19.

Randall, J. (2000). Improving Management of Nonnative Invasive Plants in Wilderness and Other Natural Areas. USDA Forest Service Proceedings, 64-73.

Regan, H., Hierl, L., Franklin, J., Deutschman, D., Schmalbach, H., Winchell, C., \& Johnson, B. (2008). Species prioritization for monitoring and management in regional multiple species conservation plans. Diversity and Distributions, 14(3), $462-471$.

Rejmanek, M., \& Richardson, D. (1996). What Attributes Make Some Plant Species More Invasive? Ecology, 77(6), 1655-1661.

San Elijo Lagoon Conservancy. (2013a). WCB Final Report. City of Encinitas, CA. San Elijo Lagoon Conservancy. (2013b). inv_veg.shp [ArcGIS shapefile]. City of Encinitas, CA.

Shartell, L. M., Nagel, L. M., \& Storer, A. J. (2011). Multi-Criteria Risk Model for Garlic Mustard. The American Midland Naturalist, 165(1), 116-127.

Starr, F., Starr, K., \& Loope, L. (2003). Cortaderia spp. Haleakala: USGS.

Store, R., \& Kangas, J. (2001). Integrating spatial multi-criteria evaluation and expert knowledge for GIS-based habitat suitability modelling. Landscape and Urban Planning, 55(2), 79-93.

Wilgen, B. W., Dryer, C., Hoffmann, J., Ivey, P., Maitre, D., Joslin, M. L., . . Wilson, J. (2011). National-scale strategic approaches for managing introduced plants: 
Insights from Australian acacias in South Africa. Diversity and Distribuitions, 17(5), 1060-1075. 


\section{Appendix A. Table of Reclassified Vegetation Types}

\begin{tabular}{|c|c|}
\hline LEGEND & Rank \\
\hline 11100 Eucalyptus Woodland & 1 \\
\hline 11200 Disturbed Wetland & 5 \\
\hline 11300 Disturbed Habitat & 5 \\
\hline 12000 Urban/Developed & 1 \\
\hline 13100 Open Water & 1 \\
\hline 13110 Marine & 1 \\
\hline 13111 Subtidal & 1 \\
\hline 13130 Estuarine & 5 \\
\hline 13133 Brackishwater & 5 \\
\hline 13140 Freshwater & 5 \\
\hline 13200 Non-Vegetated Channel, Floodway, Lakeshore Fringe & 1 \\
\hline 13300 Saltpan/Mudflats & 5 \\
\hline 13400 Beach & 3 \\
\hline 18000 General Agriculture & 1 \\
\hline 18100 Orchards and Vineyards & 1 \\
\hline 18200 Intensive Agriculture & 1 \\
\hline 18200 Intensive Agriculture - Dairies, Nurseries, Chicken Ranches & 1 \\
\hline 18300 Extensive Agriculture - Field/Pasture, Row Crops & 1 \\
\hline 18310 Field/Pasture & 1 \\
\hline 18320 Row Crops & 1 \\
\hline 32400 Maritime Succulent Scrub & 3 \\
\hline 32500 Diegan Coastal Sage Scrub & 5 \\
\hline 37000 Chaparral & 5 \\
\hline 37120 Southern Mixed Chaparral & 5 \\
\hline 37200 Chamise Chaparral & 5 \\
\hline 37900 Scrub Oak Chaparral & 5 \\
\hline 37C30 Southern Maritime Chaparral & 5 \\
\hline 37G00 Coastal Sage-Chaparral Scrub & 5 \\
\hline 37K00 Flat-topped Buckwheat* & 1 \\
\hline 42000 Valley and Foothill Grassland & 2 \\
\hline 42100 Native Grassland & 2 \\
\hline 42110 Valley Needlegrass Grassland & 2 \\
\hline 42200 Non-Native Grassland & 2 \\
\hline 45110 Wet Montane Meadow & 1 \\
\hline 45400 Freshwater Seep & 1 \\
\hline 52120 Southern Coastal Salt Marsh & 5 \\
\hline 52300 Alkali Marsh & 5 \\
\hline 52310 Cismontane Alkali Marsh & 5 \\
\hline
\end{tabular}




\begin{tabular}{|l|l|}
52400 Freshwater Marsh & 5 \\
\hline 52410 Coastal and Valley Freshwater Marsh & 5 \\
\hline 52440 Emergent Wetland & 5 \\
\hline 61000 Riparian Forests & 5 \\
\hline 61300 Southern Riparian Forest & 5 \\
\hline 61310 Southern Coast Live Oak Riparian Forest & 5 \\
\hline 61330 Southern Cottonwood-willow Riparian Forest & 5 \\
\hline 62000 Riparian Woodlands & 5 \\
\hline 62400 Southern Sycamore-alder Riparian Woodland & 5 \\
\hline 63000 Riparian Scrubs & 5 \\
\hline 63300 Southern Riparian Scrub & 5 \\
\hline 63310 Mule Fat Scrub & 5 \\
\hline 63320 Southern Willow Scrub & 5 \\
\hline 71100 Oak Woodland & 3 \\
\hline 71160 Coast Live Oak Woodland & 3 \\
\hline 71161 Open Coast Live Oak Woodland & 3 \\
\hline 71162 Dense Coast Live Oak Woodland & 3 \\
\hline 71180 Engelmann Oak Woodland & 3 \\
\hline 71181 Open Engelmann Oak Woodland & 3 \\
\hline 71182 Dense Engelmann Oak Woodland & 3 \\
\hline 83140 Torrey Pine Forest & 1 \\
\hline
\end{tabular}




\section{Appendix B. Invasive Prioritization Tool Description \& Help}

\section{ISP}

Title ISP

\section{Summary}

Ranks invasive species locations based on a number of variables that affect the species' distribution, risk to native habitats, and cost for treatment. Overlays several rasters based on individual species weights.

Illustration

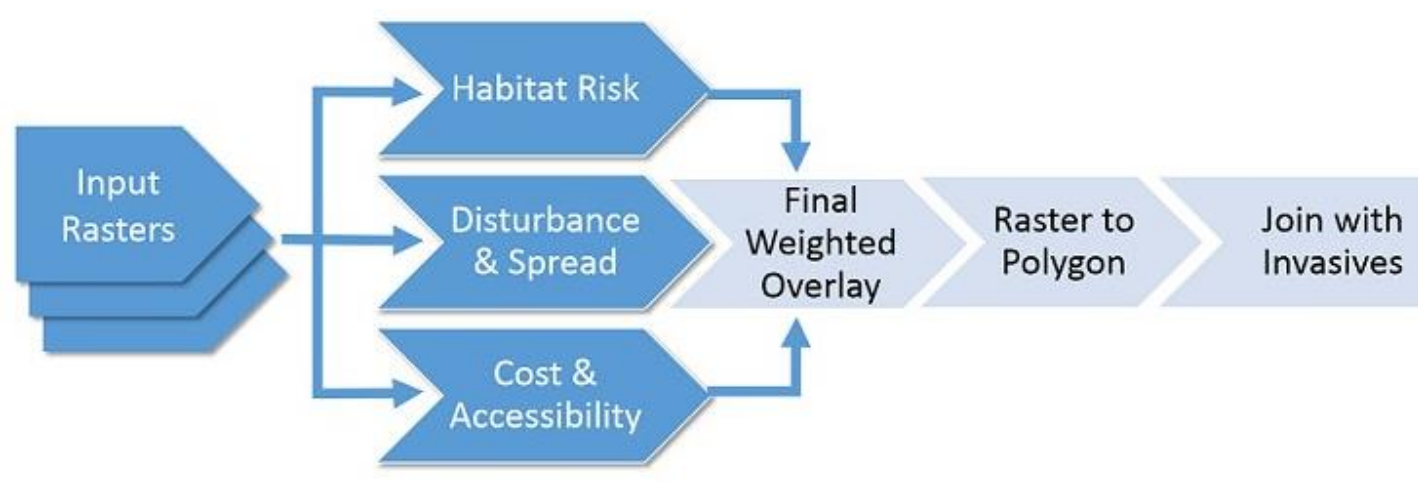

Usage

- All inputs used in weighted overlays must be rasters containing only integer values

- Each input raster is weighted according to its significance in affecting risk to native habitats, and cost for treatment.

- Three sub-weighted overlays will be calculated then combined into one final output suitability raster:

- Risk to Native Habitat

- Dispersion Potential

- Cost/Accessibility

- The sum of the weights for each sub-weighted overlay must equal 100

- The weights can be adjusted by editing the "Species_Weights" table in the source GDB

- New species can also be added to the "Species_Weights" table

- The 3 sub and final weighted overlay are performed for each species in the "Species_Weights" table

- The final output feature class recombines all species and creates a complete output of ranked species locations 
Syntax

ISP (Source_Geodatabase, Final_Output)

\begin{tabular}{|l|l|l|}
\hline Parameter & Explanation & Data Type \\
\hline Source_Geodatabase & Dialog Reference & Workspace \\
\hline $\begin{array}{l}\text { Select the geodatabase containing the feature classes and } \\
\text { raster datasets required for spatial analysis. }\end{array}$ & There is no python reference for this parameter. & Feature Class \\
\hline Final_Output & Dialog Reference & \\
\hline & Select where the final output invasive species location \\
\hline feature class will be stored.
\end{tabular}

\section{Code Samples}

There are no code samples for this tool.

Side-panel Help Illustration

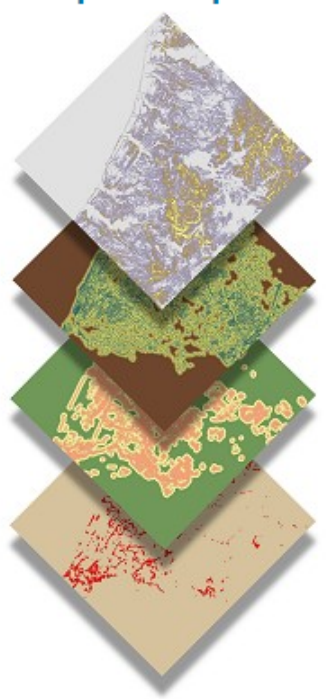

Tags

SELC, CWN

Credits

SELC, SanGIS

\section{Use limitations}

There are no access and use limitations for this item. 


\section{Appendix C. Invasive Prioritization Tool Script}

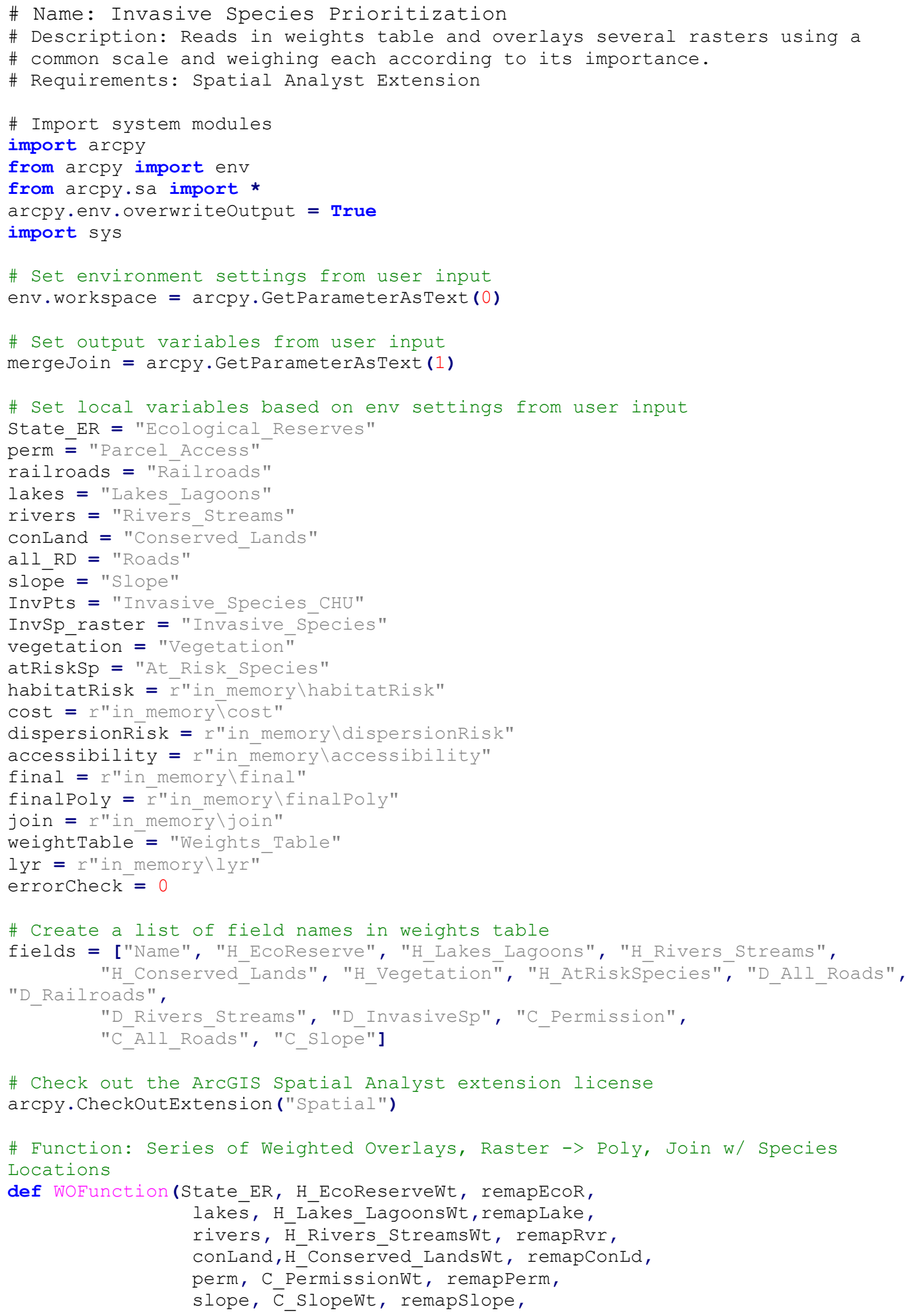




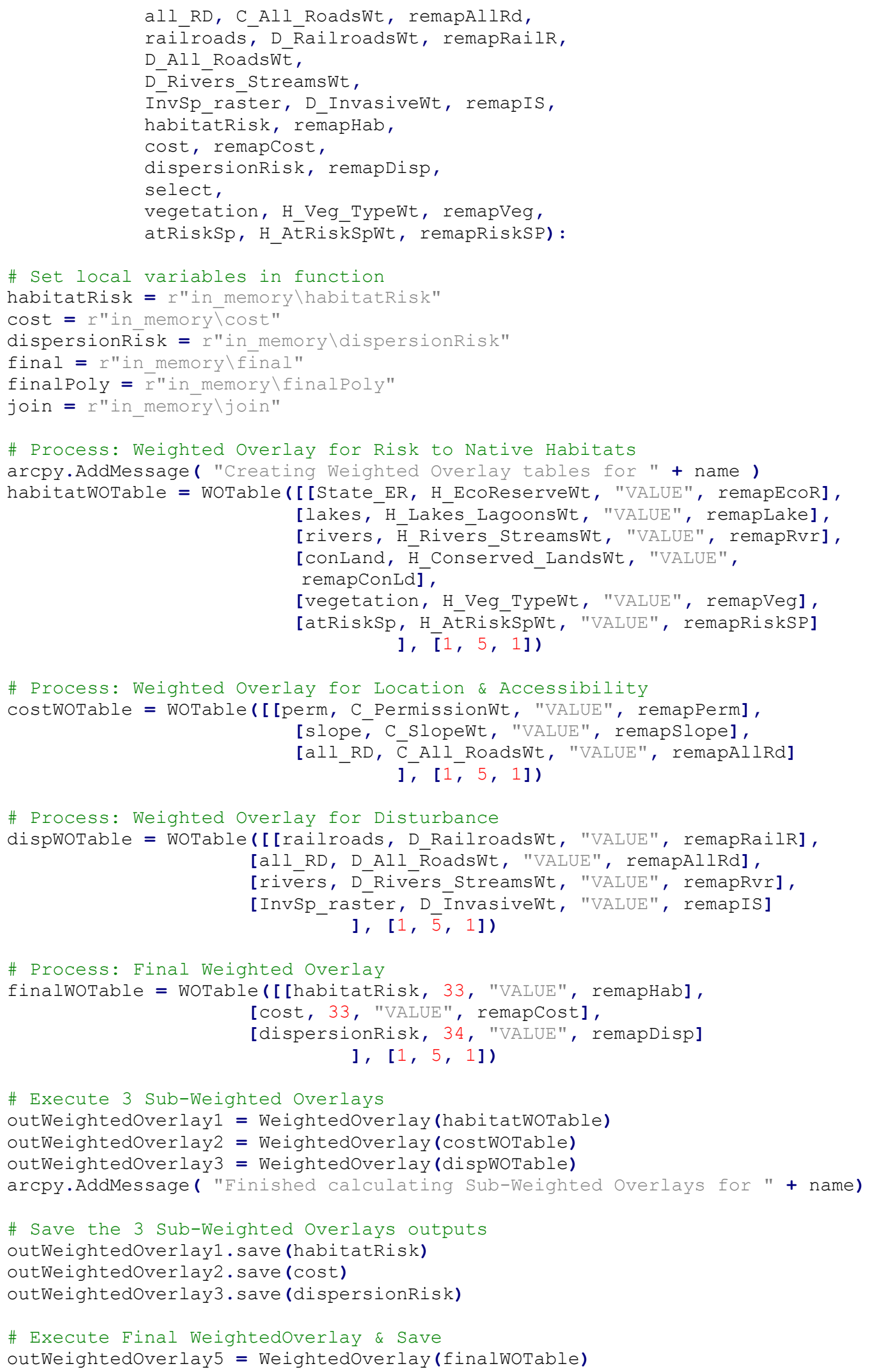




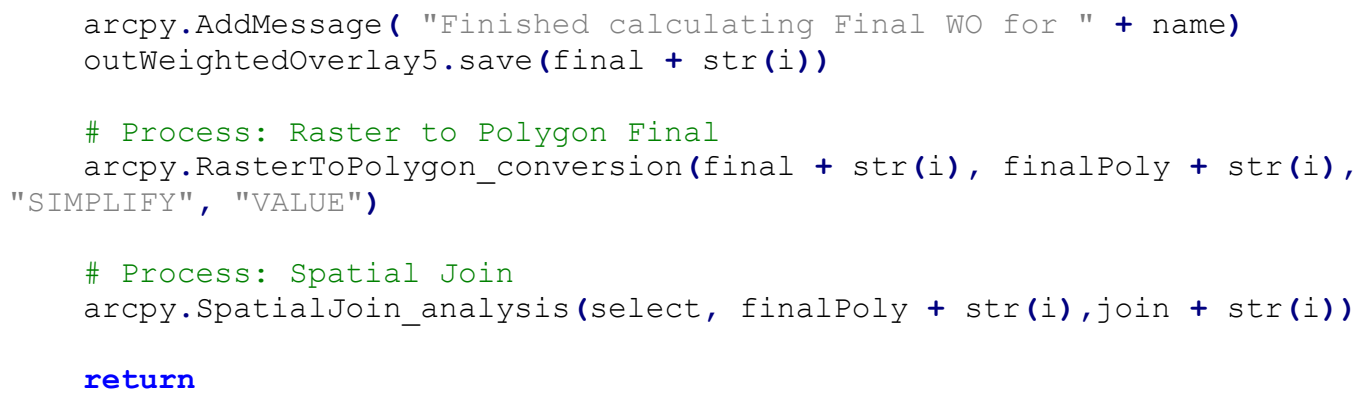




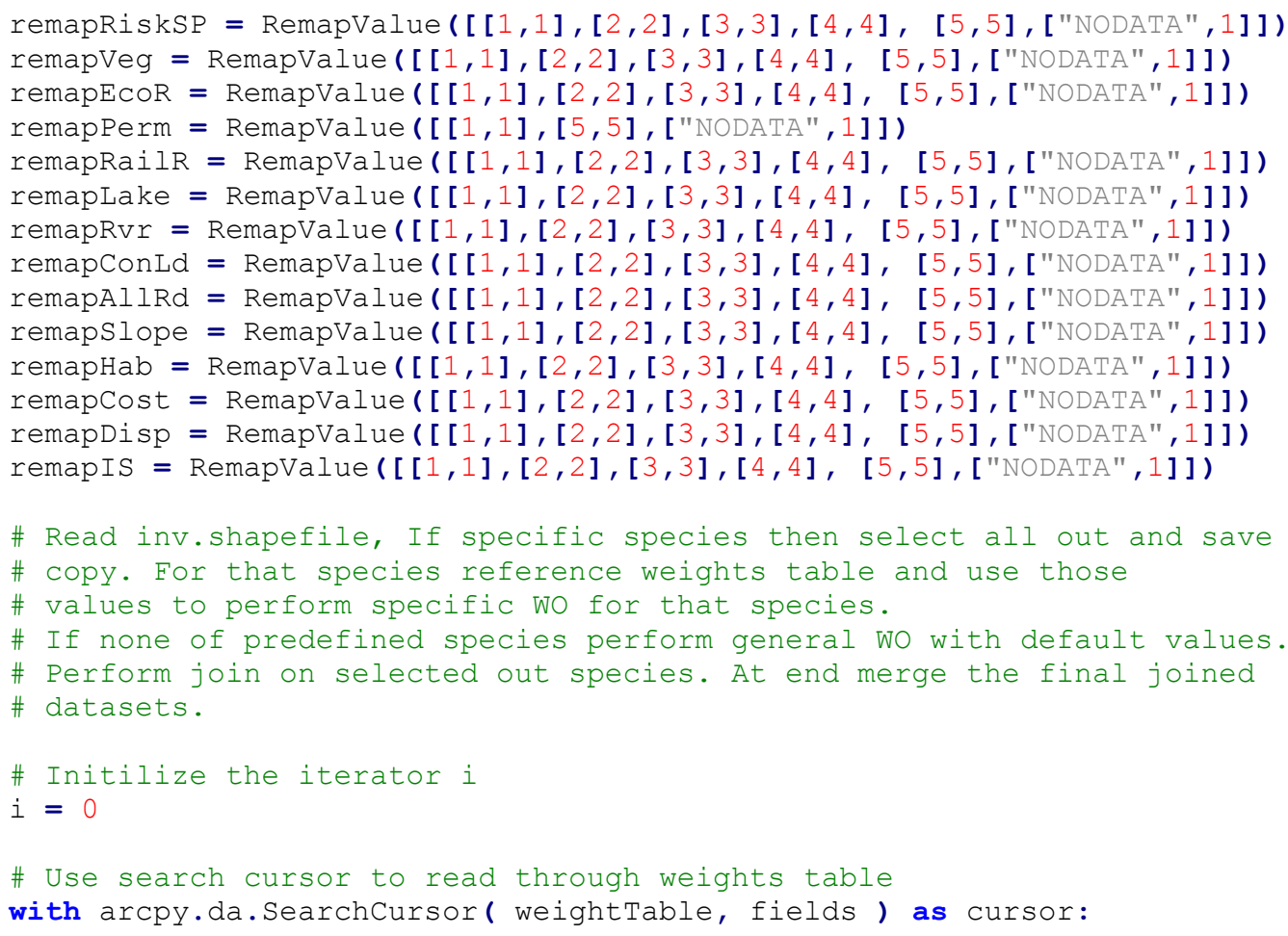




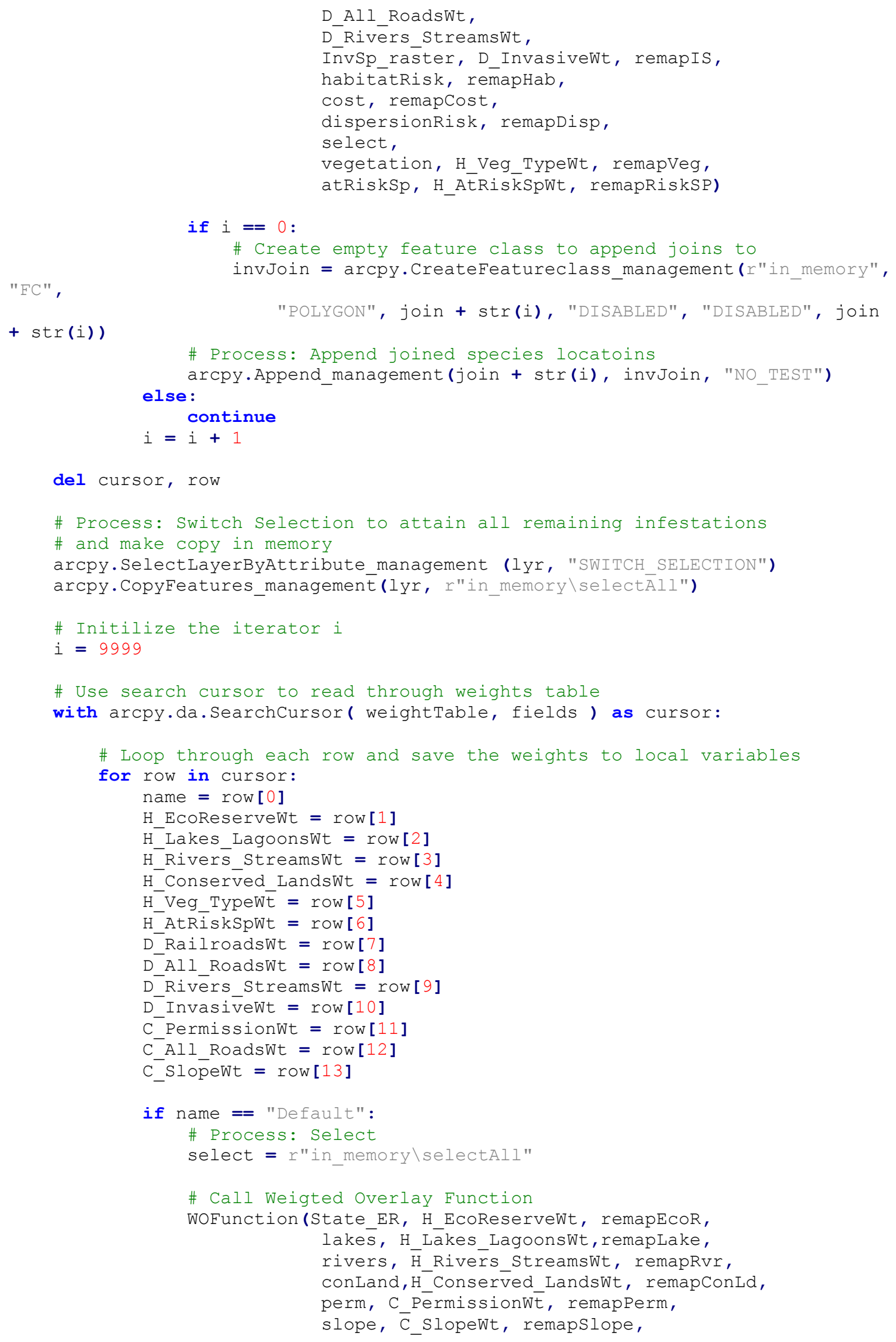


else:

all RD, C All RoadsWt, remapAllRd, railroads, D_RailroadsWt, remapRailR, D All RoadsWt,

D Rivers StreamsWt,

InvSp_raster, D_InvasiveWt, remapIS, habitatRisk, remapHab,

cost, remapCost,

dispersionRisk, remapDisp,

select,

vegetation, H_Veg_TypeWt, remapVeg,

continue

atRiskSp, H_AtRiskSpWt, remapRiskSP)

$i=i+1$

del cursor, row

\# Process: Merge all joined invasive species locations

arcpy.AddMessage ( "Creating final output" )

arcpy.Merge_management([invJoin, join + "9999"], mergeJoin) 


\section{Appendix D. Invasive Prioritization Tool's Item Description/Tool Help}

\section{Priority Analysis ToolUser Guide}

A) Run the tool with given weights:

1. Open ArcMap

2. Open ArcCatalog inside ArcMap application

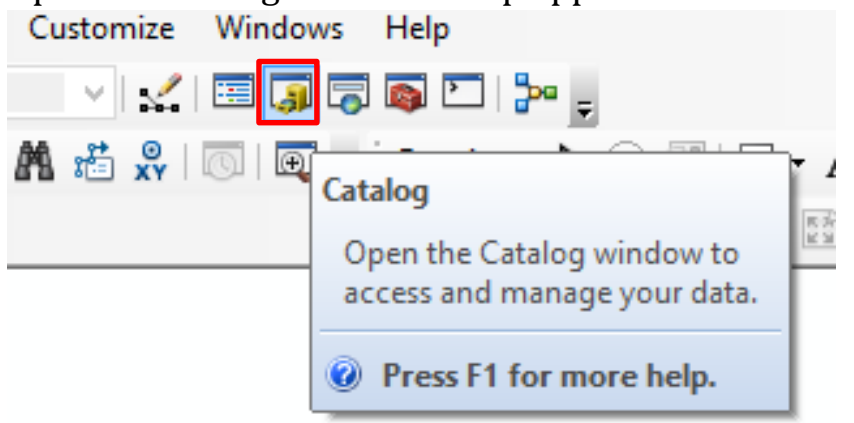

3. Open the ISP toolbox

4. Click the ISP script tool to open the tool's dialog box

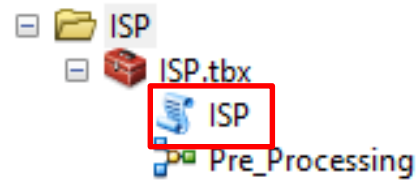

5. Enter the source geodatabase

6. Enter where the output will be saved

7. Run the tool (takes $\sim 10$ minutes to run)

8. Review the output of the tool

B) Run the tool with altered weights:

1. Open ArcMap

2. Open Weights Table in ArcMap

3. Start Edit Session

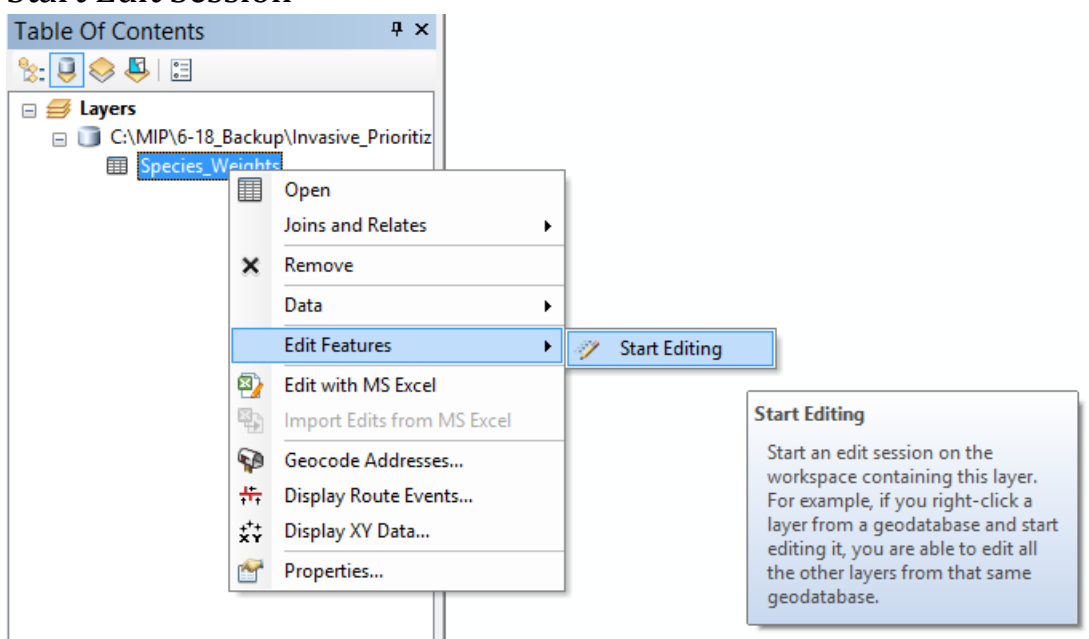


4. Open Weights Table attribute table

\begin{tabular}{|c|c|c|c|c|}
\hline \multicolumn{4}{|c|}{ Table } & $\square \times$ \\
\hline \multicolumn{5}{|c|}{ 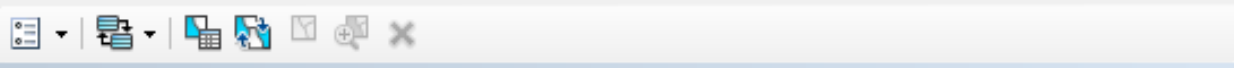 } \\
\hline \multicolumn{3}{|c|}{ Weights_Table } & & $\times$ \\
\hline OBJECTID* & Name & H_EcoReserve & H_Lakes_Lagoons & H_Rivers_Streams \\
\hline 1 & Arundo donax & 16 & 13 & 13 \\
\hline 2 & Cortaderia sp. & 16 & 13 & 13 \\
\hline 3 & Default & 16 & 13 & 13 \\
\hline \multicolumn{2}{|l|}{$<$} & & & $>$ \\
\hline \multicolumn{2}{|l|}{141} & ( 0 out of 3 Selec & ed) & \\
\hline \multicolumn{2}{|l|}{ Weights_Table } & & & \\
\hline
\end{tabular}

5. Edit weights or add new species

6. Save edits and then stop editing

7. Follow steps 1-8 in (A) 